\title{
Organic management of Mexican bean beetle (Epilachna varivestis Mulsant) in snap bean (Phaseolus vulgaris L.)
}

\author{
Tiffany L. Fess \\ West Virginia University
}

Follow this and additional works at: https://researchrepository.wvu.edu/etd

\section{Recommended Citation}

Fess, Tiffany L., "Organic management of Mexican bean beetle (Epilachna varivestis Mulsant) in snap bean (Phaseolus vulgaris L.)" (2008). Graduate Theses, Dissertations, and Problem Reports. 2607. https://researchrepository.wvu.edu/etd/2607

This Thesis is protected by copyright and/or related rights. It has been brought to you by the The Research Repository @ WVU with permission from the rights-holder(s). You are free to use this Thesis in any way that is permitted by the copyright and related rights legislation that applies to your use. For other uses you must obtain permission from the rights-holder(s) directly, unless additional rights are indicated by a Creative Commons license in the record and/ or on the work itself. This Thesis has been accepted for inclusion in WVU Graduate Theses, Dissertations, and Problem Reports collection by an authorized administrator of The Research Repository @ WVU. For more information, please contact researchrepository@mail.wvu.edu. 


\title{
Organic Management of Mexican Bean Beetle (Epilachna varivestis Mulsant) in Snap Bean \\ (Phaseolus vulgaris L.)
}

\author{
Tiffany L. Fess \\ Thesis submitted to the \\ Davis College of Agriculture, Forestry, and Consumer Sciences \\ at West Virginia University \\ in partial fulfillment of the requirements \\ for the degree of \\ Master of Science \\ in \\ Horticulture
}

Sven Verlinden, Ph.D., Major Professor

Linda Butler, Ph.D

James Kotcon, Ph.D

Department of Plant and Soil Sciences

Morgantown, West Virginia

2008

Keywords: Green snap beans, Mexican Bean Beetle, Pediobius foveolatus, Organic production, Row cover, Planting date 


\title{
Abstract \\ Organic Management of Mexican Bean Beetle (Epilachna varivestis Mulsant) Infestations in Snap Bean (Phaseolus vulgaris L.) Crops
}

\section{Tiffany L. Fess}

\begin{abstract}
Various methods have been suggested to control or deter MBB from attacking bean crops, however conclusive data detailing the effectiveness of control methods and their effects on green bean yield are limited. Two separate experiments were performed to compare MBB management practices in snap bean crops and determine snap bean varieties with natural tolerance to $\mathrm{MBB}$ infestations. $P$. foveolatus in snap bean crops significantly $(\mathrm{P}<0.05)$ reduced the larval and adult $\mathrm{MBB}$ populations, while increasing the bean yield in optimal growing conditions. The use of row cover and staggering of planting date proved to be unsuccessful $(\mathrm{P}>0.05)$ increasing bean yield, however MBB larval, pupal, and adult populations were found to be different $(\mathrm{P}<0.05)$ when growing conditions wee optimal. When MBB populations were above the economic threshold (11.5 MBB larvae per plant) in the test, tolerance to MBB infestation was not observed $(\mathrm{P}>0.05)$ in any of the varieties studied.
\end{abstract}




\section{Acknowledgments}

I thank all the people at West Virginia University and the surrounding community who helped me to complete my study and achieve my Master's degree in Horticulture. First, I would like to thank Dr. Sven Verlinden for believing in my abilities and allowing me a chance to advance academically along with providing great advice and guidance. To Dr. James Kotcon for helping me solve in-field dilemmas, providing me with research space, and rescuing me from dehydration. To Dr. Linda Butler for her wisdom and knowledge in entomology. To Dr. Baker for admitting me into the program, providing me with an opportunity to develop scientifically and academically. To Dr. George Seidel for helping with my statistical calculations and analyses. I would also like to thank Jim \& Sue Myers and Don \& Susan Sauter (Flying Ewe Farm) for allowing me space to conduct my research in their personal gardens. Lastly, I would like to thank Tom Dorsey from the NJDA Philip Alampi Beneficial Insectary, for supplying the P. foveolatus for my research, and to interested community members. Funding provided by USDA CSREES and WVA under the Hatch project WVA 004477. 


\section{Table of Contents}

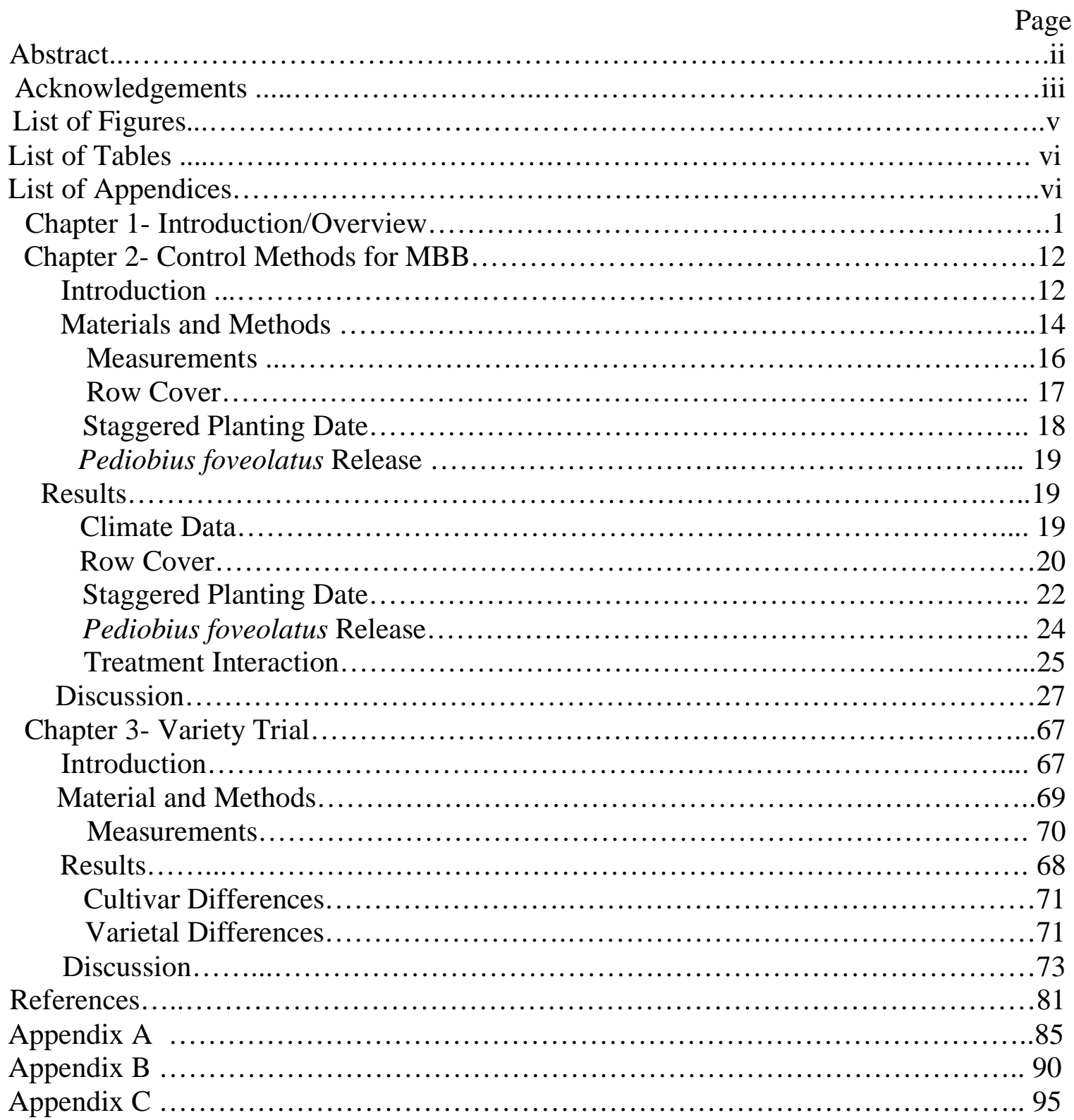




\section{List of Figures}

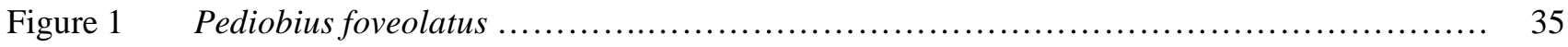

Figure 2 Comparison of Parasitized and Healthy MBB Larvae............................... 35

Figure $3 \quad$ Size Reference for P. foveolatus................................................ 36

Figure $4 \quad$ Parasitized MBB Larvae Containing P. foveolatus Larvae................................... 36

Figure $5 \quad$ Map of Morgantown, WV and the Surrounding Area................................ 37

Figure $6 \quad$ Map of Morgantown, WV ........................................................ 37

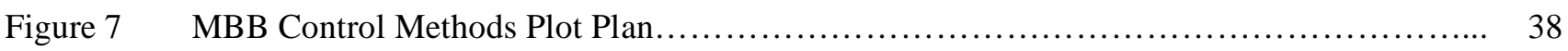

Figure $8 \quad$ Insect Defoliation Levels of Soybean Leaflets............................................... 39

Figure 9 Comparison of Season Precipitation Totals from 2004 and $2005 \ldots \ldots \ldots \ldots \ldots \ldots \ldots \ldots \ldots \ldots \ldots$

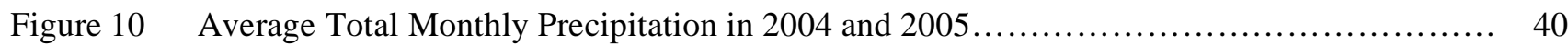

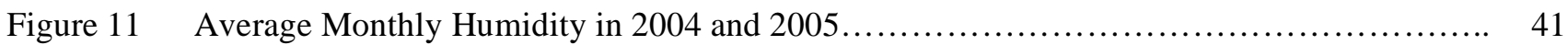

Figure 12 Comparison of Monthly Temperatures from the 2004 and 2005 Seasons................... 41

Figure 13 Average Snap Bean Yield in 2004 and 2005 from Row Cover and Control Subplots......... 42

Figure 14 Average Snap Bean Yield from Varieties in Row Cover Treated and Control Subplots....... 45

Figure 15 Average MBB Population Weeks 1-5 from Control and Row Cover Treated Subplots

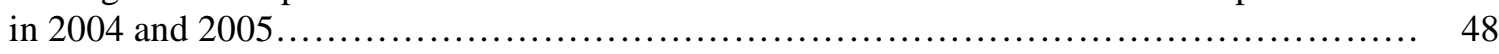

Figure 16 Average Total Snap Bean Yield from Staggered Planting Dates in Treated and Control Subplots for the 2004 and 2005 Seasons......................................... 49

Figure 17 Average MBB Population from Staggered Planting Dates in Treated and Control

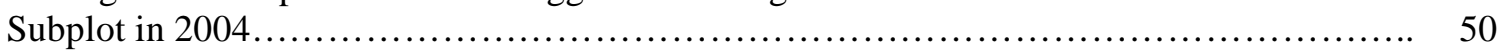

Figure 18 Average MBB Population from Staggered Planting Date in Treated and Control

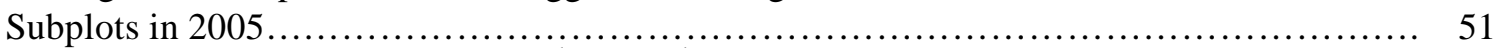

Figure 19 Average Final MBB from the $1^{\text {st }}, 2^{\text {nd }}$, and $3^{\text {rd }}$ Staggered Planting Date in Treated and Control Subplots During the 2004 and 2005 Seasons................................. 52

Figure 20 Average Snap Bean Yield for each Staggered Planting Date in Treated and Control Subplots During the 2004 and 2005 Seasons............................................. 53

Figure 21 Comparison of Average Snap Bean Yield in P. foveolatus Treated and Control Subplots..... 56

Figure 22 Average MBB Population over Time in P. foveolatus Treated \& Control Subplots in 2004... 57

Figure 23 Average MBB Population over Time in P. foveolatus Treated \& Control Subplots in 2005... 58

Figure 24 MBB Populations among the Pole Cultivars in P. foveolatus Control and Treated Subplots

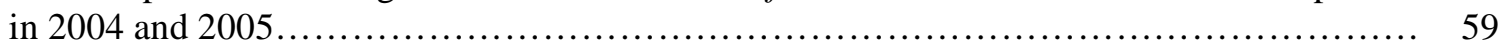

Figure 252004 and 2005 Average Total Snap Bean Yield from Each Cultivar Used in P. foveolatus Treated and Control Subplots................................................ 60

Figure 26 MBB Population among the Half Runner Cultivars in P. foveolatus Control and Treated Subplots in 2004 and $2005 \ldots \ldots \ldots \ldots \ldots \ldots \ldots \ldots \ldots \ldots \ldots \ldots \ldots \ldots \ldots \ldots \ldots \ldots \ldots \ldots \ldots \ldots \ldots \ldots$
MBB Population among the Bush Cultivars in $P$. foveolatus Control and Treated Subplots in

Figure $27 \quad$ MBB Population among the Bush Cultivars in P. foveolatus Control and Treated Subplots in

Figure 28 Average Total Number of Parasitized MBB Larvae Present in P.foveolatus Subplots in 2004 and 2005 ....

Figure 29 Comparison of Parasitized and Healthy MBB Pupae................................. 64

Figure $30 \quad$ Healthy MBB Pupae and Larvae.................................................... 64

Figure 31 Parasitized MBB Pupae Containing P. foveolatus Pupae.................................. 65 
Figure 32 Comparison of Late Season Snap Bean Plantings With and Without the Presence

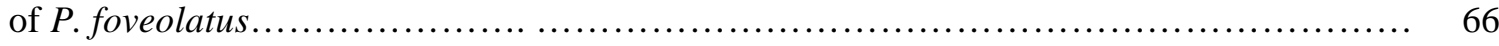

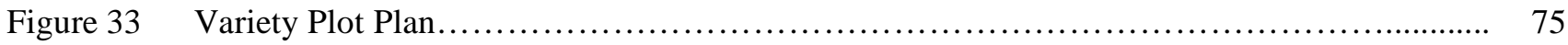

Figure 34 Map of WVU Plant and Soil Science Farm, Morgantown, WV ........................... 76

Figure 35 Average Final MBB Population Found in the Bush, Half Runner, and Pole Cultivars

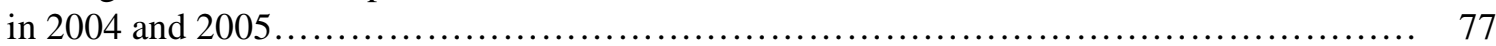

Figure 36 Average Season Yield from Bush, Half Runner, and Pole Cultivars in 2004 and 2005........ 77

Figure 37 Average Final MBB Population and Total Snap Bean Yield from Bush Varieties

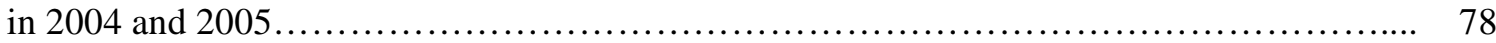

Figure 38 Average Final MBB Population and Total Snap Bean Yield from Half Runner Varieties

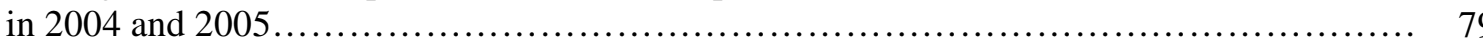

Figure 39 Average Final MBB Population and Total Snap Bean Yield from Pole Varieties in 2004 and 2005

\section{List of Tables}

Table 1 Three-way Analysis of Variance of Yield Data in Row Cover Treatment in 2004.....

Table 2 Orthogonal Contrast within Row Cover Treatment x Sampling (weeks) Interaction in Yield

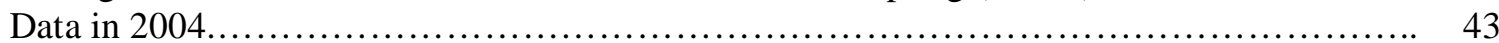

Table 3 Three-way Analysis of Variance of Yield Data in Row Cover Treatment in 2005........... 44

Table 4 Orthogonal Contrast within Row Cover Treatment x Sampling (weeks) Interaction in Yield

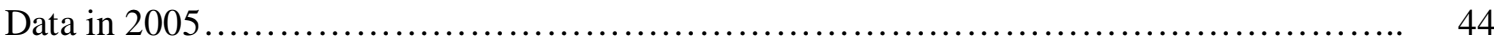

Table 5 Three-way Analysis of Variance of Yield Data in Staggered Planting Treatment in 2004..... 46

Table 6 Three-way Analysis of Variance of Yield Data in Staggered Planting Treatment in 2005..... 46

Table 7 Orthogonal Contrast within Staggered Planting Treatment x Sampling (weeks) Interaction in Yield Data in 2005 ................................................................ 47

Table 8 Three-way Analysis of Variance of Yield Data in Pediobius foveolatus Treatment in $2004 \quad 54$

Table 9 Three-way Analysis of Variance of Yield Data in Pediobius foveolatus Treatment in $2004 \quad 55$

\section{List of Appendices}

Appendix A Three-way Analysis of Variance of MBB population Density in Row Cover Treatment..... Appendix B Three-way Analysis of Variance of MBB population Density in Staggered Planting Date

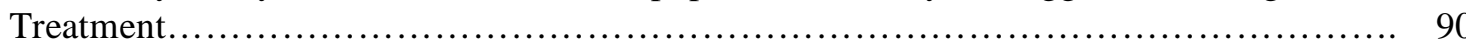

Appendix C Three-way Analysis of Variance of MBB population Density in Pediobius foveolatus Treatment 


\section{Chapter 1 \\ Introduction/ Overview}

Originating in South and Central America, the genus Phaseolus is comprised of over 55 species, however only 5 species have been domesticated and produced in significant amounts: P. acutifolius A. Gray (tepary bean), P. coccineus L. (scarlet runner bean), $P$. lunatus L. (lima bean), $P$. polyanthus Greenman (year-long bean), and $P$. vulgaris L. (common bean) (Singh, 2001). The domesticated species of Phaseolus are important staples in the diets of people all over the world and are produced in Africa, Asia, Australia, Europe, North America and South America (Gepts et al., 1996).

Phaseolus vulgaris L., common bean, is the most widely produced bean in the world, occupying $85 \%$ of all the production area dedicated to the Phaseolus species (Singh, 2001). Even though the majority of the production area for Phaseolus is sown with P.vulgaris, the genetic base of the common bean cultivars found in the market is narrow because only a small percent of wild common bean populations have been domesticated (Singh, 2001).

Historically, wild populations were not limited to one specific region and are known to have multiple sites of domestication in Middle and Andean South America (Singh, 2001). Archaeological evidence of domesticated common bean seed dates to approximately 5500 BCE (7,500 years ago) in Northern Peru, and by 5000 BCE domestication was evident in southern Mexico (ARC, 2005). Further advancement into North America was delayed because of the lack of travel through the vast deserts of the Southwestern U.S, however by the 1400's common beans were a staple crop in North America and in Europe and Africa by the 1500's (Singh, 2001; ARC, 2005). Today, small wild populations can still be found distributed from southern Mexico to Northwestern Argentina (Singh, 2001).

The domestication of $P$. vulgaris has caused it to evolve from its wild ancestors. The common bean has changed from an indeterminate climber to, in some cases, a determinate bush and from a long day to a day neutral plant (Singh, 2001). Seed size also changed, from small seeds capable of prolonged dormancy because of their water 
impermeable seed coats, to a larger seed with a water permeable seed coat, and therefore shorter dormancy (Singh, 2001).

The genetic diversity in domesticated common beans found in the markets today can be categorized into two main gene pools, Andean and Middle American. These can then be further divided into six races: Chile, Nueva Granada, Peru, Durango, Jalisco, and Mesoamerica, each with their own distinct characteristics, ecological adaptations and agronomic traits (Singh, 2001). Varieties from the same race are more likely to be vulnerable to the same pathogens and environmental stresses (Gepts et al., 1996).

Commercially, there are two main classes of $P$. vulgaris available, dry and snap, both of which are important economical crops in many countries around the world. In 1994, the world production of $P$. vulgaris cultivars, as both dry and snap beans, was 20 million metric tons (Gepts et al., 1996). Dry beans are more commonly produced and are harvested for their mature, protein rich seeds, the fibrous pods are considered undesirable by consumers (Bradley and Ellis, 1997). The majority of dry beans are produced in Brazil, the United States, Mexico, and Europe; with the United States as the leading exporting nation, exporting 40\% of all dry beans produced (Gepts et al., 1996).

Snap bean varieties have thickened, succulent mesocarps with reduced to no fiber content in the pods, making the pods desirable for fresh consumption. Snap beans are an important vegetable crop in developed nations and are becoming increasingly more important in developing countries as consumers demand variety in their diets while farmers seek additional sources of income (Gepts et al., 1996). According to the Food and Agriculture Organization of the United Nations (FAO) the United States is the world's top snap bean producer, contributing $60 \%$ of the total output worldwide, while France, Mexico, Iraq, and Argentina complete the top five (Lucier and Lin, 2002). Snap bean pods are generally harvested for three distinct markets in the U.S; fresh, freezing, or canning (Gepts et al., 1996; Lucier and Linn, 2002).

Snap beans are produced in every state, with 9,118 farms producing processing or fresh snap beans (Lucier and Lin, 2002). Of the 2.1 billion pounds of snap beans produced in the U.S, over 50\% are destined for various canneries. Canning beans, worth $\$ 112$ to $\$ 144$ million annually in sales, are produced on an estimated 218,000 acres found mainly in Wisconsin, Oregon, New York, and Michigan (Lucier and Lin, 2002). Fresh 
market snap beans account for only $25 \%$ of all the snap beans in the U.S, although the crop produced is valued at approximately $\$ 138$ million annually (Lucier and Lin, 2002). The majority of fresh market beans are produced in Florida, California, Georgia, and Tennessee on approximately 89,600 acres (Lucier and Lin, 2002). As well as being the world's largest producer of snap beans, the U.S. is also the leading exporter and importer of snap beans. In the 1990's, the U.S. exported 11\% of its fresh market supply, with approximately $80 \%$ of it being shipped to Canada, mainly the months of April through July (Lucier and Lin, 2002). Fresh snap beans are largely imported from December through March when domestic production is limited due to cold weather, with 92\% of imported snap beans arriving from Mexico (Lucier and Lin, 2002).

Production of snap beans in the United States remained stable for the two decades, 1970's and 80's. However in the early 1990's production output began to rise largely due to consumer demand. Fresh bean production was 90\% higher 1998-2000 than it was in 1988-1990 (Lucier and Lin, 2002; Gepts et al., 1996). Consumption of fresh snap beans in the United States increased 83\% during the same time,1998-2000, compared to 1988-1990, averaging 519 and 284 million pounds annually, respectively. (Lucier and Lin, 2002). In 2000, the consumption per capita of snap beans was 2.1 pounds, the highest it has been since 1964 (Lucier and Lin, 2002).

Snap bean production can often be limited by both abiotic and biotic constraints (Singh, 2001). Common abiotic factors affecting the production of beans are low soil fertility, especially deficiencies in nitrogen, phosphorus, and zinc, or the build up of aluminum and manganese. High temperatures $\left(>30^{\circ} \mathrm{C}\right.$ day and/or $>20^{\circ} \mathrm{C}$ night) or low temperatures (below $15^{\circ} \mathrm{C}$ ) for extended periods also severely limit bean yields (Singh, 2001). However, drought is the most common and wide spread abiotic factor influencing production world wide and in the United States, and complete crop failures due to arid conditions are not uncommon (Singh, 2001).

Insect pests are the most important biotic factor affecting bean production, in the United States, Epilachna varivestis (Mexican Bean Beetle), Cerotoma trifurcata (bean leaf beetle), Empoasca kraemeri (leafhopper) and Apion godmani (bean pod weevils) are the largest problem pests for producers (Singh, 2001). Bacterial and fungal diseases, 
such as bacterial blight, rust, anthracnose, and root rot, and viruses like such as mosaic can also severely reduce yields (Singh, 2001).

Moderate levels of resistance for drought stress, rust, anthracnose, root rot, and bean pod weevil have been bred into many varieties of $P$. vulgaris found in the market, but resistance to Mexican Bean Beetle (MBB) has not been achieved (Singh, 2001). The lack of resistance in common beans and the high mobility of the MBB populations makes them the most devastating factor with which snap bean producers in the Eastern United States have to contend, especially in late maturing varieties (Singh, 2001). Moderate resistance to MBB may be present in wild varieties that have not been domesticated. However, much of the genetic variability available within $P$. vulgaris has not been utilized for cultural improvements (Singh, 2001).

Epilachna varivestis (MBB), a member of the lady beetle family Coccinellidae in the order Coleoptera, is a relative of beneficial lady beetles. However, E. varivestis is one of only three destructive members in the family Coccinellidae (Sanchez-Arroyo, 2005). MBB are native to the plateau region of southern Mexico where summer months are wet, and have slowly migrated into northern Mexico and North America over the last 100 years (Sanchez-Arroyo, 2005). Populations were not seen inside the United States until $P$. vulgaris production had become significant. In addition, increased human travel to and from northern Mexico aided in the spread of this insect. Records indicate MBB infestations in the Southern U.S. during the late 1800's, where they remained restricted until the 1920's (Sanchez-Arroyo, 2005). Today, MBB can be found from Guatemala to southern Canada, Asia and Africa (Sanchez-Arroyo, 2005). In the United States, serious and devastating pest infestations occur annually in most states east of the Rocky Mountains, where precipitation can be heavy during the hot summer months (SanchezArroyo, 2005). In the western areas of the United States, populations are confined to regularly irrigated areas with high summer temperatures (Sanchez-Arroyo, 2005).

The lack of genetic resistance found in snap bean varieties to MBB has made controlling populations difficult for conventional and organic producers alike. In conventional production areas where MBB has become an economic pest, a chemical treatment is commonly applied when defoliation reaches $20 \%$ pre-bloom or $10 \%$ during pod formation (Tuckey, 2001; Roberts and Douce, 1999). The application of systemic 
insecticides has become the standard and normally takes place during egg hatch or emergence of second generation adults (Sanchez-Arroyo, 2005; Tuckey, 2001). One application of a systemic insecticide does not provide enough protection to reduce the economic damage resulting from MBB infestations for an entire season, and therefore multiple applications are required to result in effective control (Sanchez-Arroyo, 2005). The increased costs associated with multiple insecticide applications are then passed on to the consumer. For early season infestations, foliar sprays are commonly used for controlling MBB populations. Foliar insecticides are capable of suppressing the MBB for up to two weeks after application (Sanchez-Arroyo, 2005). The ability of MBB populations to migrate from surrounding areas combined with the inability of insecticides to completely suppress MBB adult populations, dictates the use of a pesticide with a high initial efficacy and long-residual effects to maintain populations below the economic threshold (1-1.5 larvae per plant) throughout the season (Sanchez-Arroyo, 2005). Common chemicals used to control MBB populations are Capture 2EC® (bifenthrin), Dimilin ${ }^{\circledR}$ (diflubenzuron), Lannate LV® (methomyl), Sevin XLR ${ }^{\circledR}$ (carbaryl), Warrior ${ }^{\circledR}$ (cyhalothrin), and Asana XL® (esfenfalerate) (Tuckey, 2001; Lambdin et al., 1987; Burkhardt et al., 1986). The heavy application of insecticides over many decades has caused the beetles to develop moderate resistance, ultimately decreasing the effectiveness of most commercial chemicals to control MBB populations (Sanchez-Arroyo, 2005).

The increasing resistance developed by the MBB from repeated and prolonged exposure to certain chemicals has made it even more difficult for organic producers to suppress populations (Dobrin and Hammond, 1983; Sanchez-Arroyo, 2005). Currently under the National Organic Production (NOP) standards the use of sythetic chemicals to control pests, weeds, and diseases are strictly prohibited. In 1933, rotenone, permitted under organic rules and regulations, was developed for use on MBB, but by 1949 MBB resistance to it was reported in the Eastern United States (USDA 1954; Whalon et al., 2003). Without the aid of pesticides such as rotenone, organic producers have developed alternative techniques to control MBB populations. Common practices that have been tried include the destruction of overwintering locations, crop rotations, alternating planting times, the frequent application of approved organic chemicals, such as Neem, pyrethrum, garlic oil, or the use of biological control agents (Ellis and Bradley, 1996). 
Most of these methods show limited efficacy in much the same way conventional insecticides have. Organic control methods show the same inability to control a potentially migrating population of MBB for extended periods, leaving both conventional and organic producers seeking new methods to suppress MBB populations below economic thresholds (Ellis and Bradley, 1996).

Mexican Bean Beetles can be found on a variety of leguminous crops, such as cowpeas, black-eyed peas, soybean, clover, and alfalfa, however Phaseolus vulgaris L. and lima beans, $P$. lunatus are the most preferred crops (Sanchez-Arroyo, 2005; Roberts and Douce, 1999). The natural host is believed to be beggarweed, Desmonium spp, although other closely related weeds are susceptible to attack (Sanchez-Arroyo, 2005).

E. varivestis adults can be confused with beneficial lady beetles because they appear similar to the untrained eyed. Highly mobile adults are $6.0-8.5 \mathrm{~mm}$ in length and oval in shape (Sanchez-Arroyo, 2005). When newly emerged, either from overwintering sites or pupation, they are a light yellow color without spots. However, shortly after emerging eight black spots appear on each wing in three distinct rows (Sanchez-Arroyo, 2005; Sorensen et al., 2004). The color of the adult beetles also darkens as they age, becoming coppery-orange. Male beetles are generally smaller than females and can be distinguished from the females by the small notch on the ventral side of the last abdominal segment (Sanchez-Arroyo, 2005).

Eggs can be found, secluded from possible predators, on the underside of bean leaves, in clusters of 20 to 60 . Orange elliptical eggs are approximately $1.3 \mathrm{~mm}$ in length and $0.6 \mathrm{~mm}$ in width (Sanchez-Arroyo, 2005).

The larvae when first hatched are light yellow in color and are approximately 1.8 $\mathrm{mm}$ in length (Sanchez-Arroyo, 2005). The grub-like larvae have soft bodies that taper posteriorly to the anal segment where a sucker-like apparatus attaches the body to the feeding surface (Sanchez-Arroyo, 2005). The MBB larvae undergo four molts before reaching maturity and entering pupation (Sorensen et al., 2004; Sanchez-Arroyo, 2005). The bodies of the larvae are covered in spines that are colorless upon hatching but grow darker as the larvae become larger. Each segment of the body contains 4 to 6 spines arranged in rows, which provide the larvae with their only defense mechanism. When 
disturbed the spines secrete a defensive compound which has been shown to deter spiders, ants, and other common predators (Laurent et al., 2003).

Pupation begins once the larvae have reached their full maturity and attach themselves by the posterior to the underside of leaves, stems, or pods of the snap beans. They can also be found isolated on nearby non-host plants (Sanchez-Arroyo, 2005). Once attached the larval skin is pushed back to the abdomen where it remains. The pupae now appear to be the size and shape of an adult, except for their bright yellow color (Ratcliffe et al., 2004; Sanchez-Arroyo, 2005).

After overwintering in protected moist places, such as along fence rows, hedgerows, ditchbanks, and woodlands, adult Mexican bean beetles begin to emerge after prolonged warm temperatures (430-500 growing degree days, base $50^{\circ} \mathrm{F}$ ), usually by the end of May (Roberts and Douce, 1999; Sorensen et al., 2004; Barrigossi et al., 2001; Grubinger, 1999). Emergence can occur over several weeks largely because temperature and precipitation can have a direct influence on the rate at which the adult beetles emerge. Winters with heavy precipitation tend to increase the survival of overwintering adults (Barrigossi et al., 2001). The percentage of emergence can also be positively correlated to temperatures during rainfall periods, while dry conditions can delay emergence (Barrigossi et al., 2001). Emerging adults seek out $P$. vulgaris immediately, feeding on young tender bean leaves for one to two weeks, after which mating will begin (Ratcliffe et al., 2004). By June, females begin depositing eggs, laying as many as 600 in clusters of 30 on average (Sorensen et al., 2004; Sanchez-Arroyo, 2005). Eggs hatch in approximately one week in warm weather, although humidity and temperature can influence the hatching time (Roberts and Douce, 1999; Barrigossi et al., 2001). When first hatched the larvae tend to feed together but spread out as they molt and grow in size. Temperature and humidity are directly correlated to the rate at which the larvae consume leaf material, which generally occurrs for a total of two to five weeks (Barrigossi et al., 2001; Sanchez-Arroyo, 2005). Once the larvae reach maturity, pupation begins, lasting from 5 to 10 days, depending on ambient air temperatures (Sanchez-Arroyo, 2005). In the Eastern United States there are two to three generations per season, with peak populations occurring in late July-August (Barrigossi et al., 2001). 
Damage to snap beans by E. varivestis, can cause a total crop loss if the population reaches economically damaging levels (Sorensen et al., 2004). Damage results only from the feeding of adults and larvae, with the greatest amount of damage attributed to the larval populations, likely due to their limited mobility (Sanchez-Arroyo, 2005). The adults and larvae consume flowers and pods, but prefer leaf tissue, leaving both small and large veins untouched (Peterson et al., 1998). Feeding occurs generally on the lower leaf surface, which causes the upper surface to dry out quickly, giving the leaf a skeletonized or lace-like appearance (Peterson et al., 1998; Sanchez-Arroyo, 2005; Sorensen et al., 2004). The adults and larvae use mandibles to chew the leaf tissue, but only the resultant juices are consumed (Ratcliffe et al., 2004). Leaves, blossoms, and immature pods may die and drop off before the crop has reached maturity if damage is extensive. However, even when leaves are not shed they are unable to regain the same photosynthetic productivity as prior to injury (Flanders, 1985; Petersen et al., 1998). Seasons with high infestations can lead to complete defoliation, ultimately reducing the yield and causing economic loss for the farmer, increasing the need for the development of efficient and economic control methods (Flanders, 1985; Sorensen et al., 2004; Ratcliffe et al., 2004).

Since snap beans have little genetic tolerance to the MBB, coupled with MBB resistance to chemical insecticides, finding effective methods that are affordable and practical can be and has been difficult. However the parasitic wasp, Pediobius foveolatus has shown the most potential at controlling MBB populations. P. foveolatus is a small, 2.0-3.5 mm, gregarious wasp that parasitizes MBB larvae (NJDA, 2004). P. foveolatus is native to India and has been imported to the U.S. since the early 1960's for biological control research. Since that time it has shown potential at significantly reducing populations of Mexican bean beetles in soybean, Glycine max, in many eastern states (Sanchez-Arroyo, 2005; Schaefer et al., 1983).

$P$. foveolatus lack the ability to undergo diapause and have no suitable overwintering host in the Eastern United States, resulting in the inability to survive the winter months (Sanchez-Arroyo, 2005; Schaefer et al., 1983). P. foveolatus has found suitable alternative overwintering hosts in other parts of the world where it has been released for control of MBB. In Pakistan and Japan, it has been observed overwintering 
in Epilachna sp.nr. ocella Redt., and Epilachna admirabilis Crotch (Schaefer et al., 1983). The lack of an overwintering host in the Eastern United States requires that the wasp be released each year, allowing for ecological stability since native insects are not displaced by the presence of $P$. foveolatus.

Upon being released into the field, P. foveolatus begins to mate and search for food, generally wildflower nectar. The female wasps lay eggs inside the MBB larvae by inserting their ovipositors through the cuticle of the larvae (NJDA, 2004). The female lays approximately 20 eggs per larvae, preferring $2^{\text {nd }}$ to $4^{\text {th }}$ instars, and is capable of parasitizing several larvae during her reproductive period, which generally occurs for 3 to 4 weeks after emergence (Stoner, 2002). The eggs placed inside the MBB larvae begin to hatch after several days. P. foveolatus larvae use the MBB larvae as an energy source and begin feeding, eventually killing the host (Stoner, 2002). Approximately three days after being parasitized the MBB larvae stop feeding and by ten days post-parasitization, the bodies of MBB larvae change from yellow to dark brown, resulting in a mummified appearance (Stoner, 2002; NJDA, 2004). The mummified MBB larvae remain attached to the underside of the bean leaves while $P$. foveolatus completes its life cycle inside. The parasitic wasps develop from larvae through pupae, and eventually adults emerge by breaking small holes in the outer skin of the mummified larvae and climbing out (Stoner, 2004). New adults emerge from the MBB larval host in approximately 14-18 days from oviposition, depending on ambient temperatures, ready to find food and mate (NJDA, 2004).

The presence of the parasitic wasp can provide effective control of MBB when releases are timed properly. A population of $P$. foveolatus can build quickly in the field because of its short development time and the numerous new wasps, 20 on average, emerging from each parasitized larva (NJDA, 2004). The parasitic wasp can be effective at reducing the MBB larvae populations and therefore limit the number of MBB adults that develop during the release season, which can furthermore decrease the number of overwintering adults that can infest the following season's crop (NJDA, 2004).

There has been some research conducted, mostly in the late 1970's and early 1980's, on the effectiveness of P. foveolatus at controlling E. varivestis (Stevens et al., 1975; Reichelderfer, 1979; Barrows and Hooker, 1981; Schaefer et al., 1983; Cantwell et 
al., 1985). Most of these studies concentrated on the ability of $P$. foveolatus to act as a biological control with population dynamics as the main data reported. The early work was also mainly conducted on soybeans, G. $\max$, and dry beans, due to their greater economic importance than snap beans. From this early work, several states have implemented successful preventative release programs, especially in the DELMARVA (Delaware, Maryland, and Virginia) area and New Jersey (Sanchez-Arroyo, 2005; Roberts and Douce, 1999).

The ability of $P$. foveolatus to control populations of $E$. varivestis has recently sparked interest again, fueled by the need of conventional and organic producers to find efficient and safe methods of MBB control. Recent studies have concentrated on the efficacy of the wasp in reducing MBB populations in soybeans and have begun to include snap beans but only as a trap crop in soybean production systems. The results have supported the idea that $P$. foveolatus is an effective biological control agent for MBB. However detailed data on timing rates, yield changes, and potential economic profit are still lacking. The release of $P$. foveolatus is increasing the public's awareness of its use and efficacy as a biological control which has resulted in the demand for further information about its abilities.

The reason for our research is that the effectiveness of alternative control methods for reducing MBB populations in snap beans in the Northeast and West Virginia, in particular, has not been addressed. In West Virginia, the production of snap beans is becoming more important, particularly for fresh market production distributed through local farmer's markets and cooperative groceries. In the 2002 season, a total of 116 farms harvested snap beans on 101 acres in West Virginia, totals which have decreased over the past ten years possibly due to a lack of effective control methods for MBB (USDA, 2002; Perez, 1995). Use of row covers, timed plantings, and the release of $P$. foveolatus at controlling MBB populations and increasing harvests for fresh consumption in snap bean crops alone, without the presence of soybean crops, have not been adequately addressed. The evaluation of $P$. foveolatus using more than one cultivar and variety has also not yet been tested. This is especially important in light of the increased production of snap bean varieties in the United States over the last ten years (Lucier and Lin, 2002; Gepts et al., 1996). 
Our research will therefore focus on determining if MBB populations in snap bean crops can be controlled through well-timed releases of $P$. foveolatus. Possible increases in the productivity and profit due to $P$. foveolatus releases in different varieties will also be examined. Other control methods such as the use of row cover, different varieties with possible resistance, and alternating planting times will also be tested for their effectiveness at reducing MBB populations, and possibly increasing yield and profit. The ultimate goal of our research is to find an effective control method or methods for $\mathrm{MBB}$, while increasing the yield and profits of producing snap beans for the farmer. 


\section{Chapter 2 \\ Control Methods for MBB}

\section{Introduction}

In the United States, Phaselous vulgaris or snap beans are a commonly grown and economically valuable crop, often produced on a large scale as well as in market garden settings for fresh consumption. Beans intended for fresh market account for approximately $25 \%$ of snap beans produced in the U.S. and are valued at approximately $\$ 1540$ per acre (Lucier and Lin, 2002). Fresh snap beans are becoming an increasingly important crop in many states as consumers demand more variety in their diets and as farmers try to diversify and find additional sources of income (Gepts, et al., 1996). In West Virginia, the production of fresh market snap beans has begun to increase after a decade long decrease, in 2002 a total of 116 farms produce snap beans on an estimated 101 acres (USDA, 2002).

Mexican Bean Beetle (MBB), Epilachna varivestis Mulsant, infestations are the most devastating pest and the largest factor reducing productivity in snap bean crops in the Eastern U.S. (Sanchez-Arroyo, 2005). A member of the lady beetle or Coccinellidae family, MBB is one of only a few destructive species in this family (Sanchez-Arroyo, 2005). MBB can be found on several leguminous crops however snap beans are the most preferred (Roberts and Douce, 1999). The damage caused by MBB can lead to a total crop loss if the population is allowed to reach economically damaging levels, 1-1.5 larvae per plant (Lambdin et al., 1987; Fan et al., 1993). MBB adults and larvae generally consume lower leaf surfaces resulting in a skeletonized appearance, but they can also consume flowers and developing pods (Peterson et al., 1998; Sorensen, 2004; Ratcliffe et al., 2004).

In an organic production system, treatment of pests with synthetic insecticides is strictly prohibited, leaving producers with few alternatives to control MBB populations. This makes snap beans one of the most difficult crops to produce organically (Hodges, 1990). The most common methods used in organic systems for control of MBB are the

application of agricultural lime to the foliage or removing the MBB from the plants by 
hand. Both methods are highly labor intensive and require many applications throughout the growing season to effectively control MBB populations. In addition, most pesticides approved for use in an organic system are virtually ineffective against MBB, leaving producers limited options. Possible other methods that could be employed by organic producers are the use of a lightweight row cover, the staggering of planting date, or the release of Pediobius foveolatus, a parasitic wasp.

The use of row cover may shelter bean plants from early MBB infestations, allowing for maximum growth and development of natural defense mechanisms before being exposed to the pest. It may be possible that the damage resulting from MBB after the row cover is removed does not necessarily reduce yields since $P$. vulgaris is able to sustain a substantial amount of injury before changes in yield are seen (Sanchez-Arroyo, 2005; Barrigossi et al., 2001).

Another method that could help organic producers maintain MBB populations below economically damaging levels is to stagger the planting dates. Several rows planted every two weeks results in the presence of several developmental stages of bean plants within a field. This method generates the possibility of limiting MBB populations to only the most desired developmental stages, giving those plants not preferred time to grow before beetle populations increase or for bean plants to recover from brief infestations.

Another possible control method to reduce damage below economic thresholds is the use of a biological control. Pediobius foveolatus is a small, $2.0 \mathrm{~mm}-3.5 \mathrm{~mm}$, parasitic wasp that has shown potential at controlling MBB populations effectively (Figure 1). Adult female wasps place eggs inside the bodies of MBB larvae, which is used as an energy source after the wasps hatch and grow inside (Figure 2). The developing wasps eventually kill the MBB larvae, causing them to become mummified (Figure 3), changing from bright yellow to dark brown. The adult wasps emerge from the mummified MBB larvae after a short pupation by cutting small holes in the sides of the mummified host (Figure 4). The entire $P$. foveolatus metamorphosis from egg to adult takes 14-18 days, depending on ambient temperatures, with warm temperatures and high humidity reducing the amount of time required to make the transformation from egg to adult (NJDA, 2004). The short developmental cycle allows for several generations and rapid population 
growth within the bean crop in a given season. $P$. foveolatus has the ability to limit the number of MBB larvae that develop into mature adults, and is therefore is capable of decreasing the levels of destructive populations during the release season, overwintering adults, and the following season's emerging population (NJDA, 2004). P. foveolatus is native to India and is therefore intolerant of the winter temperatures in the Eastern U.S. The inability to overwinter requires that $P$. foveolatus be released each season (SanchezArroyo, 2005; Schaefer et al., 1983).

Over the past ten years the production of $P$. vulgaris has increased in the U.S, leading to an increased demand from producers to find efficient and economical methods to control MBB populations (Lucier and Lin, 2002). Although row cover, staggered planting date, and $P$. foveolatus could possibly be effective in controlling MBB, little study has gone into their actual ability to limit MBB populations in snap bean crops while increasing yields and economic returns. The main goal of our research is to develop efficient economical control methods for MBB on snap bean crops. In order to accomplish this, row cover, staggered plantings, and the release of $P$. foveolatus were employed over two seasons in separate subplots. Data collected on changes in MBB population and yields were correlated with potential economic gains to determine effectiveness. The effectiveness of $P$. foveolatus in West Virginia was also examined by observing changes in the wasp population density compared to those seen in MBB population density.

\section{Materials and Methods}

Our study consisted of six plots, three replicates with (treated plots) and three replicates without (control plots), control methods applied during the 2004 and 2005 growing seasons. Each plot measured $2.7 \mathrm{~m}$ x $9.0 \mathrm{~m}$ and was assigned to one of five locations in the Morgantown area of West Virginia (Figure 5). Three plots were located near small scale certified organic market gardens, two of these were located on the WVU Plant and Soil Science Farm (Rt. 705; Morgantown, WV; 39³8’45.08’N $79^{\circ} 56^{\prime} 16.98^{\prime \prime W}$ ) and one at the Flying Ewe Farm (Rt. 4; Bruceton Mills, WV; $39^{\circ} 41^{\prime} 45.36$ 'N $\left.79^{\circ} 52^{\prime} 22.45^{\prime} \mathrm{W}\right)$. Others were located in sustainable small scale market 
gardens on the WVU Agronomy Farm (Agronomy Farm Rd; Morgantown, WV; 39³9'32.00”N 7954'16.42”W), at 414 Tyrone-Avery Rd; Morgantown, WV (39³8'42.44”N 7954'16.42”'W; owned by Dr. Jim Kotcon), and on Rt. 19;

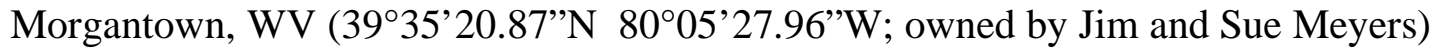
(Figure 6). Each plot, treated or control, was divided into three subplots, each one testing the efficacy of either row cover, parasitic wasp release, or staggered plantings to reduce MBB populations (Figure 7). Treated plots included all three control methods, each randomly assigned to a subplot. Control plots had snap bean plants arranged in similar subplots, but did not include any control methods to deter MBB. Soil preparations started with groundbreaking using a rear tine tiller (BCS, Portland, OR) cutting to a depth of approximately $20 \mathrm{~cm}$. Compost from the WVU Plant and Soil Science Farm was applied at a rate of ten tons per acre (dry weight) subsequently turned under using the same rear tine tiller. Exception to this method occurred at 414 Tyrone-Avery Rd. and Rt. 19, Morgantown where, due to confined space all soil preparations were performed by hand.

Each plot had a total of sixteen rows of various snap bean varieties, which were divided into three separate subplots. Each subplot was designated for testing one MBB control method. The subplot for testing row cover consisted of five rows, each of a different bush bean variety. The subplot testing the staggering of planting dates contained five rows of the variety Provider. The final subplot designated for release of $P$. foveolatus had six rows total; two rows of bush, half-runner, and pole bean varieties. All seeds were inoculated with a Rhizobium spp. (N-Dure, Microbials LLC; Kentland, IN) slurry prior to planting, which did not occur until the soil temperature reached $12^{\circ} \mathrm{C}$ $14^{\circ} \mathrm{C}$. Seeds were sown at a depth of $2.5-3.0 \mathrm{~cm}$ below the soil surface at a rate of 27 seeds/meter in $2.4 \mathrm{~m}$ rows placed $0.3 \mathrm{~m}$ apart for bush varieties, $0.4 \mathrm{~m}$ for half-runner, and $0.6 \mathrm{~m}$ for pole bean varieties. The five varieties of bush beans grown were Black Valentine (Fedco Seeds; untreated), Blue Lake 274 (Peaceful Valley Farm Supply; certified organic), Contender (Peaceful Valley Farm Supply; certified organic), Provider (Fedco Seeds; certified organic), and Royalty (Peaceful Valley Farm Supply; certified organic). The half-runner variety planted was Mountaineer (Vegetable Warehouse; untreated) and the pole variety used was Kentucky Wonder (Peaceful Valley Farm Supply; certified organic). All plots were prepared and planted during a ten-day period 
(May 26-June 6) in both 2004 and 2005 under similar soil and weather conditions. Conditions during this period consisted of a moderately moist soil without any significant precipitation. All plots were watered promptly after sowing to aid in germination. Electrified fences were put in place around each plot to discourage damage from vertebrate pests, especially deer and groundhogs. Once seedlings emerged hay mulch (certified organic) produced on the WVU Plant and Soil Science Farm was applied to the entire plot to a depth of $5 \mathrm{~cm}$ to discourage weed growth. Trellises were built for halfrunner and pole varieties at this time using $2.4 \mathrm{~m}$ and $3.0 \mathrm{~m}$ untreated pine lumber measuring $4.5 \mathrm{~cm} \times 4.5 \mathrm{~cm}$. In order to maintain similar levels of pest pressure $15 \mathrm{MBB}$ adults and $100 \mathrm{MBB}$ larvae, $1^{\text {st }}-2^{\text {nd }}$ instars, were randomly placed into the bean crop at each plot prior to first flower.

Weekly observations on each variety began after seedling emergence and included height, growth and developmental stage of $P$. vulgaris, MBB adult population, MBB pupal population, MBB larval population, parasitized MBB larval counts, number of MBB egg masses, percent defoliation, and snap beans yields. Statistical analyses were performed using JMP (SAS Institute, Cary, NC) in order to determine if significant differences occurred among treated and control subplots using a one-way analysis of variance (ANOVA) with a least significant difference (LSD) of $\mathrm{P}<0.05$. Three-way ANOVA tests with a least significant difference (LSD) of $\mathrm{P}<0.05$ were used to determine the significance of treatment, sampling week, and cultivar as factors.

\section{Measurements}

Variety height was averaged using five plants randomly selected within each row. Data were collected in inches using a standard measuring tape, then converted to meters using the equation: height $(\mathrm{m})=$ height $(\mathrm{in}) \times 0.0254 \mathrm{~m} / \mathrm{in}$. The various stages of growth were also noted: vegetative, anthesis or first flower, and pod formation.

All MBB populations were estimated by counting the number of individual egg masses, larvae, regardless of instar, pupae, and adults found on the underside of seventyfive randomly chosen trifoliate leaves within each row of every variety on a weekly basis beginning at seedling emergence. 
Counts of parasitized larval were recorded using the same protocol used for all other MBB populations (see above) starting after the first release of the parasitic wasps. MBB were considered parasitized when they appeared mummified, changing from yellow to brown. Parasitized MBB larvae were no longer counted once the adult wasps had emerged, indicated by small exit holes in the sides of the mummified larvae.

Percent defoliation was estimated for each variety by randomly selecting ten trifoliate leaves, each from a different plant. From each trifoliate the least and most damaged leaves were disregarded, the remaining leaf was then compared to a damage MBB assessment chart for soybeans (Wilson, 1989) (Figure 8). The weekly estimates were obtained by averaging the values for the 10 leaflets measured within each variety.

Beans were harvested weekly by hand as they reached maturity for the particular variety, varying from 58-70 days. Bean harvests were weighed in $\mathrm{kg}$.

Weekly and monthly precipitation, temperature, growing degree days accumulated, and humidity data were collected from the National Weather Service (NWS). The data were analyzed using a one-way ANOVA with a LSD of $\mathrm{P}<0.05$ to determine if seasonal differences existed.

\section{Row cover}

To test the efficacy of row cover to limit MBB populations and damage, five rows of bush beans were planted in a $2.0 \mathrm{~m}$ x $2.4 \mathrm{~m}$ subplot. Each $2.4 \mathrm{~m}$ row was randomly assigned to one variety; Black Valentine, Blue Lake 274, Contender, Provider, or Royalty.

After plot preparations were complete light-weight $\left(0.55 \mathrm{oz} / \mathrm{sq}\right.$ yd) Agribon ${ }^{\mathrm{TM}}$ AG19 (PGI, North Charleston, SC) row cover measuring $5.0 \mathrm{~m}$ x $6.0 \mathrm{~m}$ was loosely laid over the subplot area. The row cover was held down using 20 galvanized u-shaped anchors and soil placed around the perimeter. The seedlings were able to emerge through the hay mulch and remained underneath the row cover until the first harvest of green beans (self pollinators), when the row cover was permanently removed (July 10-20). After removing the row cover weekly observations were made and data were collected including plant height, growth and development stage of the snap beans, counts on all MBB populations, percent defoliation, and green bean yields. 
Data were analyzed using a one-way ANOVA to test the effect of the row cover application on yield and MBB population. Three-way ANOVA test was used to determine the significance of interactions between the independent variables, row cover treatment by sampling week, and cultivar on the dependent variables, yield and MBB populations.

\section{Staggered Planting Date}

A $2.0 \mathrm{~m} \times 2.4 \mathrm{~m}$ subplot was planted with one $2.4 \mathrm{~m}$ row of Provider bush bean every 14 days for a total of five plantings each during the 2004 and 2005 experiment (May 26-August 10). After beans emerged from each row the following observations were made weekly: plant height and growth stage, counts of all MBB populations, percent defoliation, bean yield and parasitized larvae counts.

A one-way ANOVA test with an LSD of $\mathrm{P}<0.05$ was used to analyze the effect of the treatment on yield and MBB population in the subplot. Three-way ANOVA with a LSD of $\mathrm{P}<0.05$ was used to determine the effect interactions of the treatment, planting date, and sampling week as independent factors on dependent factors such as green bean yield and MBB population density.

\section{Parasitic Wasp Release}

In a subplot $5.0 \mathrm{~m} \times 2.4 \mathrm{~m}$, two $2.4 \mathrm{~m}$ consecutive rows of Provider bush, Mountaineer half runner, and Kentucky Wonder pole beans were used to test the efficacy of releasing the parasitic wasp, Pediobius foveolatus, on MBB populations and defoliation, and the resulting snap bean yield. One $2.4 \mathrm{~m}$ row of buckwheat (Fagopyrum esculentium) and one $2.4 \mathrm{~m}$ row of a wildflower mix (Beneficial Bug Mix, Territorial Seeds and Northern Lights Wildflower Mix, Johnny's Select Seeds) were planted at both ends of the subplot, $0.3 \mathrm{~m}$ apart, to provide a nectar food source for P. foveolatus. Wildflower mixes contained the species Lanceleaf Coreopsis (Coreopsis lancelata), California Poppy (Rudbeckia hirta), Shasta Daisy (Chrysanthemum maximum), Sweet Alyssum (Lobularia maritime), Forget-Me-Not (Myosotis sylvatica), Dill (Anethum graveolens), Cilantro (Coriandrum sativum), and Yarrow (Achillea millefolium). Natural 
populations of Queen Anne's Lace (Daucus carota) that were present in the experiment area also were available as a nectar source.

The first wasp release was made when MBB second and third larval instars were observed in the bean crop. A second release occurred one week later (July 16-July 30). Parasitized MBB larval mummies were purchased from the New Jersey Department of Agriculture (Phillip Alampi, Insect Rearing Laboratory, Trenton, NJ) at 50ф per mummy plus shipping (standard overnight at approximately \$30). To release wasps, five mummified larvae were placed in a small screen bag made of $2 \mathrm{~mm}$ mesh. To protect the mummies from possible predators and weather, the bag was tied to a stem beneath the canopy. Adult wasps emerged within a few days after being tied in the plot. Weekly observations and measurements were taken on plant height and growth stage, population counts on all stages of $\mathrm{MBB}$, parasitized larval counts, percent defoliation, and bean yield.

Data were analyzed using a one-way ANOVA to determine if the application of $P$. foveolatus of MBB had significant effect on the yield of snap beans and the MBB population present. Three-way and two-way ANOVA test was used to determine if the interactions of the independent variables, treatment method, time (weeks), and cultivar had an effect of the dependent variables, yield and MBB population density. Orthogonal contrasts were used to test to the means within the interaction.

\section{Results}

\section{Climate data}

The weather data showed that there were significant differences $(\mathrm{P}<0.05)$ between the 2004 and 2005 seasons in precipitation only (Figure 9). Differences in humidity, maximum temperature, mean temperature and the average degree days were all found to be similar over both seasons. In the 2004 season May-September precipitation totaled $50.3 \mathrm{~cm}$. The months June-September all had similar rainfall totals averages $10.0 \mathrm{~cm}$, May was the only month that was different, with only $4.8 \mathrm{~cm}$ of total rainfall (Figure 10). In the 2005 season the total precipitation was $28.5 \mathrm{~cm}$ for the months May-September. 
The months June-September were found to again have similar monthly rainfall totals, however they only averaged $4.5 \mathrm{~cm}$. May again was found to have statistically different $(\mathrm{P}<0.05)$ total precipitation, $10.6 \mathrm{~cm}$, than the other months in the growing season.

Humidity was found to be similar for both seasons. The 2004 season showed an average of $76 \%$, while the 2005 showed an average of $69 \%$ daily relative humidity (Figure 11).

The maximum and mean temperatures were similar for both the 2004 and 2005 seasons (Figure 12). In 2004 the average maximum daily temperature was $25^{\circ} \mathrm{C}$ and the mean daily temperature $19.6^{\circ} \mathrm{C}$. The 2005 season showed an average daily maximum temperature of $27^{\circ} \mathrm{C}$ with a mean of $21.5^{\circ} \mathrm{C}$. Average daily minimum temperatures were found to be similar for both seasons, $14.2{ }^{\circ} \mathrm{C}$.

The average growing degree days (DD) were similar for both the 2004 and 2005 seasons. In each season an average of 19 degree days were gained per day starting in May. Only the month of May was found to be different between seasons, with an average DD gained per day of 17 in 2004 compared to only 8 in 2005.

\section{Row cover}

The two-way interactions of row cover treatment-by-sampling (weeks) and variety-by-sampling (weeks) were significant $(\mathrm{P}<0.05)$ in 2004 (Table 1). The 2004 season total yields averaged $14.7 \mathrm{~kg} / \mathrm{m}^{2}$ and $11.4 \mathrm{~kg} / \mathrm{m}^{2}$ for treated and control subplots, respectively. Orthogonal contrast of the row cover treatment-by-sampling (weeks) interaction was significant in weeks $3,4,6$, and 7. Row cover treated subplots produced larger yields early in the season, week 3, and again late season, weeks 6-7. Week 4 showed to have larger yields from the control subplots. The variety Blue Lake 274 had low germination in treated and control subplots in both seasons, however showed significantly different $(\mathrm{P}>0.05)$ yields in 2004 compared to the other varieties tested (Figure 13). The one-way test showed significant differences $(\mathrm{P}<0.05)$ in green bean yield between row cover treated subplots and control subplots in 2004.

In 2005 the two-way interaction of row cover treatment-by-sampling (weeks) was again found to have a significant effect on yield $(\mathrm{P}<0.05)$ (Table 3). The 2005 season yields averaged $5.9 \mathrm{~kg} / \mathrm{m}^{2}$ per treated subplot and $6.1 \mathrm{~kg} / \mathrm{m}^{2}$ per control subplot. 
Orthogonal contrast showed significant differences in the row cover treatment-bysampling (weeks) interaction during sampling weeks 3, 4, 5, 6, 7, and 8 (Table 4). Weeks $3,4,5$, and 8 all had greater yields from row cover treated subplots. Weeks 6 and 7 had larger yields from control subplots. The one-way showed that the overall green bean yield between row cover treated and control subplots was not significant in 2005.

Differences in the yield of green beans from subplots receiving row cover treatment and subplots without row cover (control) were not similar in either 2004 or 2005 (Figure 14). Green snap bean yields were significantly higher $(\mathrm{P}<0.05)$ in 2004 than in 2005.

In both seasons MBB adult, pupal, and larval populations were found to be different between treated and control subplots, however, this is true only for weeks 2-5 of observations (Figure 15A, Appendix A). The MBB population one week (sample week 4) after the row cover was removed averaged 1 adult, 1 pupa, 8 larvae, and 2 egg masses per treated subplot, while control subplots averaged 8 MBB adults, 5 pupae, 31 larvae, and 2 egg masses. No parasitized larvae were present in either subplot. The MBB population at the end of the season, several weeks after the row cover had been removed, in 2004 still showed significantly different larval and adult populations between treated and control subplots (Figure 15B, Appendix A). The final MBB population averaged 17 adults, 43 pupae, 53 larvae, and 1 egg mass per subplot with row cover, while control subplots had an average of 61 adults, 75 pupae, 150 larvae, and 2 egg masses. The treated subplot had an average of 6 parasitized larvae due to migration of $P$. foveolatus into these subplots however mummies were not observed until week 7. P. foveolatus were not found in control subplots either season. At the end of the 2005 season, only larval populations were significantly different in treated subplots compared to control subplots. Adult, pupal, and egg mass counts were all found to be similar between treated and control subplots. The treated subplot average was 8 adults, 20 pupae, 72 larvae, and 2 egg masses while control subplots averaged a MBB population of 6 adults, 42 pupae, 139 larvae, and 1 egg mass. In 2005, an average of 7 parasitized larvae was found in treated subplots, no parasitized larvae were found in control subplots.

The plant height was not different in treated subplots compared to control subplots, although a trend toward increased plant height in treated plots was observed. 
Provider plants under row cover reached approximately $0.6 \mathrm{~m}$, while those without also grew to $0.6 \mathrm{~m}$ on average. The variety Purple Royalty reached $0.7 \mathrm{~m}$ and $0.6 \mathrm{~m}$ while Contender reached $0.5 \mathrm{~m}$ and $0.4 \mathrm{~m}$ on average for treated and control subplots, respectively. Although both seasons produced taller plants under the row cover treatment, the 2005 season produced a leggy crop that had trouble holding itself upright. The 2005 bean crop also appeared to suffer from the extremely high temperatures observed beneath the row cover. The 2004 row cover crop was taller, and more full and vigorous (personal observation). No differences were observed in the growth and development of $P$. vulgaris in any of the varieties tested.

\section{Staggered planting date}

A three-way interaction of staggered planting treatment-by-planting date-bysampling (weeks) was found to be significant in only the 2005 season (Table 6). In the 2004 and 2005 seasons a two-way interaction of planting date-by-sampling (weeks) was found to be significant (Table 5 and 6). In 2005, an additional two-way interaction was also found to exist. The interaction of staggered planting treatment-by-sampling (weeks) was found to be significant. An orthogonal contrast further showed that the interaction had significant yield effect during sampling weeks 4 and 6 (Table 7). The one-way test showed that the difference in total green bean yield from treated and control subplots was not significant during either season ( $\mathrm{P}>0.05)$ (Figure 16).

Adult, pupae, and larvae MBB populations were found to be different $(\mathrm{P}<0.05)$ in treated subplots compared to those found in control subplots during the 2004 season, all other populations were similar (Figure 17, Appendix B). Treated subplots had an average final population of 4 adults, 5 pupae, 18 larvae, 1 egg mass, and 18 parasitized larvae compared to 0 adults, 0 pupae, 0 larvae, 0 egg masses and 0 parasitized larvae averaged in control subplots. Only adult MBB populations in the 2005 season were significant between treated and control subplots over the season (Figure 18, Appendix B). Treated subplots had an average final MBB population consisting of 4 adults, 19 pupae, 25 larvae, 0 egg masses, and 33 parasitized larvae on average while control subplots had a similar final population averaging 5 adults, 9 pupae, 43 larvae, 1 egg mass, and no parasitized larvae. 
All MBB populations (Figure 19A), percent defoliation, and resulting snap bean harvests (Figure 20) were all found to be similar $(\mathrm{P}>0.05)$ in treated and control subplots for the first of the five staggered plantings during both seasons. Treated subplots yielded $2.0 \mathrm{~kg} / \mathrm{m}^{2}$ of green beans, while control subplots yielded $2.5 \mathrm{~kg} / \mathrm{m}^{2}$, with both treated and control subplots having approximately $10 \%$ defoliation. The average final MBB population found in treated subplots consisted of 1 adult, 6 pupae, 3 larvae, 5 parasitized larvae, and 0 egg masses compared to 2 adults, 6 pupae, 16 larvae, 0 parasitized larvae, and 1 egg masses in control subplots. The second planting was also found to have similar ( $\mathrm{P}>0.05$ ) yields (Figure 20) and MBB populations (Figure 19B) in treated and control subplots. In both subplots percent defoliation averaged $20 \%$, treated areas had a final MBB population averaging 1 adult, 9 pupae, 12 larvae, 4 parasitized larvae, 1 egg masses and yielded $2.2 \mathrm{~kg} / \mathrm{m}^{2}$ per subplot of green snap beans. Control subplots yielded 1.3 $\mathrm{kg} / \mathrm{m}^{2}$ with an average final population of $6 \mathrm{MBB}$ adults, 12 pupae, 27 larvae, 0 parasitized larvae, and 1 egg mass. The third staggered planting however was found to have different bean yields $(\mathrm{P}<0.05)$ when comparing treated to control subplots, with green bean harvests of $1.6 \mathrm{~kg} / \mathrm{m}^{2}$ and $0.8 \mathrm{~kg} / \mathrm{m}^{2}$, respectively (Figure 20). The final MBB larval, pupal population and egg mass counts were similar, while adult populations were found to be different in treated compared to control subplots (Figure 19C). Treated subplots had a final MBB population of 2 adults, 7 pupae, 9 larvae, 8 parasitized larvae, and 0 egg masses with 20\% defoliations compared to 7 adults, 7 pupae, 39 larvae, 0 parasitized larvae, and 1 egg mass with 35\% defoliation found in control subplots on average. The fourth staggered planting only produced beans in treated subplots during the 2004 season (Figure 20), with an average yield of $1.2 \mathrm{~kg} / \mathrm{m}^{2}$ of green beans per subplot and $10 \%$ defoliation. MBB populations were found to be different for the fourth planting between treated and control subplots, except for egg masses, during the 2004 season. The treated subplot final population consisted of 2 adults, 2 pupae, 9 larvae, 3 parasitized larvae, and 0 egg masses compared to 13 adults, 16 pupae, 27 larvae, 0 parasitized larvae, and 3 egg masses in control, on average. The fourth staggered planting in 2005 showed no differences in any MBB populations between treated and control subplots. The treated subplots had a final MBB population of 1 adult, 2 pupae, 12 larvae, 0 egg masses and 5 parasitized larvae compared to control subplots with 2 adults, 
3 pupae, 20 larvae, 0 egg masses, and no parasitized larvae. The treated subplots also had less damage by the end of the season than the control subplots, $10 \%$ and $20 \%$, respectively. The fifth and final planting did not produce mature beans for harvest during either season. However in 2004, plants were taller with less defoliation, $0.3 \mathrm{~m}$ and $<10 \%$ defoliation in treated subplots compared to that found in control $0.1 \mathrm{~m}$ and $20 \%$ defoliation. In 2005, both treated and control subplots reached $0.1 \mathrm{~m}$ with $20 \%$ defoliation.

\section{Pediobius foveolatus release}

A three-way interaction of wasp release treatment-by-cultivar-by-sampling (weeks) was found to have a significant ( $\mathrm{P}<0.05)$ effect on yield in 2004 (Table 8). In 2005, two-way factorial interactions of $P$. foveolatus treatment-by-sampling (weeks) and cultivar-by-sampling (weeks) were found to have a significant $(\mathrm{P}<0.05)$ effect on the green bean yield (Table 9). Orthogonal contrasts show that green bean yield is significant increased late in the season when $P$. foveolatus is released in the subplot during both seasons.

Subplots that were treated with Pediobius foveolatus were found to have significantly different $(\mathrm{P}<0.05)$ snap beans yields than those found in subplots without $P$. foveolatus in 2004, but not in 2005 (Figure 21). In 2004, the total average green bean

yield in treated subplots was $68.4 \mathrm{~kg} / \mathrm{m}^{2}$ per subplot compared to $30.4 \mathrm{~kg} / \mathrm{m}^{2}$ from each control subplot. In 2005, there were no differences observed in the resulting green bean yields between treated and control subplots, averaging $24.4 \mathrm{~kg} / \mathrm{m}^{2}$ and $20.2 \mathrm{~kg} / \mathrm{m}^{2}$, respectively. Significantly different $(\mathrm{P}<0.05)$ average green snap bean yields were found between treated subplots in 2004 compared to $2005,34.2 \mathrm{~kg}$ and $12.2 \mathrm{~kg}$, respectively.

In 2004 differences between treated and control subplots in adult, pupal, and larval MBB populations and parasitized larvae were found to be significant $(\mathrm{P}<0.05)$ (Figure 22, Appendix C). The average final MBB populations in treated subplots consisted of 22 adults, 20 pupae, 17 larvae, 1 egg mass and 25 parasitized larvae compared to the $32 \mathrm{MBB}$ adults, 43 pupae, 49 larvae, 1 egg masses and 0 parasitized larvae found in control subplots. In 2005, only the MBB larval population and parasitized larvae were significantly different $(\mathrm{P}<0.05)$ between treated and control 
subplots (Figure 23, Appendix C). Treated subplots had an average final MBB population of 6 adults, 32 pupae, 57 larvae, 3 egg masses, and 72 parasitized larvae, while control subplots had 7 adults, 43 pupae, 132 larvae, 3 egg masses, and 0 parasitized larvae. Peak populations of $P$. foveolatus followed those of the peak MBB larval populations. The highest MBB larval counts occurred weeks 4-5 during the 2004 season (Figure 22), and week 5 during 2005 (Figure 23), while peak parasitized larval counts occurred during week 6 and week 7, respectively.

The pole bean cultivar, Kentucky Wonder, showed significantly different $(\mathrm{P}<0.05)$ MBB adult and larval populations between treated and control subplots for both seasons (Figure 24). The average final MBB population consisted of 5 adults, 13 pupae, 10 larvae, 19 parasitized larvae, and 1 egg mass in treated subplots compared to 0 adults, 14 pupae, 17 larvae, 0 parasitized larvae, and 1 egg mass in control subplots. The pole bean yield harvested in the 2004 season was different $(\mathrm{P}<0.05)$ in treated and control subplots, $11.8 \mathrm{~kg} / \mathrm{m}^{2}$ per subplot and $6.0 \mathrm{~kg} / \mathrm{m}^{2}$ per subplot, respectively (Figure 25). The 2005 pole bean yield was not different $(\mathrm{P}>0.05)$ among the treated, $4.2 \mathrm{~kg} / \mathrm{m}^{2}$ per plot, and control, $2.4 \mathrm{~kg} / \mathrm{m}^{2}$, subplots (Figure 25). At the end of the season the final percent defoliation was different among treated and control subplots for the 2004 season, however not during 2005. Treated subplots in 2004 ended with 20\% defoliation while control subplots were over 50\% defoliation. In 2005, treated plots ended with approximately $40 \%$ defoliation, while control had over $50 \%$ defoliation.

Mountaineer half runner beans showed significantly different $(\mathrm{P}<0.05) \mathrm{MBB}$ pupal, and larval populations, as well as the number of parasitized MBB larvae in treated subplots compared to control during both seasons (Figure 26). The final average MBB population in treated subplots was 5 adults, 9 pupae, 5 larvae, 19 parasitized larvae and 1 egg mass and 17 adults, 31 pupae, 49 larvae, 0 parasitized larvae, and 2 egg masses in control subplots. The green bean yields that were obtained during 2004 were $9.8 \mathrm{~kg} / \mathrm{m}^{2}$ per subplot with $20 \%$ defoliation and $6.4 \mathrm{~kg} / \mathrm{m}^{2}$ per subplot with $40 \%$ defoliation for treated and control subplots, respectively (Figure 25). In 2005, treated subplots yielded less snap beans than those in control subplots, $3.2 \mathrm{~kg} / \mathrm{m}^{2}$ and $3.8 \mathrm{~kg} / \mathrm{m}^{2}$, respectively, with an average of $40 \%$ defoliation per subplot (Figure 25). There was a significant difference 
$(\mathrm{P}<0.05)$ in snap bean yields harvested in the 2004 season compared to the 2005 season in treated subplots, but control subplot yields were similar.

Only the MBB larval populations were significantly different $(\mathrm{P}<0.05)$ between treated and control subplots for Provider bush beans during both seasons (Figure 27). Treated subplots had an average final MBB population of 1 adult, 2 pupae, 3 larvae, 7 parasitized larvae, and 0 egg masses with $30 \%$ defoliation compared to 3 adults, 6 pupae, 10 larvae, 0 parasitized larvae, and 0 egg masses with $40 \%$ defoliation in control subplots. Yields of green snap beans were also found to be similar $(\mathrm{P}>0.05)$ for both seasons (Figure 25). Treated subplots averaged $2.2 \mathrm{~kg} / \mathrm{m}^{2}$ of green snap beans while control subplots yielded an average of $1.9 \mathrm{~kg} / \mathrm{m}^{2}$ of green beans.

On average, larger $P$. foveolatus populations were found within the pole and halfrunner bean plantings compared to the bush variety during the 2004 seasons (Figure 28). Pole beans had a peak population with an average 39 parasitized larvae per subplot and half-runners averaged 69 parasitized larvae per subplot, while bush beans averaged 20 parasitized larvae per subplot. In 2005, the $P$. foveolatus populations showed no varietal differences among the pole, half-runner, and bush varieties, with averaging 58, 52, and 25 parasitized larvae per subplot, respectively (Figure 28).

Overall, Kentucky Wonder pole beans produced the greatest green bean yield, averaging $16.2 \mathrm{~kg} / \mathrm{m}^{2}$, compared to half-runner and bush varieties from treated subplots. In control subplots, Kentucky Wonder pole beans had the lowest yield, $8.4 \mathrm{~kg} / \mathrm{m}^{2}$, compared to the bush and half-runner varieties. It was found that height did not differ between treated and control subplots for any of the cultivars. The pole variety reached $2.0 \mathrm{~m}$ whereas the half runner and bush variety reached $1.2 \mathrm{~m}$ and $0.6 \mathrm{~m}$, respectively. Plant growth and development in treated and control subplots was similar during both seasons.

\section{Treatment Interactions}

The migration of $P$. foveolatus into the row cover subplots did not seem to influence yields during either season. No increases in bean yield were seen after parasitized larvae were found in the row cover subplots. 
Although not found to be significant, $P$. foveolatus in the staggered planting subplot may have given the plantings with late harvests an advantage. The migration of $P$. foveolatus into only the $4^{\text {th }}$ planting date would have been beneficial in terms of MBB population control. Earlier plantings had similar MBB populations with and without the presence of $P$. foveolatus within the treatment area. After parasitized MBB larvae were found in staggered planting subplots, the MBB population and percent defoliation remained relatively constant without significant increases, unlike what was observed in the control subplots.

\section{Discussion}

Our study showed seasonal differences in larval, pupal, and adult MBB populations, the number of parasitized larvae, and bean yields. These differences are likely a result of the weather differences, especially differences in total precipitation and precipitation patterns that occurred in the 2004 and 2005 growing seasons. The 2004 season was clearly wetter than 2005, with 2005 climatic data showing drought conditions. This important abiotic factor could have had a strong influence on the larval, pupal, adult MBB populations, the number of MBB larvae parasitized by $P$. foveolatus, and the performance of $P$. vulgaris. The most important abiotic factor influencing snap bean yields is precipitation and our results can corroborate these previous findings (Singh, 2001; Lizana et al., 2006).

In 2004, large amounts of precipitation can be linked to the rapid development of larvae, pupae, and adult MBB populations, as well as high yields of green beans. Barrigossi et al. (2001) indicated that the percentage of emergence of MBB is low under dry conditions, therefore delaying the proliferation of MBB populations. Our 2004 data clearly indicates that this may have occurred in our plots, due to the slow MBB increases during May, followed by rapid increases seen thereafter when precipitation totals increased. The month of May was found to be much drier than the months of JuneSeptember in 2004. The remaining growing season, June-September, precipitation was not limited, which allowed for rapid growth and response to MBB damage (i.e. growth of new leaves, maturation of natural defenses) by $P$. vulgaris, both of which favor higher 
bean yields (Lizana et al., 2006). In addition, low soil moisture may have contributed to less soil borne disease pressures during the initial crop establishment, allowing for the early proliferation of $P$. vulgaris (Júnior et al., 2007).

The higher humidity trends observed in the 2004 season compared to 2005 may have influenced the higher MBB and P. foveolatus populations observed in the 2004 season. Increased humidity has been shown to decrease the developmental time required for MBB and P. foveolatus to go from egg to adult (Wilson et al., 1982; Barrigossi et al., 2000; NJDA 2004). Wilson et al. (1982) also showed that humidity and the rate of fecundity are directly correlated.

Data collected in 2004 suggests that larval, pupal, and adult MBB populations increased quickly in the field when precipitation was not limited (June- September), resulting in higher MBB populations overall than those observed in 2005. However, the weather conditions were also conducive to rapid population development of $P$. foveolatus and growth of $P$. vulgaris.

As previously mentioned the 2005 season was much different than 2004, with drought conditions but also higher daily maximum temperatures. The month of May in 2005 was very different in terms of precipitation than the remaining months of the season. The heavy precipitation observed during the month of May most likely increased the percentage of adult MBB emerging from hibernation and feeding on young bean leaves (Barrigossi et al., 2001). The limited availability of water during June-September in turn could have altered the ability of $P$. vulgaris to respond to pest damage, leading to decreased yields. Chaves et al. (2002) and Osorio et al. (1998) showed that water stress on $P$. vulgaris can cause loss of plant parts, as well as biochemical, morphological, and functional changes that can ultimately decrease the growth rates and bean yield. Combined, high initial MBB populations, decreased green bean growth, and changes in snap bean development would therefore lead to the drastically lower yields observed in 2005.

High temperatures during the 2005 season could have also influenced the behavior of the larval and adult MBB. The average daily maximum temperature during this season was $27^{\circ} \mathrm{C}$, which Wilson et al. (1982) found was the optimal temperature for the development of MBB from egg hatch to pupation, possibly accounting for the 
increased number of larvae found in both treated and control plots at the end of the season in 2005 compared to 2004. In 2005 a decreased population of MBB adults were found in both treated and control plots at the end of the season in comparison to those found in 2004, possibly due to the decreased longevity of MBB adults at high temperatures especially under water stress (Edwards and Bergman,1987; Barrigossi et al., 2001).

Greater defoliation was also observed in 2005, which may have been accelerated by water stress. It has been suggested that under water stress, leaflets of $P$. vulgaris can experience nutrient changes, which may cause diffusion of larval populations throughout the canopy, as well as increase their rate of consumption (Wilson et al., 1982; Beanland et al., 2002). High temperatures can also cause MBB larvae to spread out to find cooler locations, increasing the area damaged by the pests (Barrigossi et al., 2001).

From the data collected on the efficacy of the control methods throughout the experiment it can be suggested that larval and adult MBB populations can be reduced while increasing bean yields with the use of two of the methods that were tested, row cover and the release of the parasitic wasp, $P$. foveolatus, when water is not limited. Under water stress, larval MBB populations can be decreased using either row cover or the release of $P$. foveolatus, however a significant increase in bean yield may not be seen. Again, water availability is the key abiotic factor in obtaining increased green bean yields. The staggering of planting date was only effective when used in conjunction with the release of $P$. foveolatus, especially with late plantings.

The results from the row cover treatment indicate that row cover can be effective at deterring MBB from becoming established in a snap bean crop. However once the row cover is removed populations can build quickly. Although MBB larval populations were significantly lower in treated subplots, the yield of green beans was not significantly greater in either season. Motsenbocker and Bonanno (1989) found that row cover did not increase marketable yields of muskmelons and concluded that excessive air temperatures beneath the row cover increased plant stress and decreased plant vigor, likely the cause of the differences in yield between seasons in our experiment. In 2005, daily maximum temperature was $27^{\circ} \mathrm{C}$, beneath the row cover temperatures would have been elevated, which accompanied with little precipitation, would have created unfavorable growing 
conditions for $P$. vulgaris. Extreme temperatures were observed by Gent (1990) to cause flower abortion in tomatoes grown under row cover, which delayed harvests and decreased yields, possibly another indication of why the snap bean yields harvested in the 2005 from treated row cover subplots were less than those produced in control subplots. Optimal growth conditions for green beans include day temperatures of less than $30^{\circ} \mathrm{C}$. Higher temperatures result in dropped flowers and a decrease in pod formation (Singh, 2001).

Our data showed that plant height was increased by the presence of row cover, which supports earlier research conducted on radishes, cabbages, and sweet corn (Nelson et al., 1986). The increased plant height was not a problem in 2004, when optimal growing conditions allowed for more vigorous plants. However in 2005, the bean plants grew leggy and had trouble staying upright. The seed from variety Blue Lake 247 did not perform well at any location, in either season. Germination was around 10\%, possibly due to nonviable seeds or soil pathogens, resulting in substantially lower yields.

Although the overall yield was not found to be different between treated and control subplots, the data does suggest that a green bean yield can be harvested earlier from plants grown under row cover. The data also suggests that row cover treatment could increase the likelihood late season green bean harvests.

The data on row cover suggests that even though this method was able to reduce MBB larval populations, yield was not significantly increased. The data also indicated that row cover could induce plant stress by creating extreme high ambient temperatures and or humidty around the bean plants, which in turn could reduce yields as much as damage from MBB infestations would.

$P$. foveolatus was found to be most effective at controlling larval MBB and decreasing adult MBB populations when water was not limited. Significant increases in green bean yields in subplots with wasp release in 2004 are likely correlated to the control of both larval and adult MBB populations observed during that season.

The data collected comparing cultivars suggests that populations of $P$. foveolatus, indicated by the number of parasitized MBB larvae, were greater among pole and half runner cultivars. The greater presence of $P$. foveolatus can be correlated to two important factors. First, the increased biomass which results from multiple vegetative meristems in 
the taller cultivars that are capable of continuous growth and flowering allow for $P$. foveolatus to have greater protection from natural enemies and unfavorable weather conditions (Balasubramanian et al., 2004). The increased biomass also offers an increased food supply for MBB and protection from weather, leading to increased MBB populations, similar to what has been observed by Turchin (1988) in bush bean varieties. Secondly, the greater MBB larval populations within the two taller cultivars compared to those found among the bush cultivar, in turn leads to high host densities. The high population of MBB larvae offers mating females plenty of opportunity to deposit their eggs, increasing the population of wasp present in the cultivar. At the end of 2004, larval, pupal, and adult MBB populations were all significantly reduced by $P$. foveolatus in the pole and half runner cultivars. Bean yield was increased in all subplots with wasp release, although only significantly in pole and half runner, the later maturing varieties. The bush cultivar was harvested much earlier than the pole and half runner cultivars, at which time MBB adults had not been significantly altered by the presence of $P$. foveolatus, but had begun to decrease. Our data indicate that in order for $P$. foveolatus to maximize bean yield, both adult and larval MBB populations need to be controlled. Control of both larvae and adults did not occur until after the bush variety produced beans. The data also imply that $P$. foveolatus is the most effective at reducing larval MBB populations and the resulting MBB adult populations, ultimately increasing bean yields under optimal growing conditions. Overall, the data also suggest that inoculative releases made mid-June of $P$. foveolatus were most effective in later maturing varieties, such as pole or half-runner beans.

An important observation, of the presence of parasitized MBB pupae (Figure 29), was documented during our experiment. Several mummified MBB pupae were found each season in the treated subplots, but not until later in the season, however, when larval populations had decreased. It is unclear whether the mummified pupae were parasitized during pupation or if they were $4^{\text {th }}$ larval instars that were able to enter pupation before becoming mummified (Figure 30). Some of the parasitized pupae contained $P$. foveolatus that had developed through the larval phase and had entered pupation, suggesting that the MBB had been parasitized approximately 10-13 days prior (Figure 31). Parasitized MBB pupae have been discussed briefly by Patalappa and 
ChannaBasavanna (1979), however details were not discussed and no other research was found to mention parasitized pupae at all.

Staggering of planting date did not produce any differences in MBB populations or yield for the first and second plantings, possibly due to the smaller, first generation MBB population. Kabissa and Fronk (1986) found that the early MBB populations consist mainly of adults and $1^{\text {st }}-2^{\text {nd }}$ larval instars, which consume less leaf material than $3^{\text {rd }}$ or $4^{\text {th }}$ instars, allowing $P$. vulgaris to be largely unaffected by the damage. The third planting, which occurred in early June, showed the greatest difference in yield, larval, and adult MBB populations. Our data corroborates the findings of Balasubramanian et al. (2004), that plantings occurring at the conventional time, late-May, had higher bean yields. However, it is not completely clear if the differences are associated with planting date, climate conditions, or the possibility $P$. foveolatus migrating into the bean plants in this subplot in our experiment.

The fourth planting only produced mature beans during the 2004 season (Figure 32). These plants also had low larval and adult MBB populations, accompanied with little defoliation, a significant number of parasitized larvae, and warm temperatures (above $15^{\circ} \mathrm{C}$ ). Balasubramanian et al. (2004) concluded that later plantings, mid-June through July, can suffer damage from early frost and temperatures reaching below $15^{\circ} \mathrm{C}$ at all stages of growth (Balasubramanian et al., 2004). These finding may help explain the data recorded from the fourth and fifth planting dates of our experiment. During 2004, it was unclear if favorable weather conditions late in the season or the presence of $P$. foveolatus contributed to the differences between treated and control subplots. However, it did support our contention of the importance in controlling larval and adult MBB populations early in the growing season in order to produce higher yields in the late season plantings of bush cultivars. In 2005, the fourth planting was likely affected by unfavorable conditions including limited water, temperatures around or below $15^{\circ} \mathrm{C}$, and higher larvae and adult MBB populations. The fifth planting suffered from frost damage during both seasons, lending support to the findings made by Balasubramanian et al. (2004). However in 2004 the bean plants had very little defoliation, while those in 2005 had much more damage before being exposed to low temperatures. This is likely due to 
the significantly reduced MBB larval and adult populations observed late in the 2004 season but not in the 2005 season.

The presence of $P$. foveolatus in 2004 among the later, $4^{\text {th }}-5^{\text {th }}$, staggered plantings could have attributed to the reduced larval and adult MBB populations found and the slightly increased yields seen in the later plantings during that season. In 2005, no beans were harvested and no parasitized larvae were found in the late, $4^{\text {th }}-5^{\text {th }}$, plantings.

Our data indicate the possibility for an increase in gross income with the use of $P$. foveolatus in crops of snap beans, $P$. vulgaris, to control MBB when water is not limited. When used under optimal growing conditions, the increase in bean yield could be between 30\%-100\% compared to bean crops grown without wasp releases. The 2004 subplots used to test $P$. foveolatus produced an average of $18.98 \mathrm{~kg}$ more than the control subplots during the same season. The current market value of fresh snap beans at the Morgantown Farmer's Market is \$6.60 USD/kg (\$3.00 USD/lb), more for organic certified beans, \$7.70-9.37 USD/kg (\$3.50-\$4.25 USD/lb), depending on variety. On average, our $P$. foveolatus subplot increased gains between \$125 USD - \$146 USD per $13.5 \mathrm{~m}^{2}$ area. The cost associated with the yield increases observed in 2004 was \$5 USD for the cost of 10 mummified larvae plus \$20 for overnight shipping cost. Shipping can be even more expensive depending on location. However, cost sharing with other local producers, as we are currently practicing can significantly reduce the overall cost. Therefore a potential gross income between $\$ 100$ - \$121 USD per $13.5 \mathrm{~m}^{2}$ area, clearly justifies the use of $P$. foveolatus in our setting and market.

Overall, from the data collected throughout our experiment, the release of $P$. foveolatus is the most effective and economical factor at controlling larval and adult populations, given limited water stress in $P$. vulgaris. The data also suggested that in order to increase yields, both larval and adult MBB populations must be contained. Our results also imply that weather can greatly influence the growth of $P$. vulgaris, development of MBB, and the ability of any of the methods tested to efficiently maintain both larval and adult MBB. Regardless of the MBB control method used, water stress can be devastating and should be avoided in order to maximize the effectiveness of the method employed to control populations of MBB. 
Our data also indicate areas for further research such as, earlier releases of $P$. foveolatus in order to increase yields in bush bean cultivars and investigation into the possibility that $P$. foveolatus could also parasitize MBB pupae and its effect on adult MBB populations. 


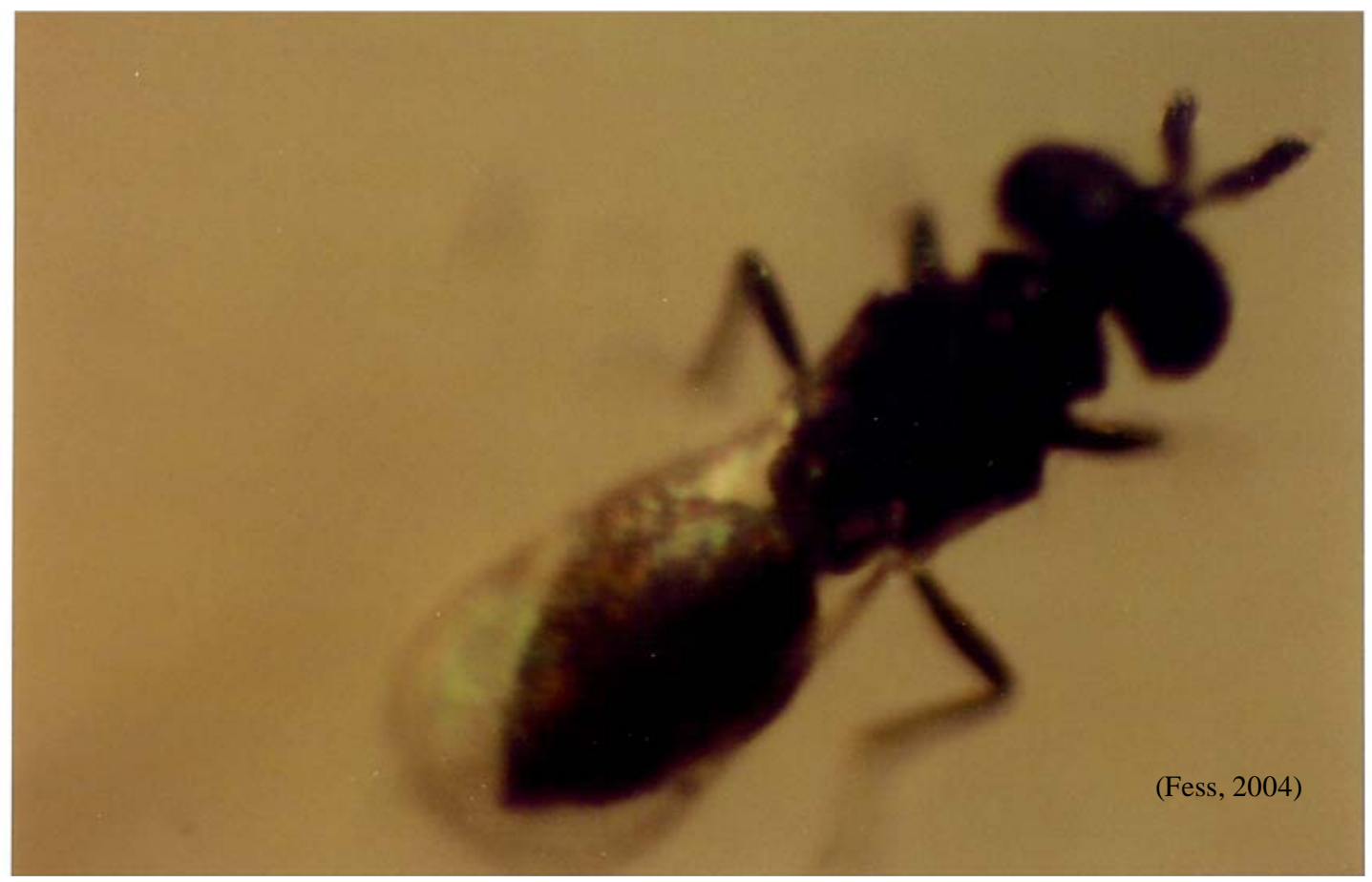

Figure 1. This photograph $(200 \mathrm{X})$ is of the parasitic wasp, Pediobius foveolatus. The small, $3 \mathrm{~mm}$, wasp is capable of reducing MBB populations in snap bean, $P$. vulgaris, crops.

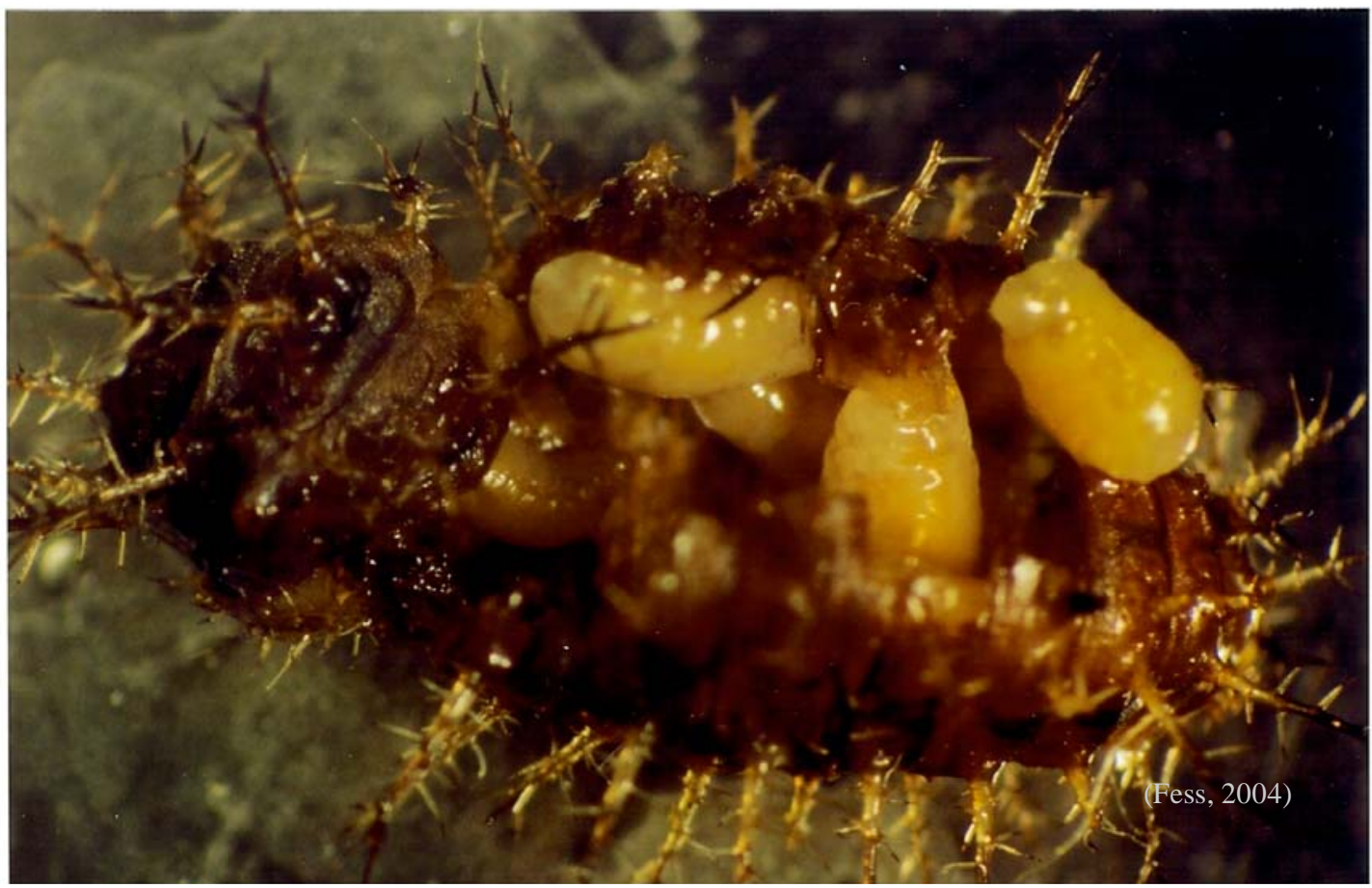

Figure 2. Photograph shows a recently parasitized MBB larva that has been dissected to expose the $P$. foveolatus larvae inside. The wasp larvae use the MBB larva as an energy source until they enter pupation. 


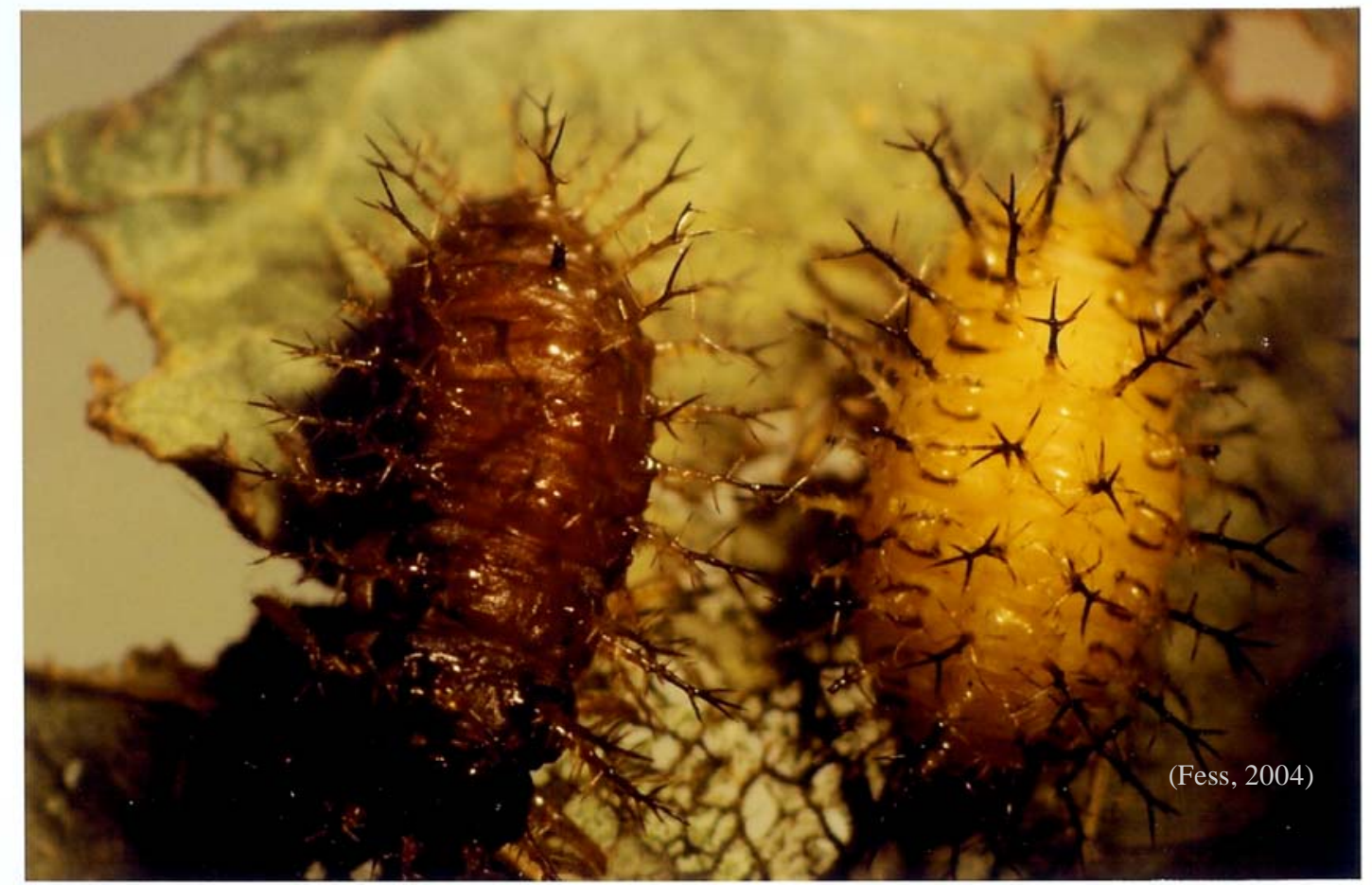

Figure 3. Photograph (20X) compares a MBB larva that has been parasitized by $P$. foveolatus (left) to a healthy MBB larva (right). Small holes made by adult wasps to emerge from the MBB host are visible on lower left side of the mummified larva.

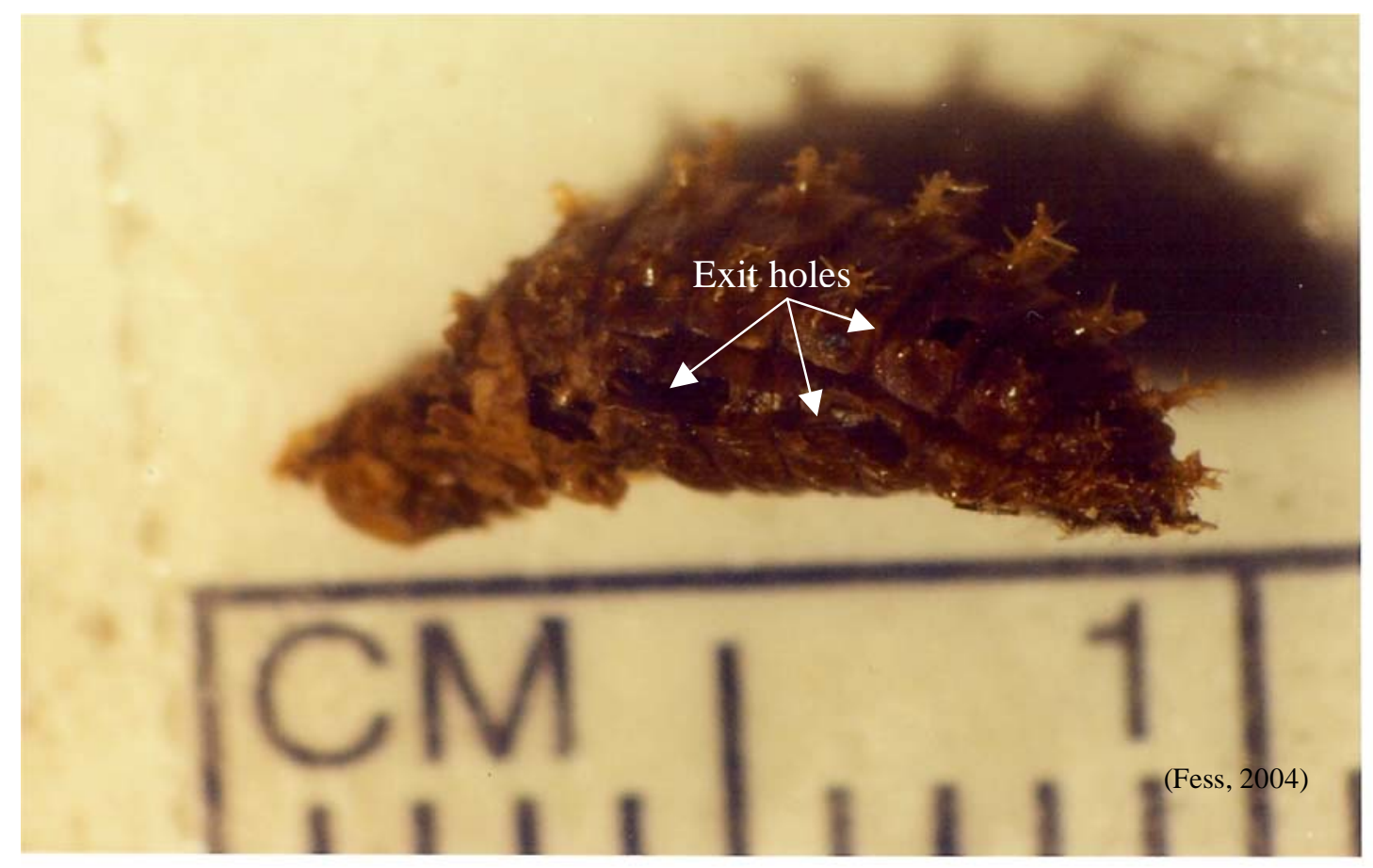

Figure 4. Size reference, $9 \mathrm{~mm}$ parasitized MBB larva. Clearly visible are the exit holes made by adult $P$. foveolatus. 


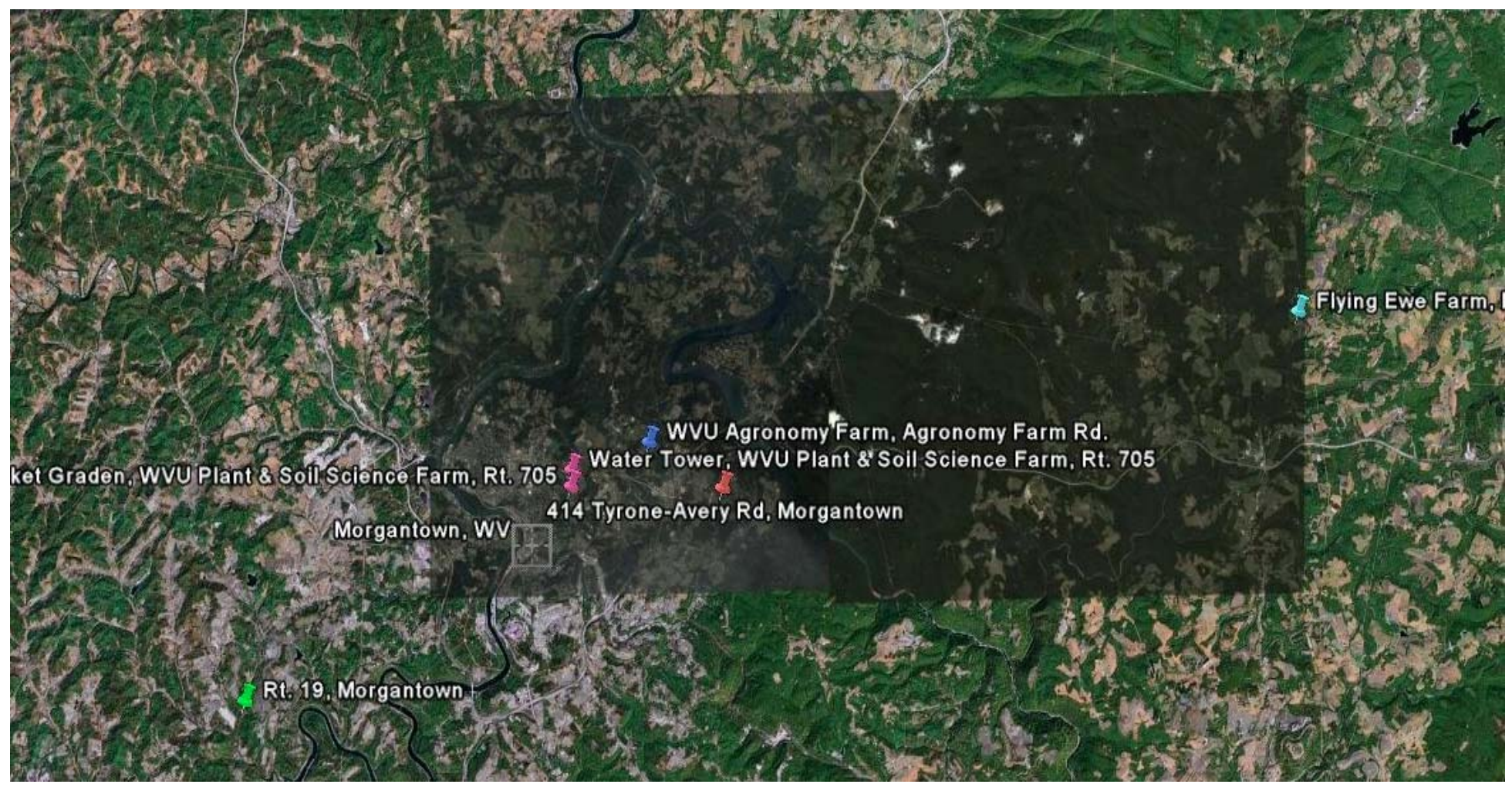

Figure 5: Map of Morgantown and outlying area showing all five farm locations (Google Earth, 2007).

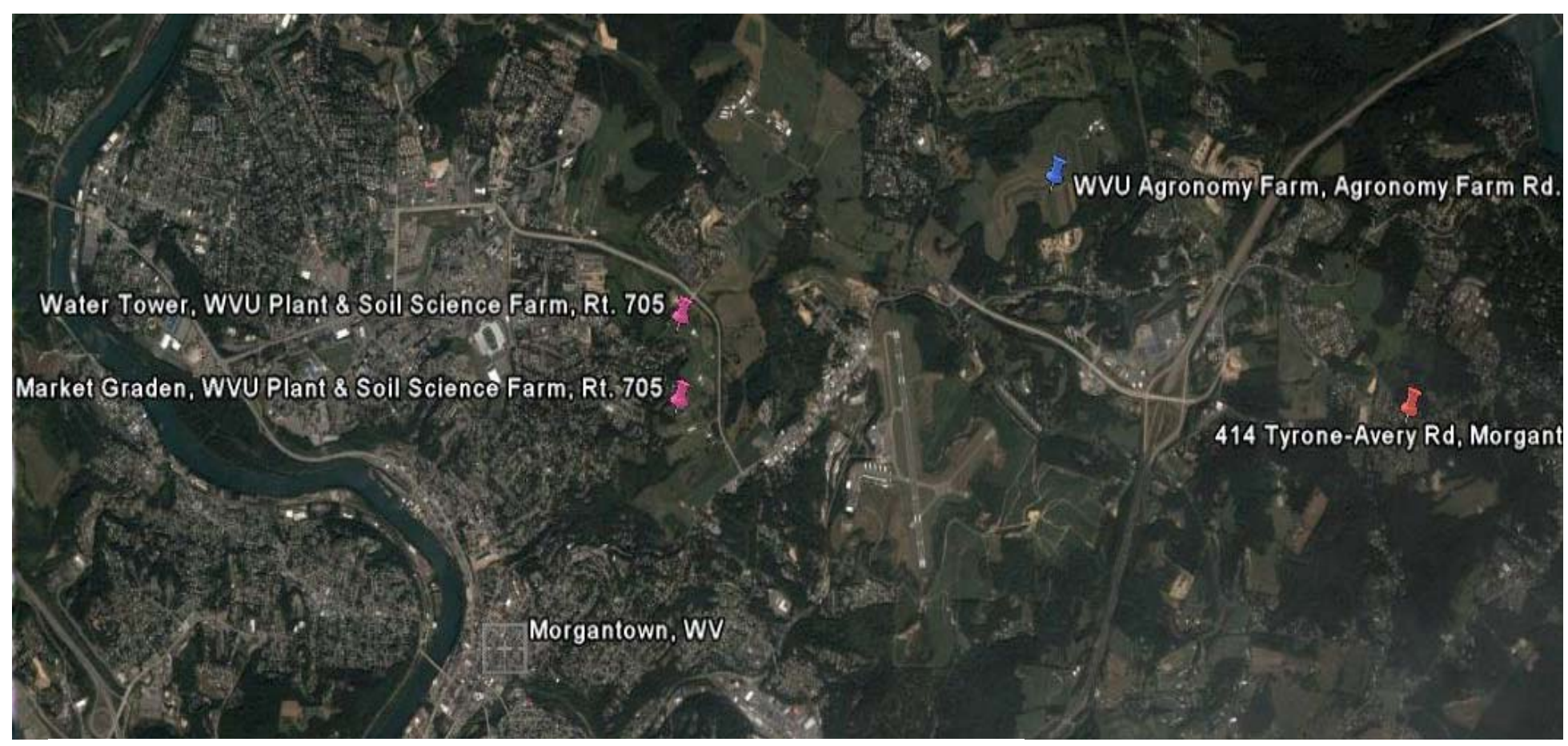

Figure 6: Map of Morgantown area (Google Earth, 2007). 


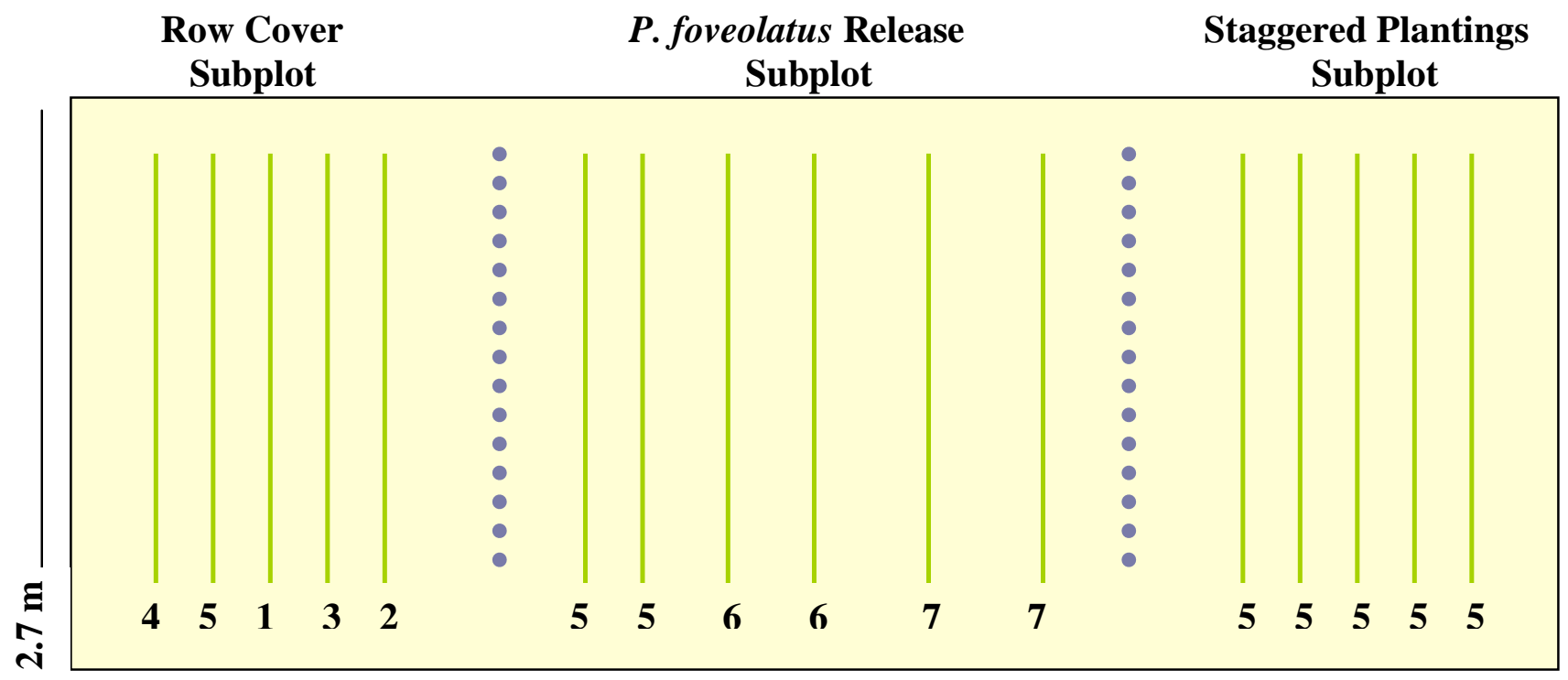

$9.0 \mathrm{~m}$

Key:

$2.4 \mathrm{~m}$ row of a $P$. vulgaris variety

$\cdots \cdots \cdots \cdots \cdots \cdot 2.4 \mathrm{~m}$ row of buckwheat or wild flower mix

Varieties:

1- Contender

2- Blue Lake 274

3- Black Valentine

4- Royalty
5- Provider

6- Mountaineer

7- Kentucky Wonder

Figure 7: Plot plan for treated and control plots. The methods used to control MBB, row cover, $P$. foveolatus release, and staggered planting date, were randomly assigned to a subplot. Control plots were configured in the same way without any of the controls applied. Varieties within each subplot were randomly assigned to rows; within the $P$. foveolatus subplot, two consecutive rows of each variety were randomly assigned. One row of buckwheat and one row wildflowers were planted at each end of the $P$. foveolatus subplot to provide food for the wasps, possibly limiting emigration (Patt et al., 1997). 


\section{Insect defoliation levels of soybean leaflets.}
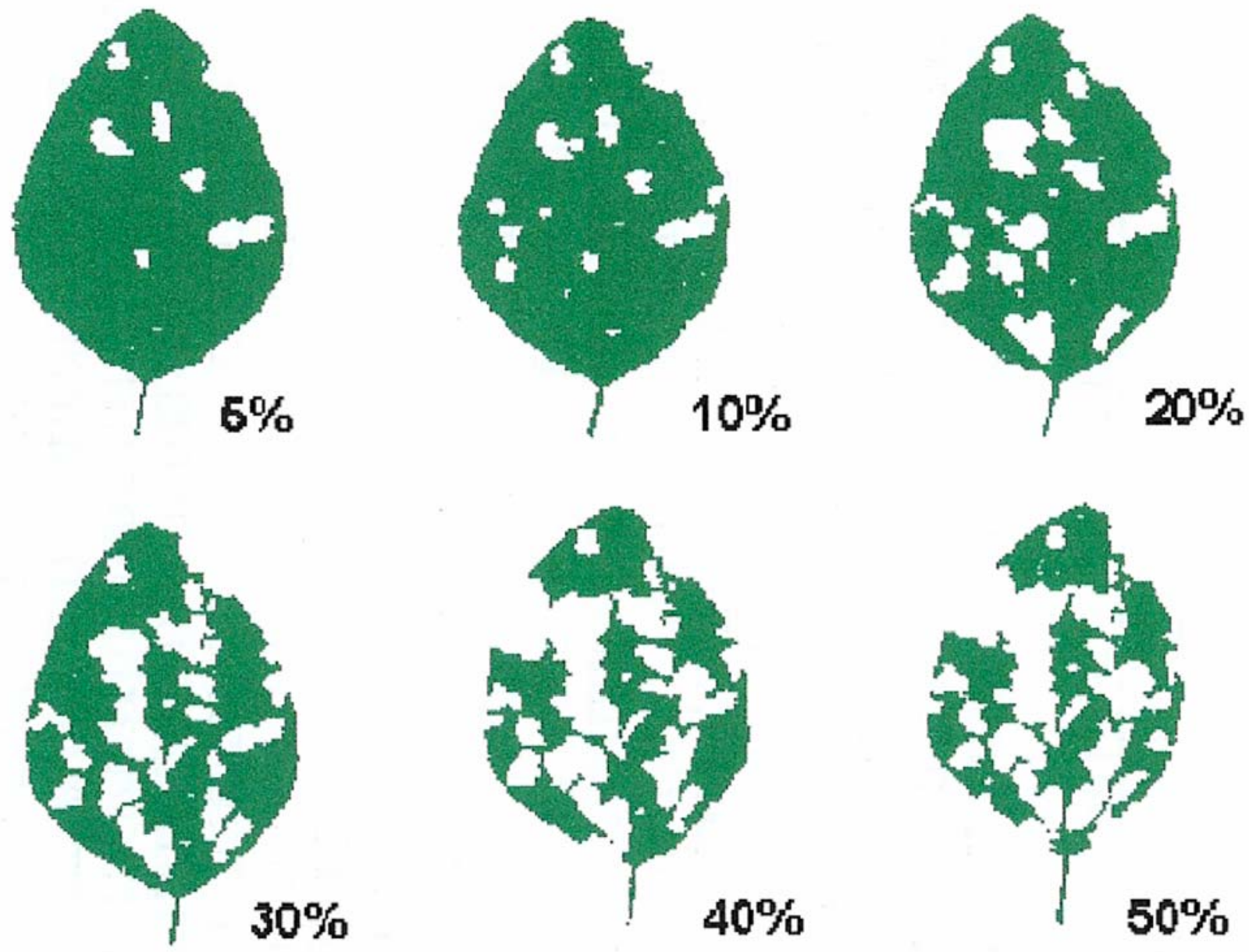

Figure 8: MBB defoliation in $P$. vulgaris was estimated using an insect defoliation chart for soybeans. MBB prefer P. vulgaris to soybeans G. max (Wilson, 1989). 


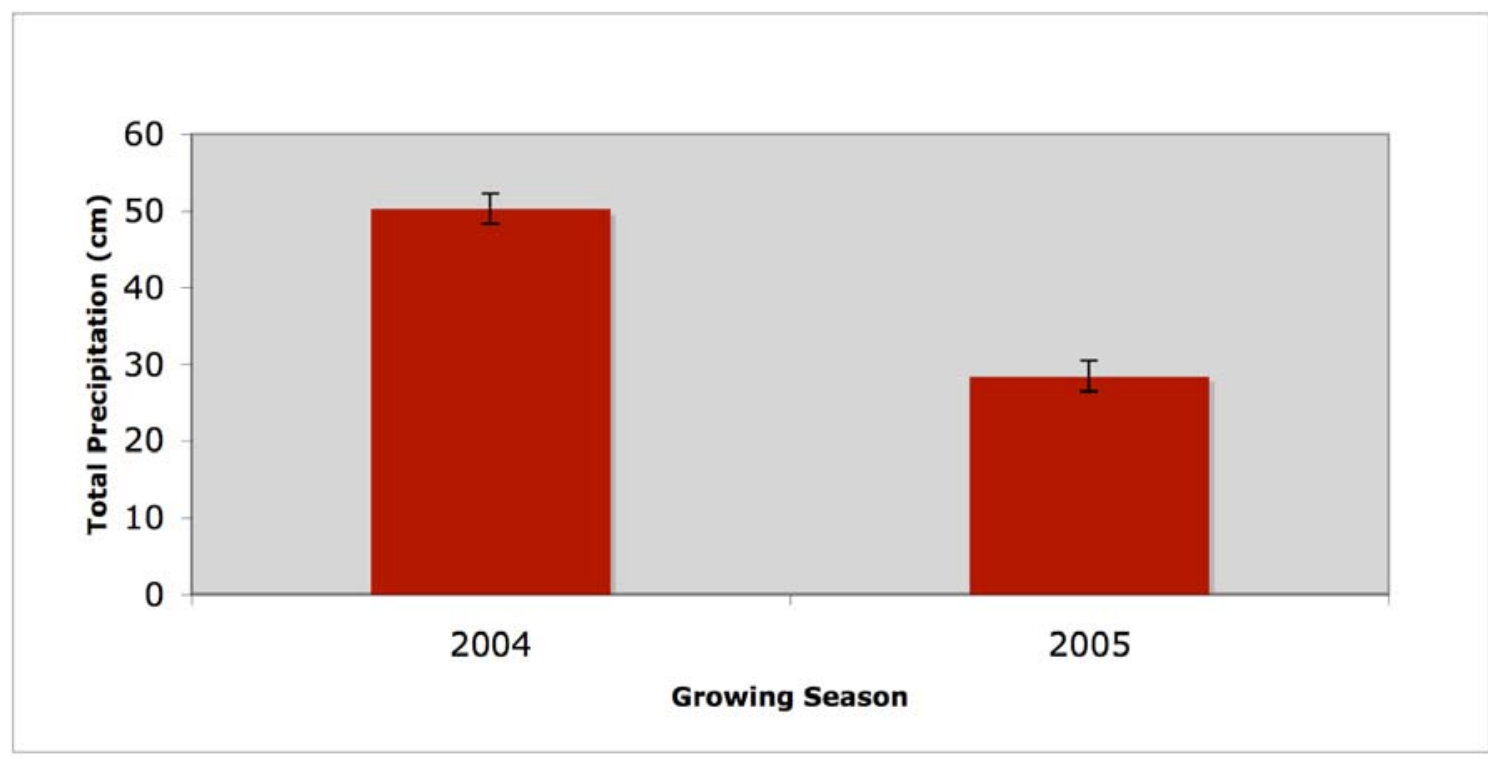

Figure 9: Comparison of seasonal precipitation totals from 2004 and 2005. Total precipitation during the 2004 season was found to be significantly different than the total precipitation during the 2005 season, $50.27 \mathrm{~cm}$ and $28.46 \mathrm{~cm}$, respectively. Standard error $=1.8$

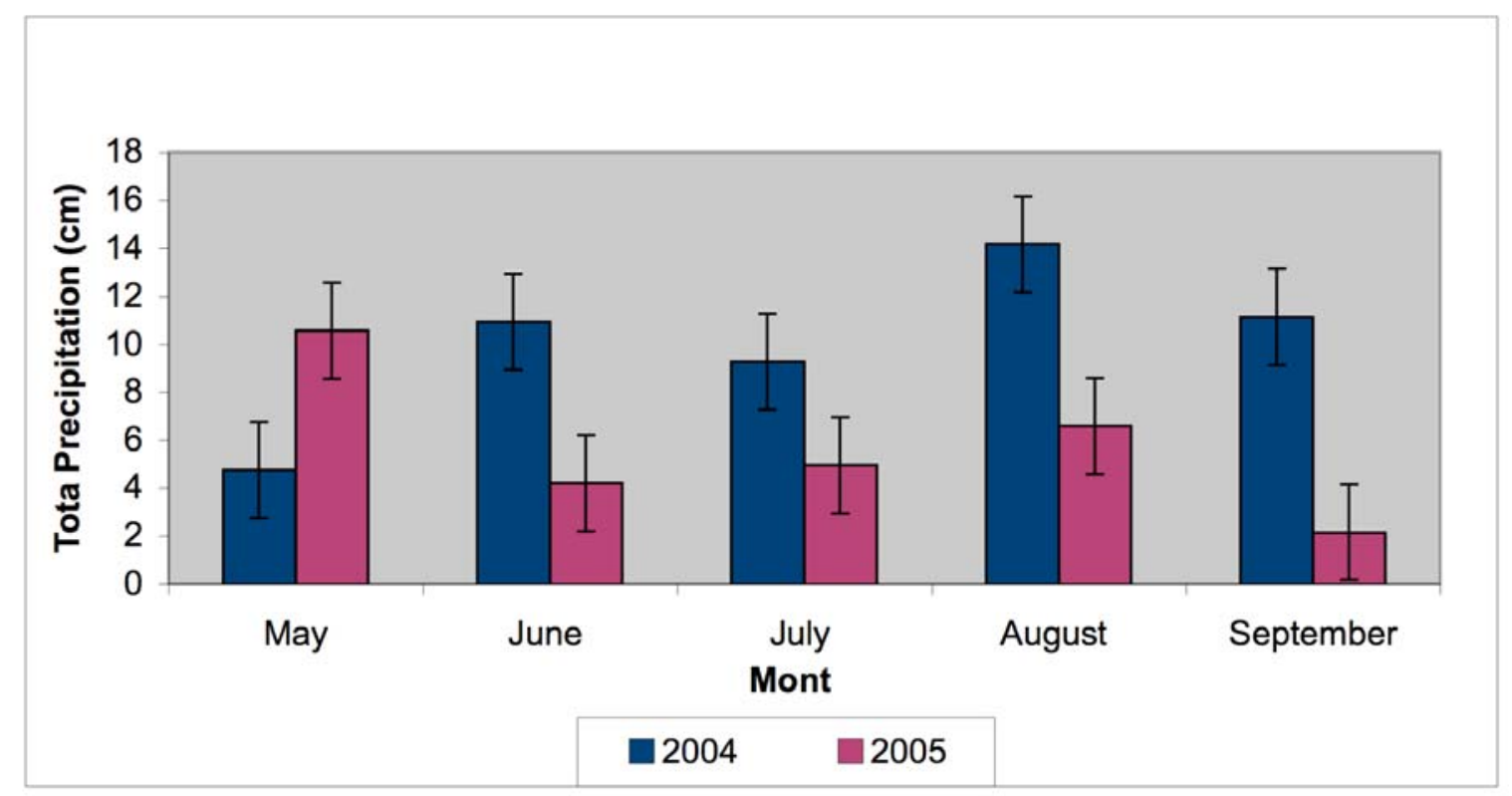

Figure 10: Average total monthly precipitation found in the 2004 and 2005 seasons. In the 2004 season, the month of May had a different monthly average, $4.76 \mathrm{~cm}$, compared to months June through September which each average $10.05 \mathrm{~cm}$. In the 2005 season, the month of May was again different than the remaining months in the season. May had an average of $10.57 \mathrm{~cm}$, while the months of June through September each had an average of $4.47 \mathrm{~cm}$. Standard error $=2.4$ 


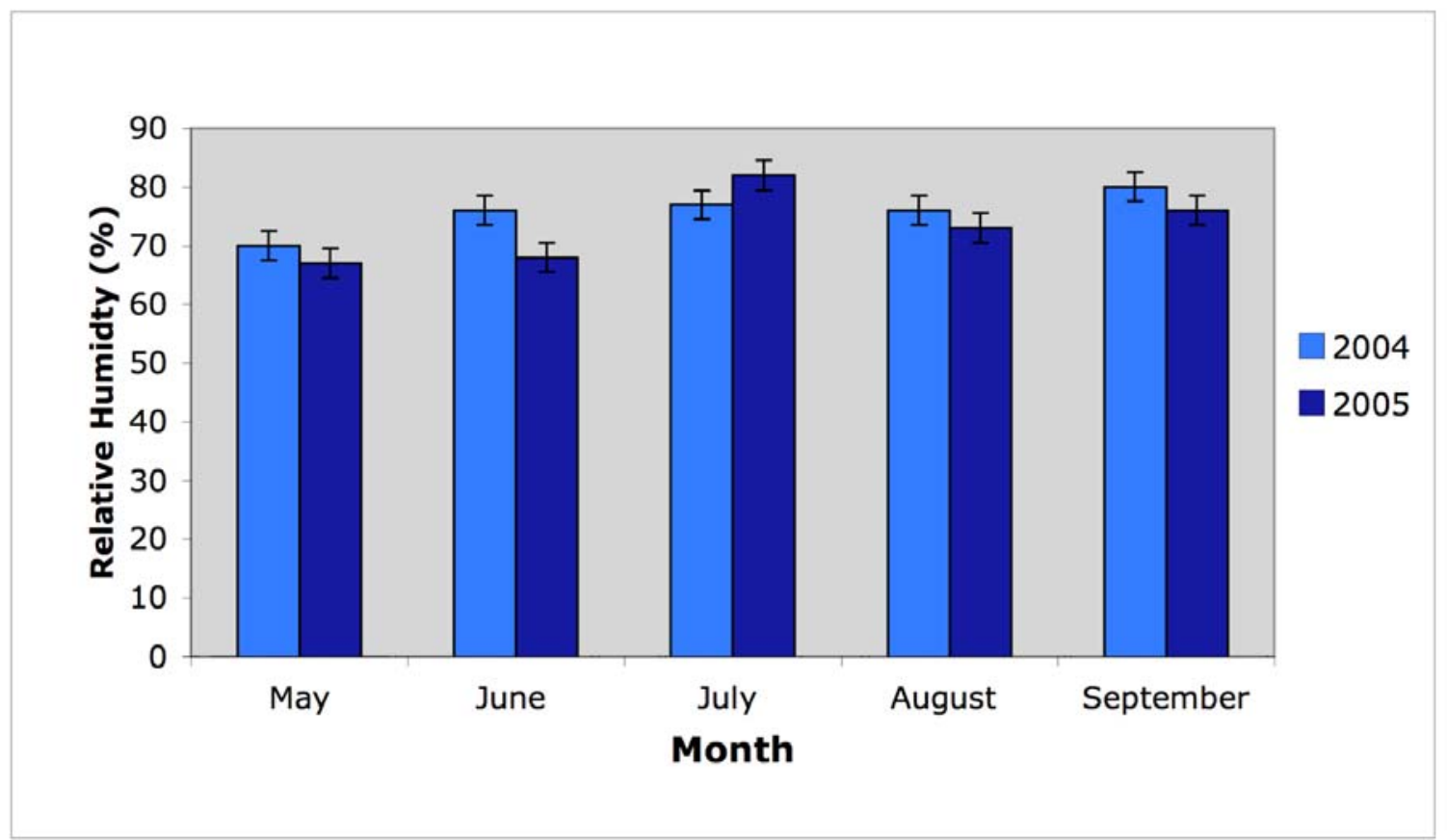

Figure 11: Average monthly relative humidity in 2004 and 2005. Seasonal relative humidity averages were found to be similar $(\mathrm{P}>0.05)$ for the 2004 and 2005 seasons, $98.1 \%$ and $93.4 \%$, respectively. Higher monthly trends, although insignificant, were observed in the 2004 season compared to the 2005 season. Standard error $=2.5$.

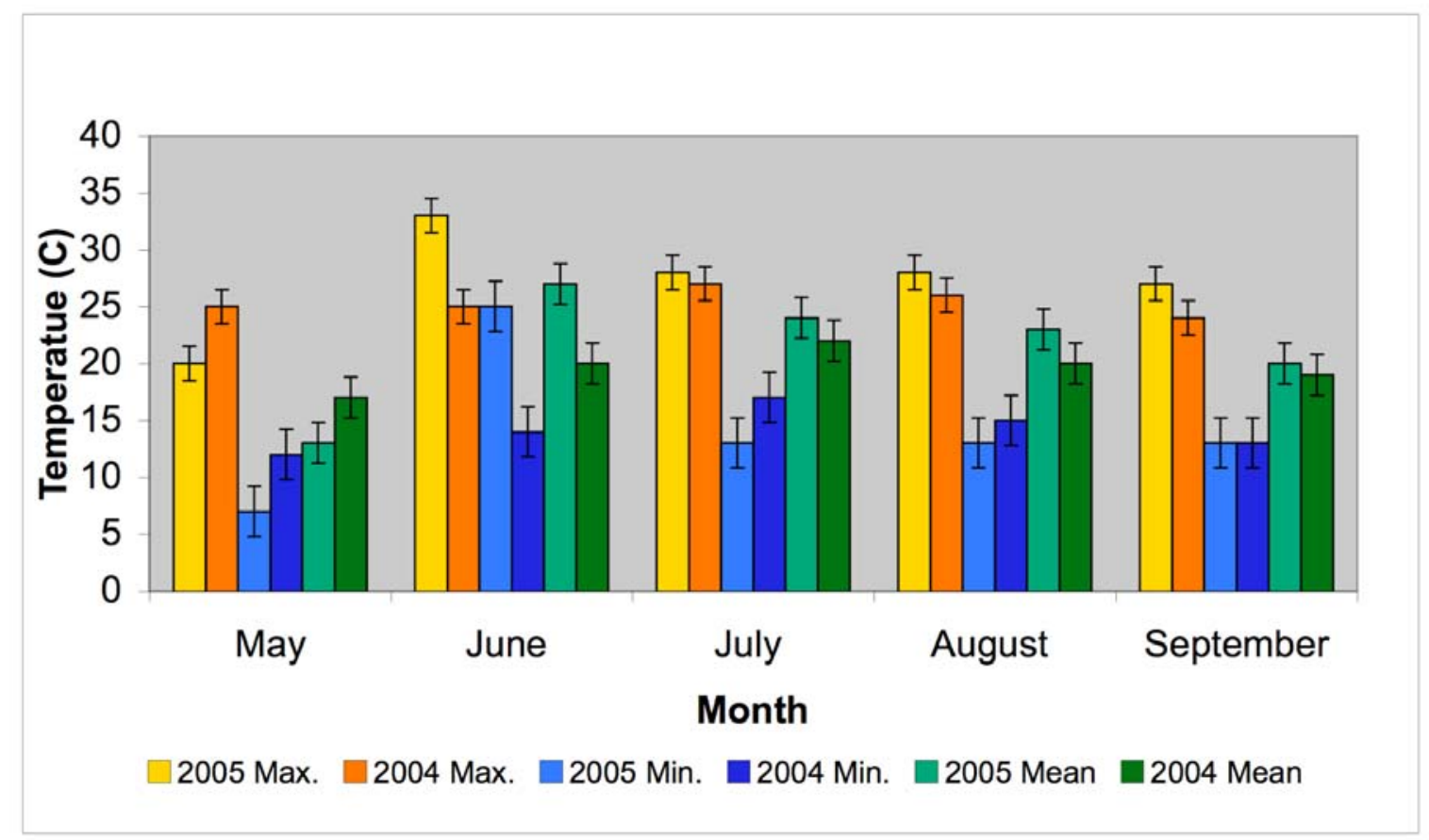

Figure 12: Comparison of average monthly temperatures from the 2004 and 2005 seasons. The 2004 and 2005 temperature data showed that average high, low and mean temperatures where similar for both seasons. Standard error for $\max =1.4$, $\min =2.2$, and mean $=1.8$ 
Figure 13: Average total snap bean yield from subplots treated with row cover compared to subplots without any row cover application. Differences between treatments were not significant in 2004 or 2005. Yield differences between seasons were significant in both treated and control subplots. Standard error in 2004 was 0.3 and 0.2 in 2005

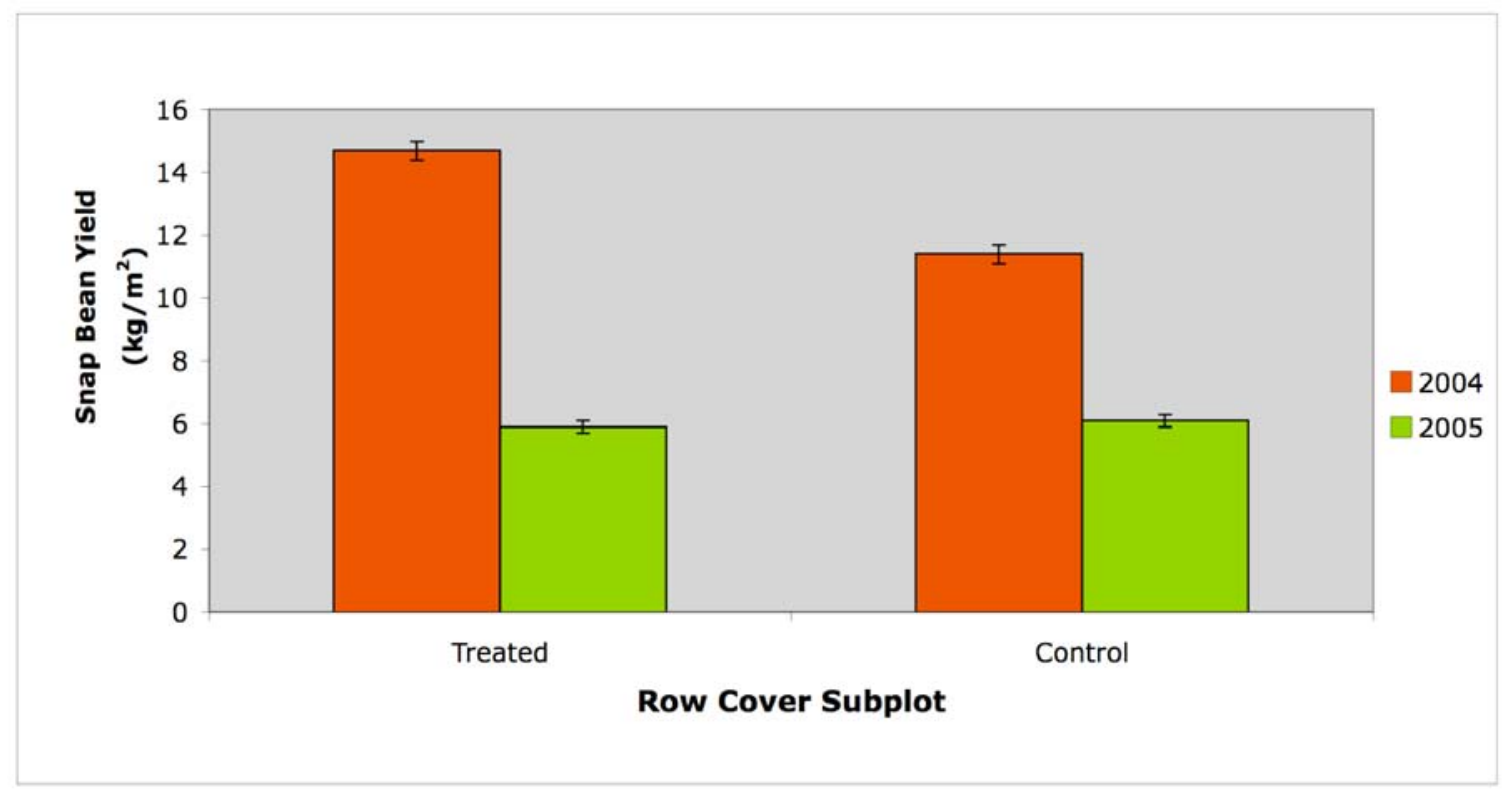


Table 1: Three-way analysis of variance of yield data in row cover experiment during the 2004 season.

\begin{tabular}{|l|l|l|}
\hline \multicolumn{1}{|c|}{ Source } & \multicolumn{1}{c|}{ DF } & \multicolumn{1}{c|}{ F Ratio } \\
\hline Row Cover 2004 & 1 & $4.55^{*}$ \\
\hline Cultivar & 4 & $9.40^{*}$ \\
\hline Sample (weeks) & 7 & $14.16^{*}$ \\
\hline Row Cover 2004*Cultivar & 4 & 0.98 \\
\hline Row Cover 2004*Sample (weeks) & 7 & $4.82^{*}$ \\
\hline Cultivar*Sample (weeks) & 28 & $3.78^{*}$ \\
\hline Row Cover 2004*Cultivar*Sample (weeks) & 28 & 0.92 \\
\hline Error & 160 & 0.100 \\
\hline
\end{tabular}

*Indicates a significant interaction

${ }^{\dagger}$ Error mean square

Table 2: Orthogonal contrast within the significant row cover treatment-bysampling(weeks) interaction in yield data from the row cover experiment for the 2004 season.

\begin{tabular}{|l|l|ll|}
\hline Sampling (weeks) & \multicolumn{1}{|c|}{ Row Cover } & \multicolumn{2}{c|}{ Yield } \\
\hline 1 & 0 & 0.08 a \\
& 1 & $-2.78 \mathrm{a}$ \\
\hline 2 & 0 & 0.60 & $\mathrm{a}$ \\
& 1 & 0.61 & $\mathrm{a}$ \\
\hline 3 & 0 & 0.29 & $\mathrm{a}$ \\
& 1 & $0.68 \mathrm{~b}$ \\
\hline 4 & 0 & $0.64 \mathrm{a}$ \\
& 1 & 0.36 & $\mathrm{~b}$ \\
\hline 5 & 0 & 0.51 & $\mathrm{a}$ \\
& 1 & 0.39 & $\mathrm{a}$ \\
\hline 6 & 0 & $0.18 \mathrm{a}$ \\
& 1 & $0.34 \mathrm{~b}$ \\
\hline 7 & 0 & $0.08 \mathrm{a}$ \\
& 1 & $0.34 \mathrm{~b}$ \\
\hline 8 & 0 & $-1.66 \mathrm{a}$ \\
& 1 & $0.08 \mathrm{a}$ \\
\hline
\end{tabular}

For each sampling week, means in a column followed by the same letter are not significant. Prob $>F$

0 control subplots

1 treatment subplots 
Table 3: Data showed significant two-way effects on yield during the 2005 season.

\begin{tabular}{|l|l|l|}
\hline \multicolumn{1}{|c|}{ Source } & \multicolumn{1}{c|}{ DF } & \multicolumn{1}{c|}{ F Ratio } \\
\hline Row Cover 2005 & 1 & 0.89 \\
\hline Cultivar & 4 & 2.15 \\
\hline Sample (weeks) & 7 & $16.12^{*}$ \\
\hline Row Cover 2005*Cultivar & 4 & 0.64 \\
\hline Row Cover 2005*Sample (weeks) & 7 & $9.878^{*}$ \\
\hline Cultivar*Sample (weeks) & 28 & 0.55 \\
\hline Row Cover 2005*Cultivar*Sample (weeks) & 28 & 0.70 \\
\hline Error & 145 & $0.05^{\dagger}$ \\
\hline
\end{tabular}

*Indicates a significant interaction

${ }^{\dagger}$ Error mean square

Table 4: Orthogonal contrast within the significant row cover treatment-bysampling(weeks) interaction of the 2005 season.

\begin{tabular}{|l|l|ll|}
\hline Sampling (weeks) & \multicolumn{1}{|c|}{ Row Cover } & \multicolumn{2}{c|}{ Yield } \\
\hline 1 & 0 & 0.19 & $\mathrm{a}$ \\
& 1 & 0.16 & $\mathrm{a}$ \\
\hline 2 & 0 & 0.02 & $\mathrm{a}$ \\
& 1 & 0.08 & $\mathrm{a}$ \\
\hline 3 & 0 & 1.94 & $\mathrm{a}$ \\
& 1 & 9.71 & $\mathrm{~b}$ \\
\hline 4 & 0 & 1.94 & $\mathrm{a}$ \\
& 1 & 9.71 & $\mathrm{~b}$ \\
\hline 5 & 0 & 1.94 & $\mathrm{a}$ \\
& 1 & 9.71 & $\mathrm{~b}$ \\
\hline 6 & 0 & 0.72 & $\mathrm{a}$ \\
& 1 & 0.04 & $\mathrm{~b}$ \\
\hline 7 & 0 & $0.42 \mathrm{a}$ \\
& 1 & $0.21 \mathrm{~b}$ \\
\hline 8 & 0 & 0.25 & $\mathrm{a}$ \\
& 1 & 0.42 & $\mathrm{~b}$ \\
\hline
\end{tabular}

For each sampling week, means in a column followed by the same letter are not significant. Prob $>F$

0 control subplots

1 treatment subplots 
Figure 14: Snap bean yields of 5 varieties in plots with and without row cover during 2004 and 2005 seasons.

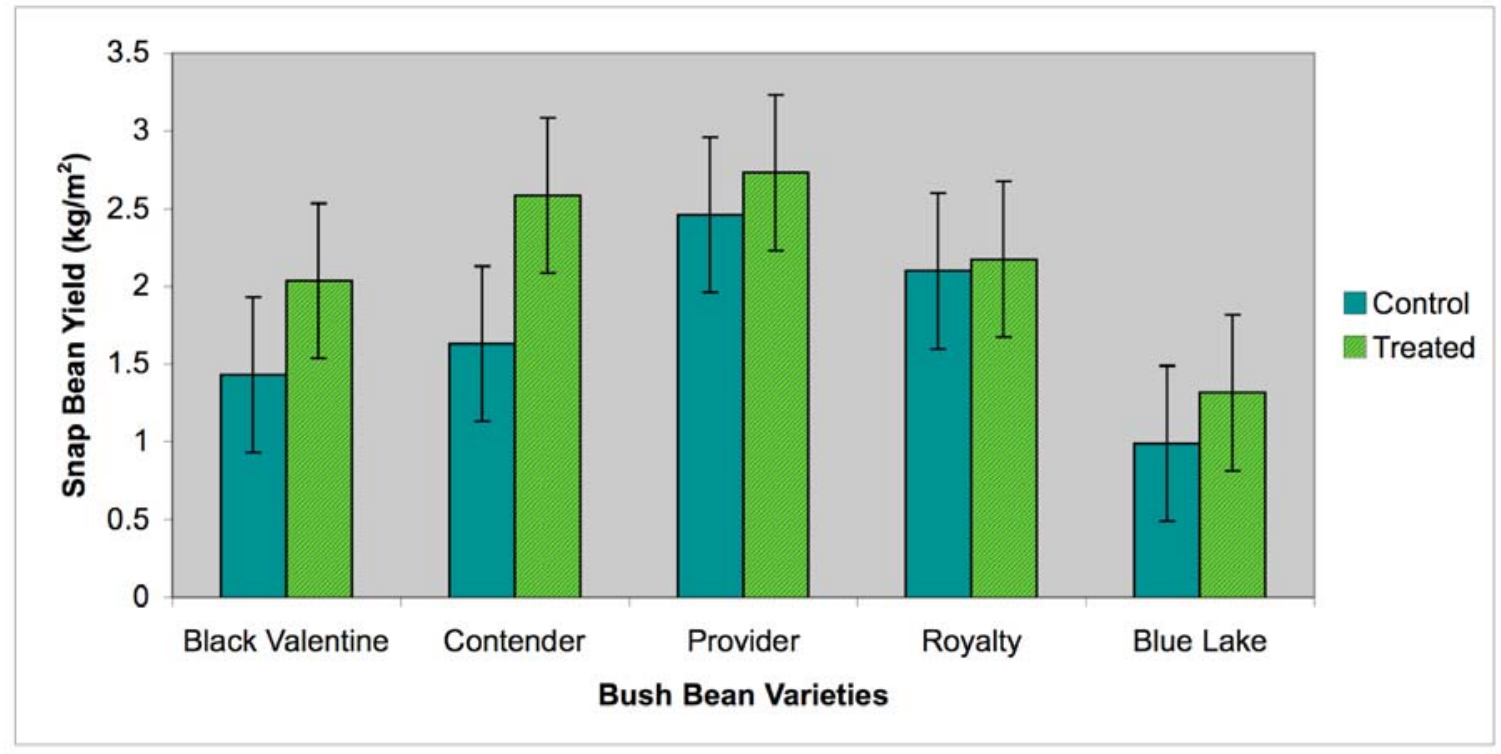


Table 5: Three-way analysis of variance of yield data in staggered planting date experiment during the 2004 season.

\begin{tabular}{|l|l|l|}
\hline \multicolumn{1}{|c|}{ Source } & \multicolumn{1}{|c|}{ DF } & \multicolumn{1}{|c|}{ F Ratio } \\
\hline Staggered Planting 2004 & 1 & 3.70 \\
\hline Planting Date & 3 & $5.47^{*}$ \\
\hline Sample (weeks) & 7 & $2.68^{*}$ \\
\hline Staggered Planting 2004*Planting Date & 3 & 1.23 \\
\hline Staggered Planting 2004*Sample (weeks) & 7 & 0.57 \\
\hline Planting Date*Sample (weeks) & 21 & $5.22^{*}$ \\
\hline Staggered Planting 2004*Cultivar*Sample (weeks) & 21 & 0.85 \\
\hline Error & 128 & $0.13^{\dagger}$ \\
\hline
\end{tabular}

*Indicates a significant interaction

${ }^{\dagger}$ Error mean square

Table 6: Three-way analysis of variance of yield data in staggered planting date experiment during the 2005 season.

\begin{tabular}{|l|l|l|}
\hline \multicolumn{1}{|c|}{ Source } & \multicolumn{1}{c|}{ DF } & \multicolumn{1}{c|}{ F Ratio } \\
\hline Staggered Planting 2005 & 1 & 1.63 \\
\hline Planting Date & 3 & $19.98^{*}$ \\
\hline Sample (weeks) & 6 & $13.45^{*}$ \\
\hline Staggered Planting 2005*Planting Date & 3 & 2.42 \\
\hline Staggered Planting 2005*Sample (weeks) & 6 & $7.42^{*}$ \\
\hline Planting Date*Sample (weeks) & 18 & $8.78^{*}$ \\
\hline Staggered Planting 2005*Cultivar*Sample (weeks) & 18 & $4.17^{*}$ \\
\hline Error & 112 & 0.04 \\
\hline
\end{tabular}

*Indicates a significant interaction

${ }^{\dagger}$ Error mean square 
Table 7: Orthogonal contrast within the significant staggered treatment-by-sampling (weeks) interaction in yield data from the staggered planting experiment for the 2005 season.

\begin{tabular}{|l|l|ll|}
\hline Sampling (weeks) & \multicolumn{1}{|c|}{ Subplot } & \multicolumn{2}{c|}{ Yield } \\
\hline 1 & 0 & 0.00 & a \\
& 1 & 0.00 & a \\
\hline 2 & 0 & 0.00 & a \\
& 1 & 0.00 & a \\
\hline 3 & 0 & 0.00 & a \\
& 1 & 0.00 & a \\
\hline 4 & 0 & 0.56 & a \\
& 1 & 0.08 & b \\
\hline 5 & 0 & 0.36 & a \\
& 1 & 0.24 & a \\
\hline 6 & 0 & 0.13 & a \\
& 1 & 0.36 & b \\
\hline 7 & 0 & 0.13 & a \\
& 1 & 0.22 & a \\
\hline 8 & 0 & 0.04 a \\
& 1 & 0.04 & a \\
\hline
\end{tabular}

For each sampling week, means in a column followed by the same letter are not significant. Prob $>F$

0 control subplots

1 treatment subplots 
Figure 15: MBB population during weeks 1-5 from row cover treated and control subplots in 2004 and 2005. Analysis of the MBB population data in 2004 and 2005 showed significant differences in MBB adult, pupal, and larval populations existed between row cover treated subplots (A.) compared to control subplots (B.) during only weeks 1 trough 5 of the observations. The row cover was removed on week 4 and populations remained significant for only one week. MBB adult, pupal, and larval populations after week 5 were no longer all longer significant.

A.

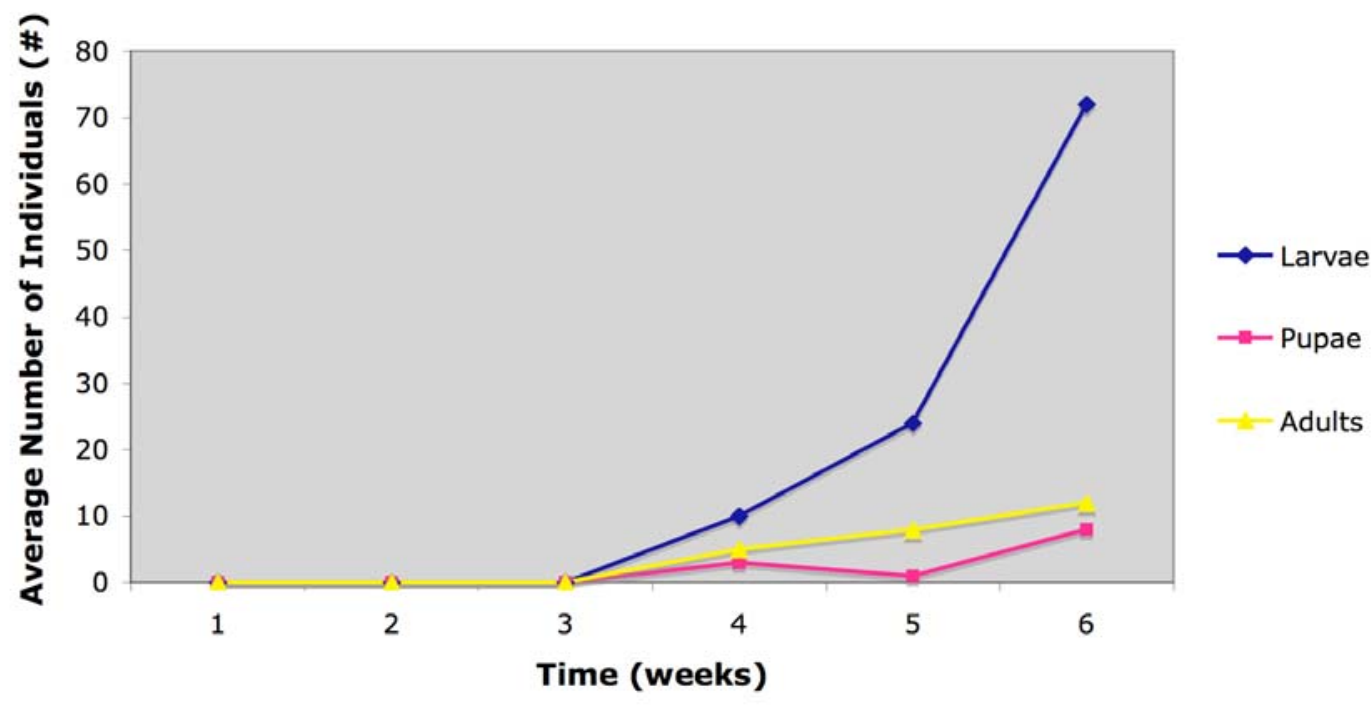

B.

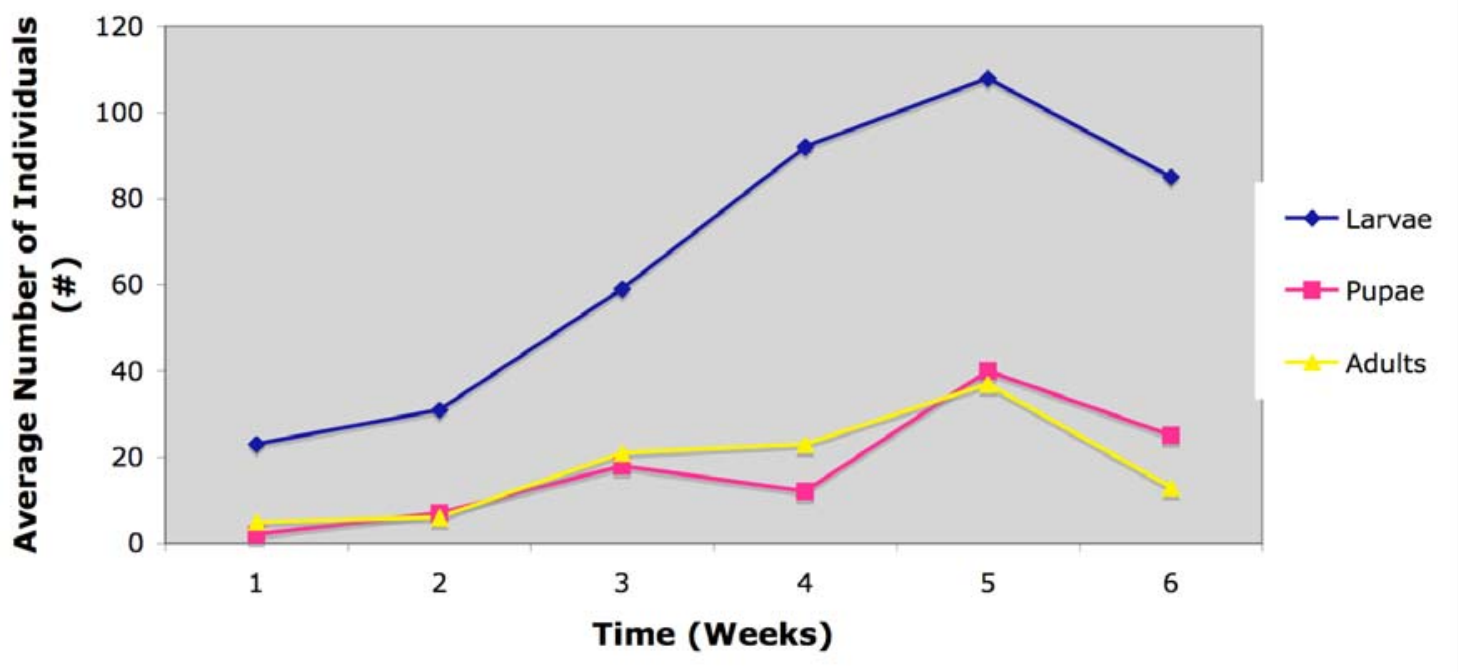


Figure 16: Average green bean yield from treated and control in 2004 and 2005. Treated subplots had an average of $6.72 \mathrm{~kg} / \mathrm{m}^{2}$ of green bean compared to $5.42 \mathrm{~kg} / \mathrm{m}^{2}$ from control subplots. A seasonal difference in yield was found to exist between treated subplots in 2004 compared to treated subplots in 2005. The yields from control subplots from 2004 and 2005 were found to be similar.

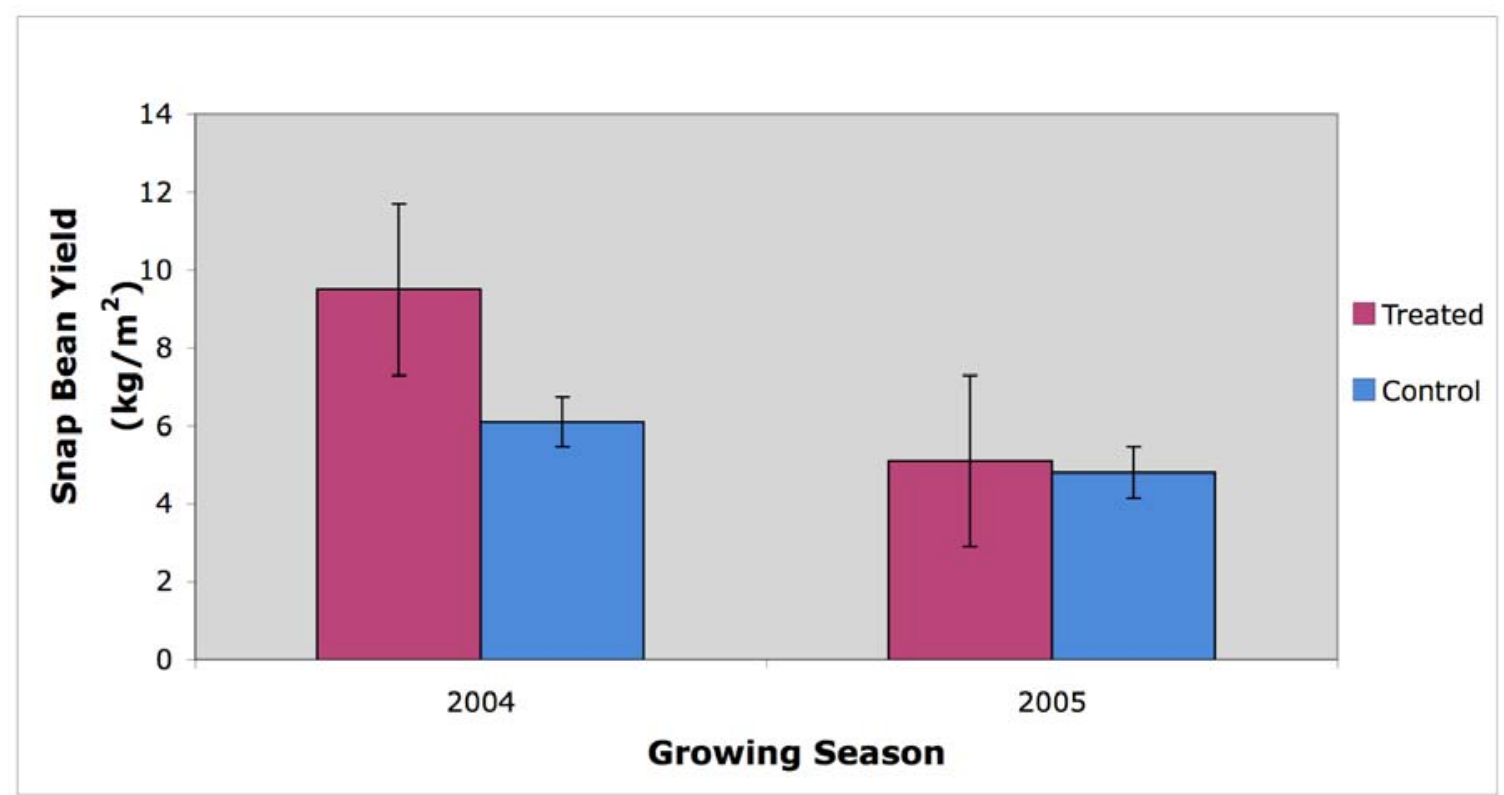


Figure 17: Average MBB adult, pupal, and larval populations found in treated subplots (A.) and control subplots (B.) during the 2004 season.

A.

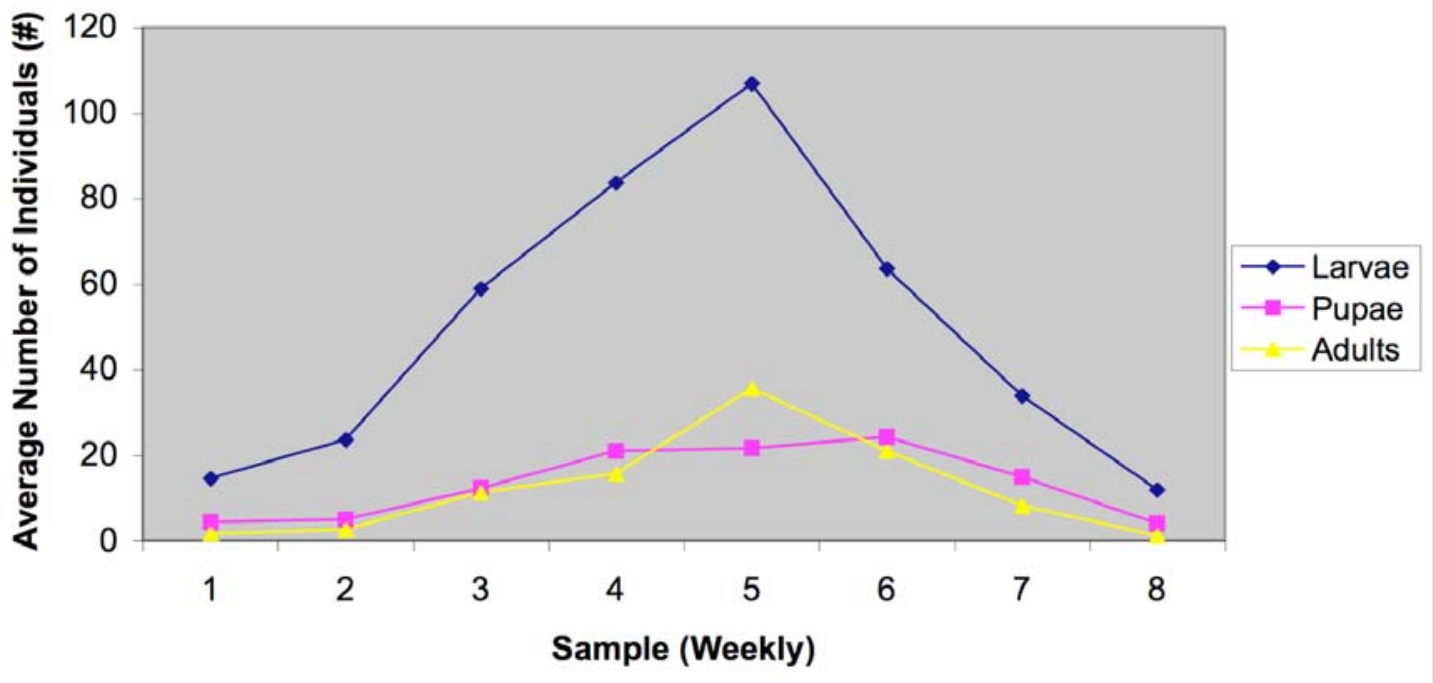

B.

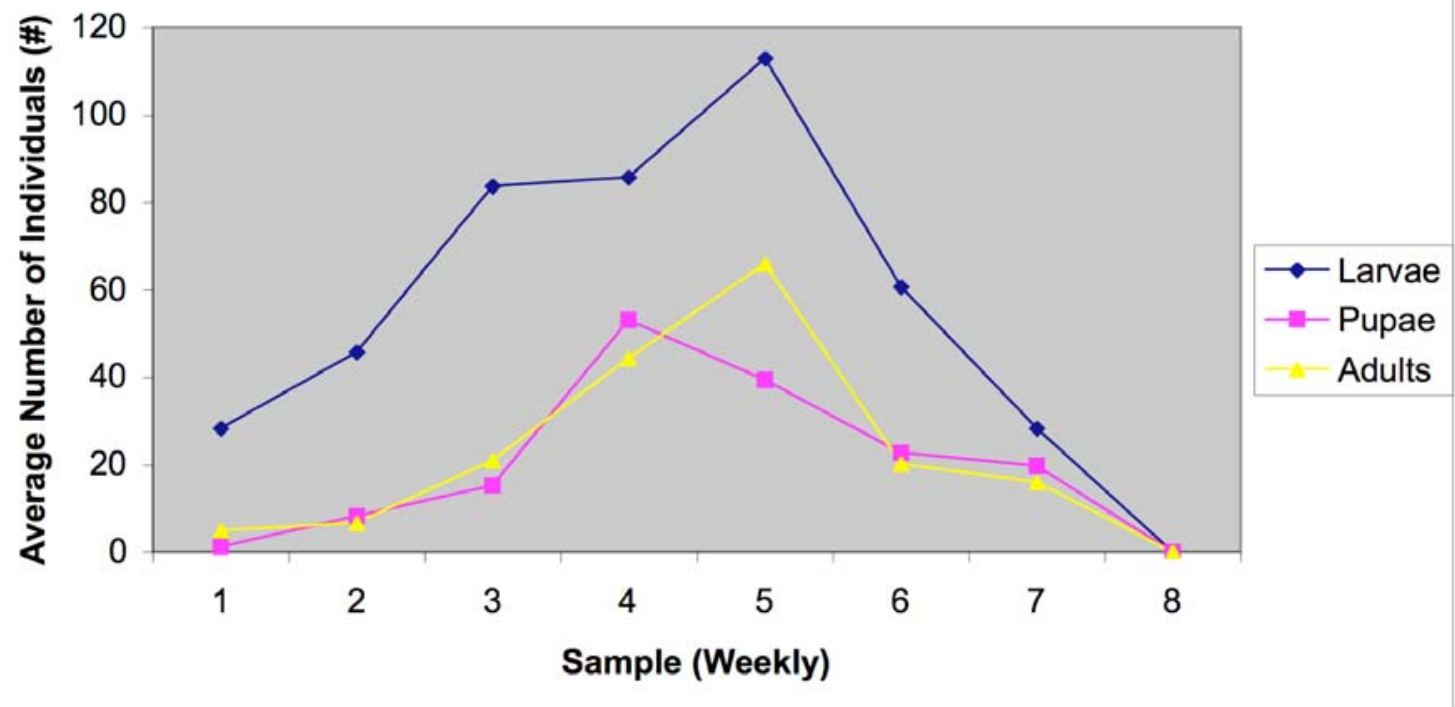


Figure 18: Average MBB adult, pupal, and larval populations, counts in treated (A.) and control (B.) subplots during the 2005 season.

A.

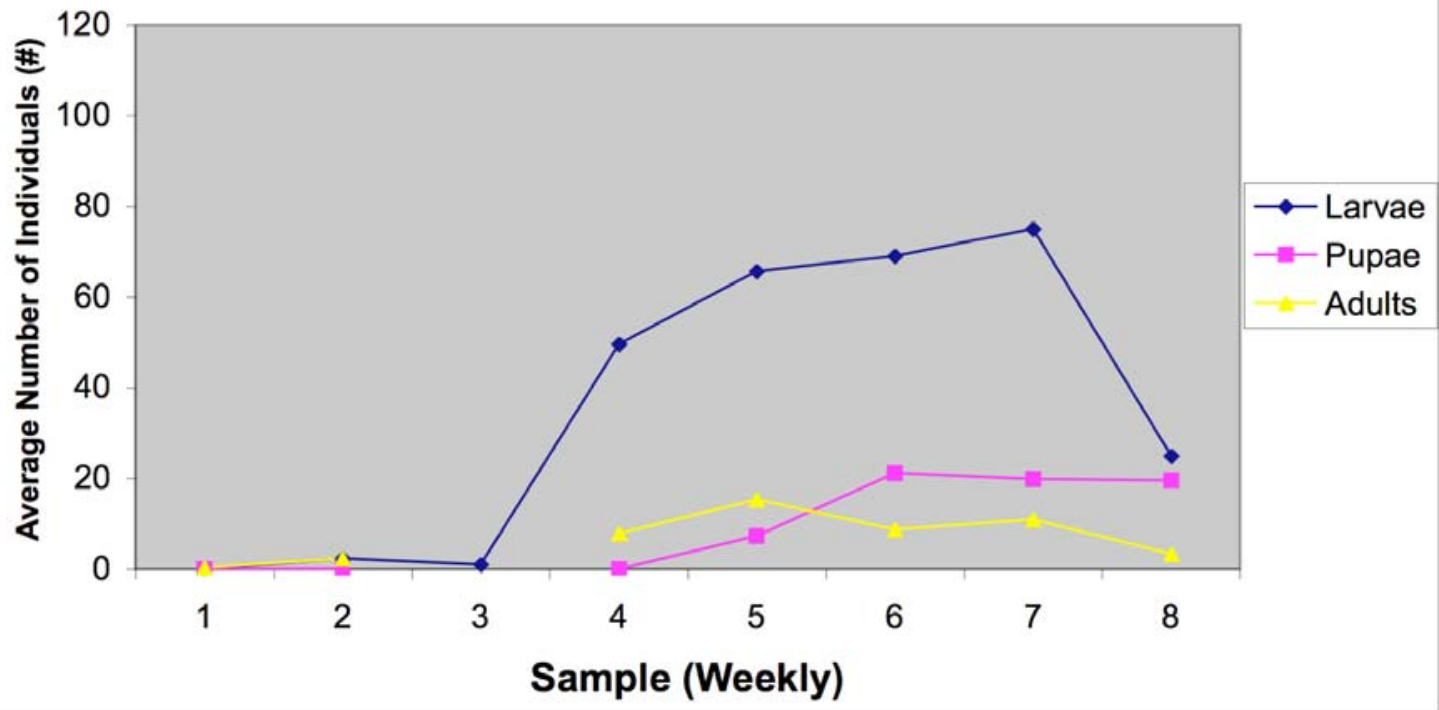

B.

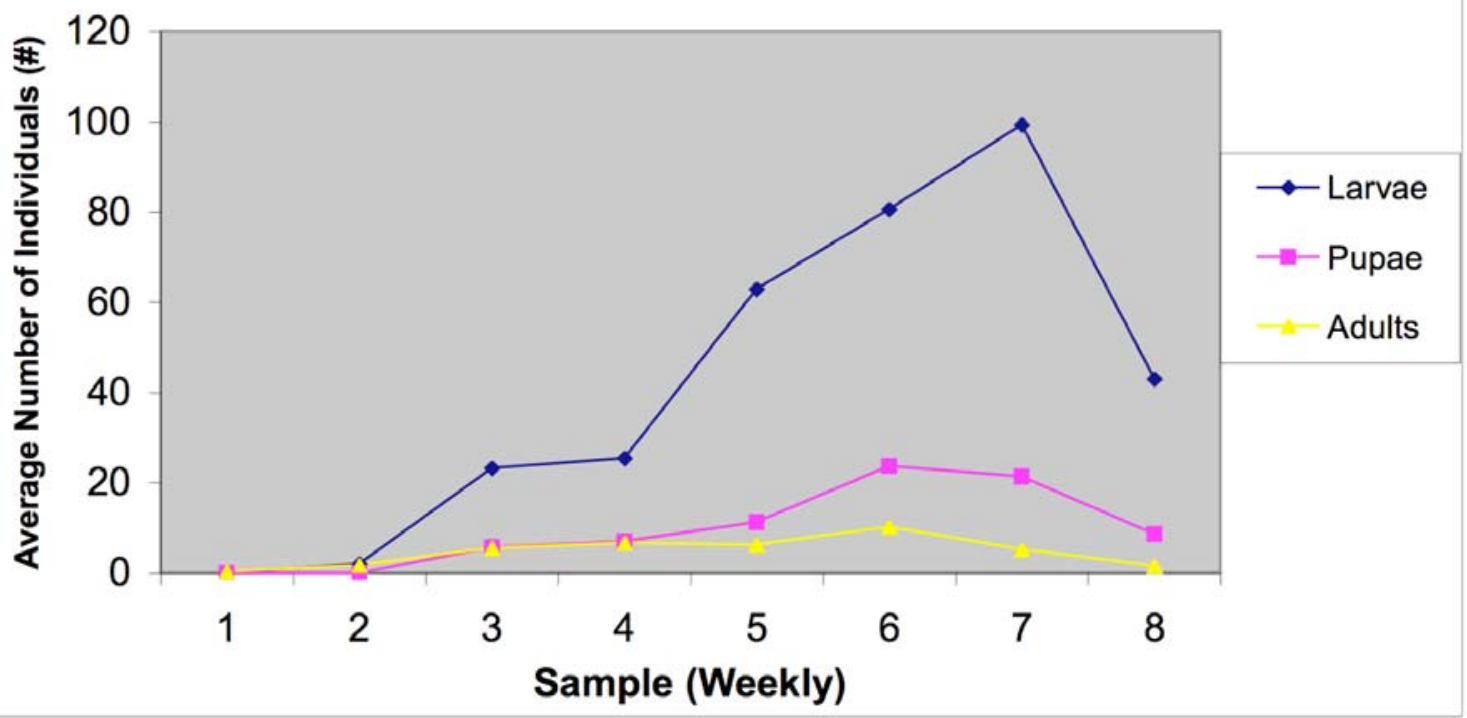


Figure 19: Average MBB populations found in the first, second, and third staggered plantings in treated and control subplots in the 2004 and 2005 seasons were all found to be similar. The first staggered planting (A.) and second staggered planting (B.) dates hosted similar populations in treated and control subplots. The third staggered planting date was found to have different MBB adult and larval populations in treated subplots compared to control subplots (C.). The MBB pupal populations and number of egg masses were found to be similar in treated and control subplots.

A.

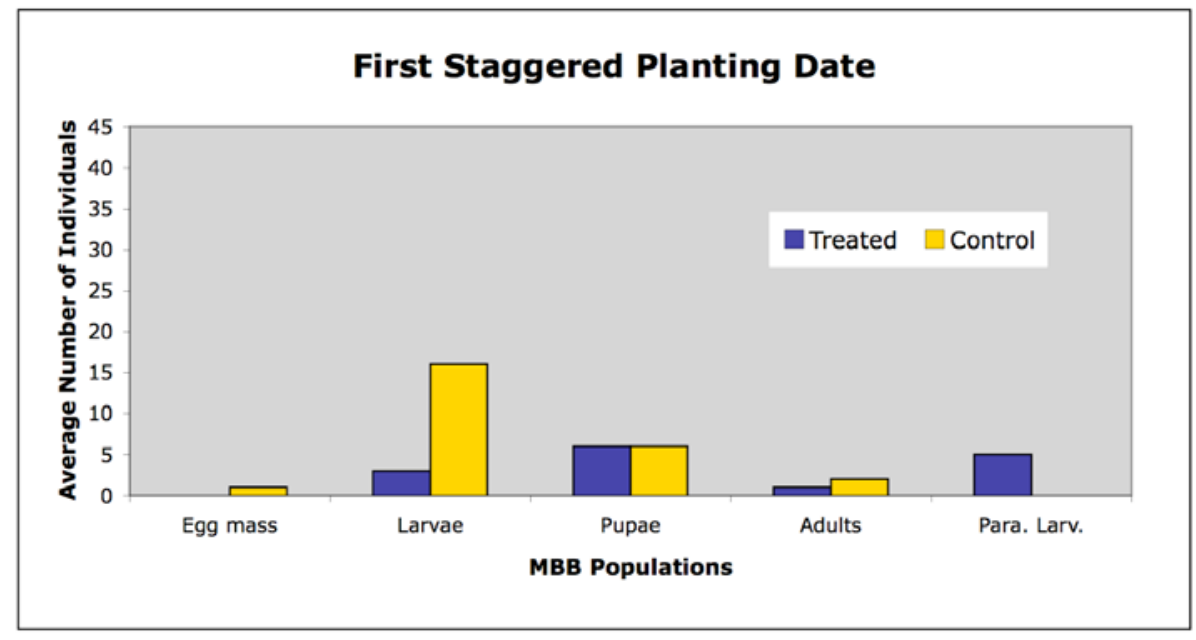

B.

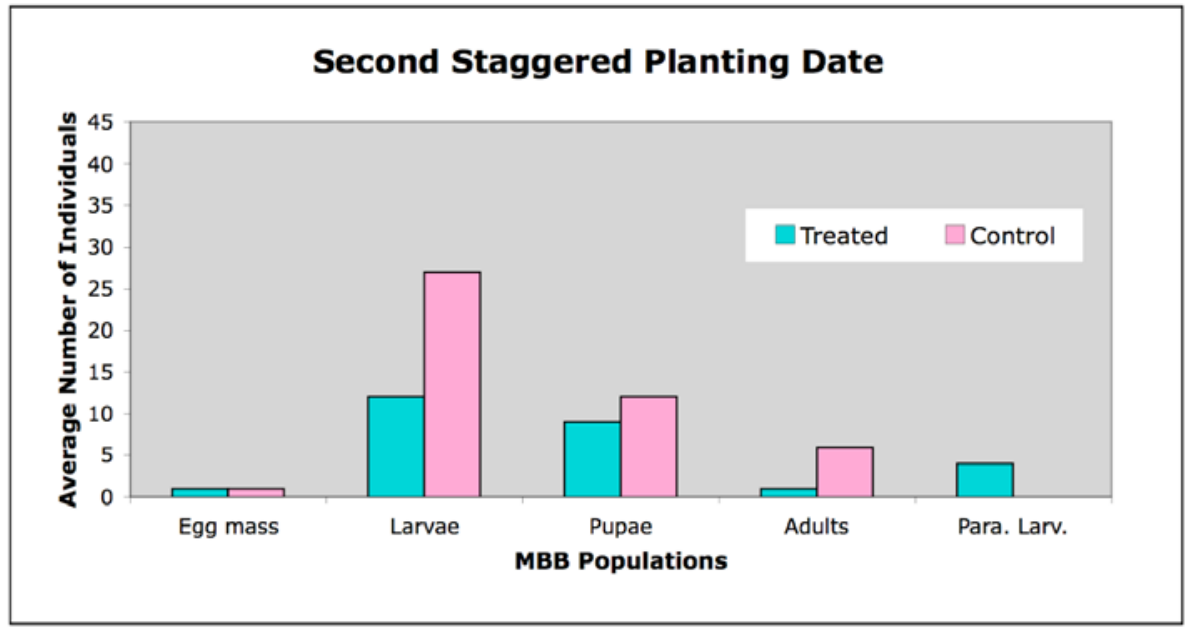

C.

Third Staggered Planting Date

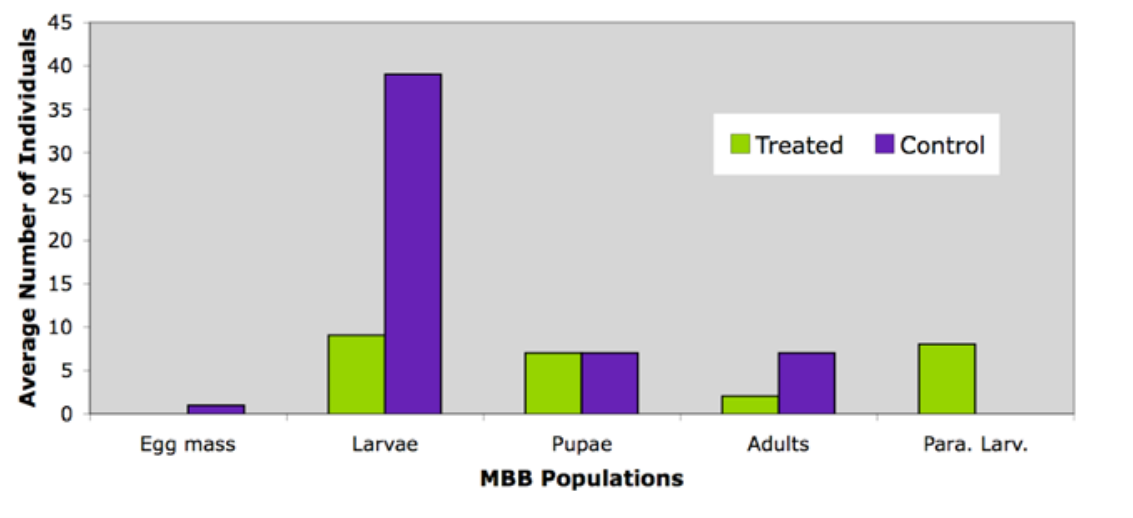


Figure 20: Green bean yields harvested from treated and control subplots were found to be similar for the first and second staggered planting dates. The average yield data for the third planting date was shown to be different in treated subplots compared to control subplots. The fourth planting date only produced beans in treated subplot during the 2004 season.

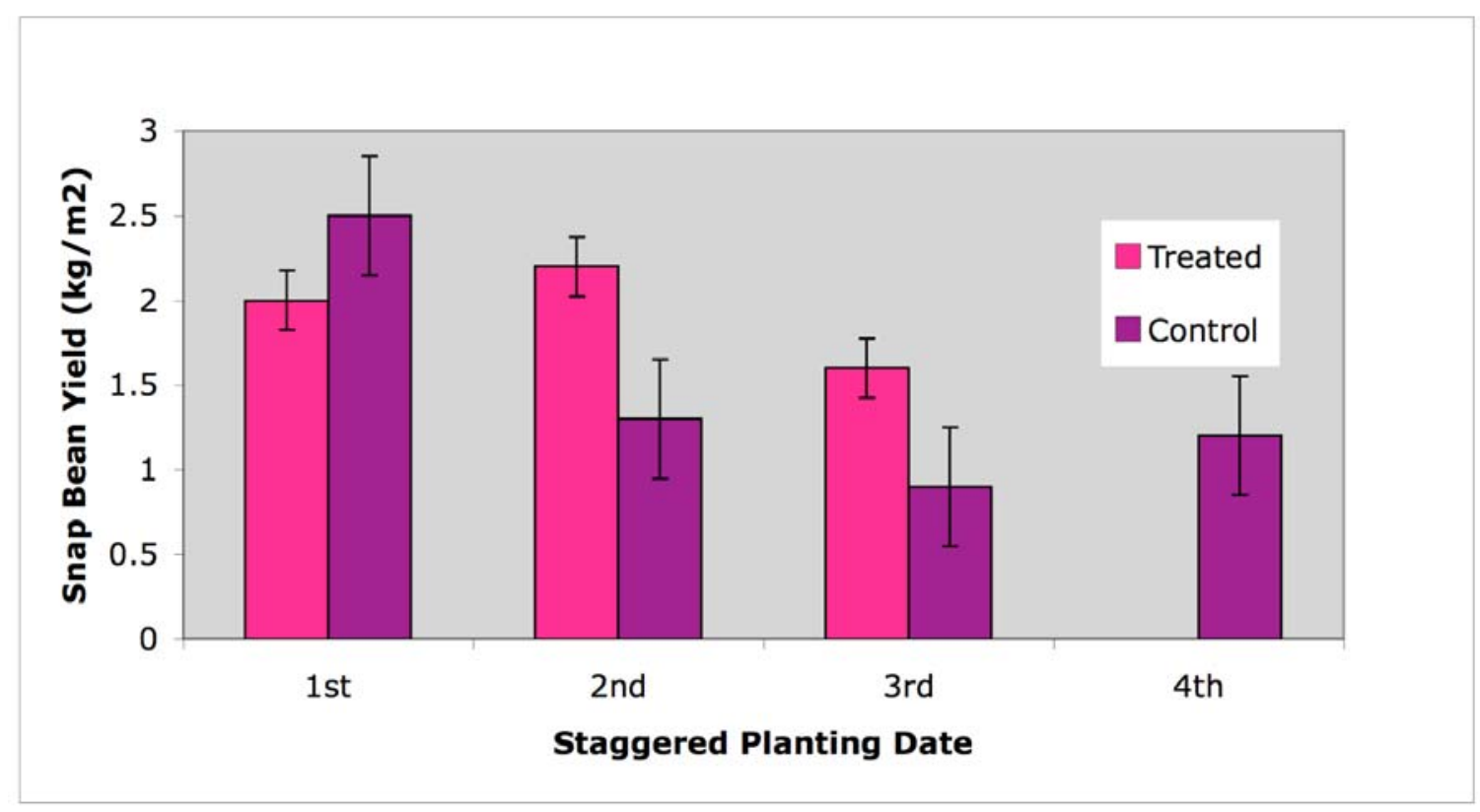


Table 8: Three-way analysis of variance of yield data in Pediobius foveolatus treatment during the 2004 season.

\begin{tabular}{|l|l|l|}
\hline \multicolumn{1}{|c|}{ Source } & \multicolumn{1}{|c|}{ DF } & \multicolumn{1}{|c|}{ F Ratio } \\
\hline P. foveolatus 2004 & 1 & $67.73^{*}$ \\
\hline Cultivar & 5 & 0.49 \\
\hline Sample (weeks) & 7 & $16.81^{*}$ \\
\hline P. foveolatus 2004*Cultivar & 5 & 3.218 \\
\hline P. foveolatus 2004*Sample (weeks) & 7 & $6.20^{*}$ \\
\hline Cultivar*Sample (weeks) & 35 & $5.32^{*}$ \\
\hline P. foveolatus 2004*Cultivar*Sample (weeks) & 35 & $2.16^{*}$ \\
\hline Error & 192 & $0.16^{\dagger}$ \\
\hline
\end{tabular}

*Indicates a significant interaction

${ }^{\dagger}$ Error mean square

Orthogonal contrast within the significant $P$. foveolatus treatment-by-sampling (weeks) interaction in yield data from $P$. foveolatus for the 2004 season.

\begin{tabular}{|l|l|ll|}
\hline Sampling (weeks) & P. foveolatus Release & \multicolumn{2}{|c|}{ Yield } \\
\hline 1 & 0 & 0.13 & a \\
& 1 & 0.12 & a \\
\hline 2 & 0 & 0.12 & a \\
& 1 & 0.69 & b \\
\hline 3 & 0 & 0.52 & a \\
& 1 & 0.67 & a \\
\hline 4 & 0 & 0.78 & a \\
& 1 & 0.79 & a \\
\hline 5 & 0 & 0.58 & a \\
& 1 & 1.10 & b \\
\hline 6 & 0 & 0.34 & a \\
& 1 & 1.11 & b \\
\hline 7 & 0 & 0.12 & a \\
& 1 & 0.97 & b \\
\hline 8 & 0 & -3.05 & a \\
& 1 & 0.28 & a \\
\hline
\end{tabular}


Table 9: Data showed a significant two-way interaction of $P$. foveolatus-by-cultivar-bysample (weeks) on yield during the 2005 season.

\begin{tabular}{|l|l|l|}
\hline \multicolumn{1}{|c|}{ Source } & \multicolumn{1}{c|}{ DF } & \multicolumn{1}{c|}{ F Ratio } \\
\hline P. foveolatus 2005 & 1 & 0.69 \\
\hline Cultivar & 5 & 0.74 \\
\hline Sample (weeks) & 7 & $39.90^{*}$ \\
\hline P. foveolatus 2005*Cultivar & 5 & 0.82 \\
\hline P. foveolatus 2005*Sample (weeks) & 7 & $4.56^{*}$ \\
\hline Cultivar*Sample (weeks) & 35 & $3.35^{*}$ \\
\hline P. foveolatus 2005*Cultivar*Sample (weeks) & 35 & 1.16 \\
\hline Error & 192 & $0.06^{\dagger}$ \\
\hline
\end{tabular}

*Indicates a significant interaction

${ }^{\dagger}$ Error mean square

Orthogonal contrast within the significant $P$. foveolatus treatment-by-sampling (weeks) interaction of the 2005 season.

\begin{tabular}{|l|l|ll|}
\hline Sampling (weeks) & P. foveolatus Release & \multicolumn{2}{|c|}{ Yield } \\
\hline 1 & 0 & 4.51 & a \\
& 1 & 1.04 & a \\
\hline 2 & 0 & 4.51 & a \\
& 1 & 1.04 & a \\
\hline 3 & 0 & 4.51 & a \\
& 1 & 1.04 & a \\
\hline 4 & 0 & 0.46 & a \\
& 1 & 0.12 & b \\
\hline 5 & 0 & 0.60 & a \\
& 1 & 0.80 & b \\
\hline 6 & 0 & 0.48 & a \\
& 1 & 0.49 & a \\
\hline 7 & 0 & 0.17 & a \\
& 1 & 0.41 & b \\
\hline 8 & 0 & 0.05 & a \\
& 1 & 0.13 & a \\
\hline
\end{tabular}


Figure 21: Analysis of snap bean yield data when P. foveolatus was present in the crop, showed that significant differences exist between treated and control subplots during the 2004 season, but differences were found to be insignificant in 2005. Further analysis showed that seasonal differences were significant in treated subplots in 2004 compared to 2005. Control subplots were found to be similar over both seasons.

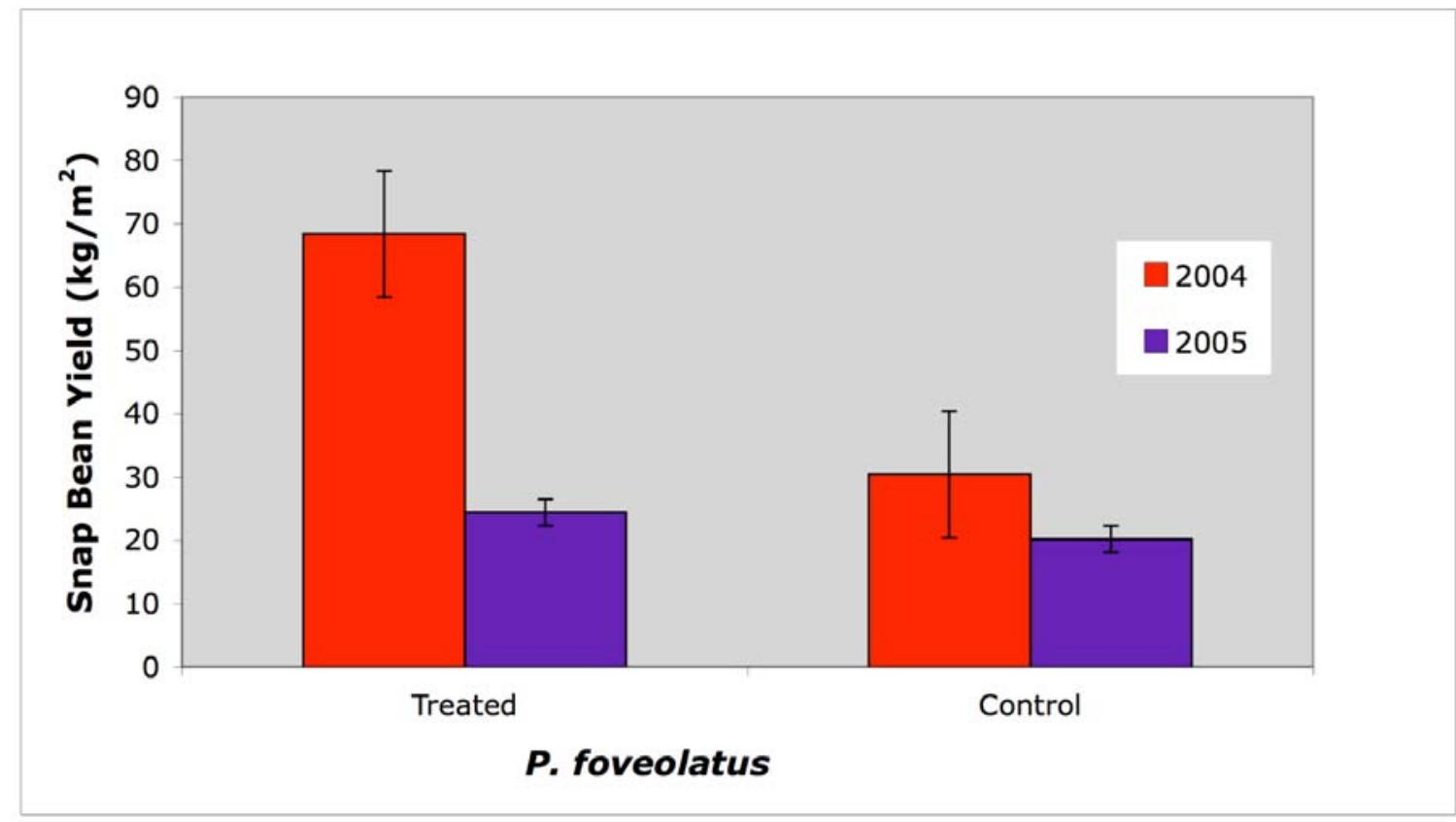


Figure 22: In 2004 the MBB population data showed significant differences in adult, pupal, and larval MBB populations in subplots treated with $P$. foveolatus (A.) compared to control subplots (B.). The number of MBB parasitized larvae was also found to be significantly different in treated subplots compared to control subplots. The number of egg masses were found to be similar in both subplots.

A.

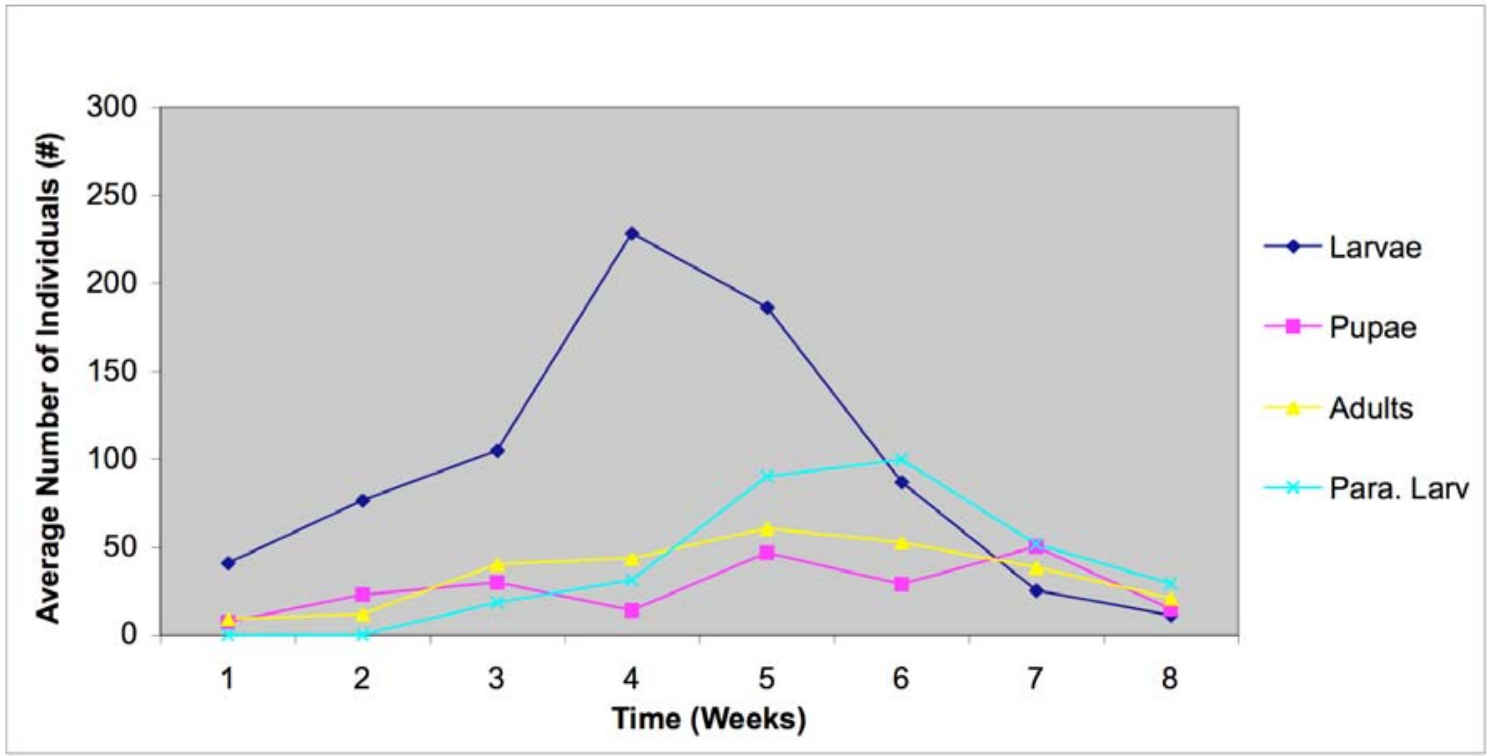

B.

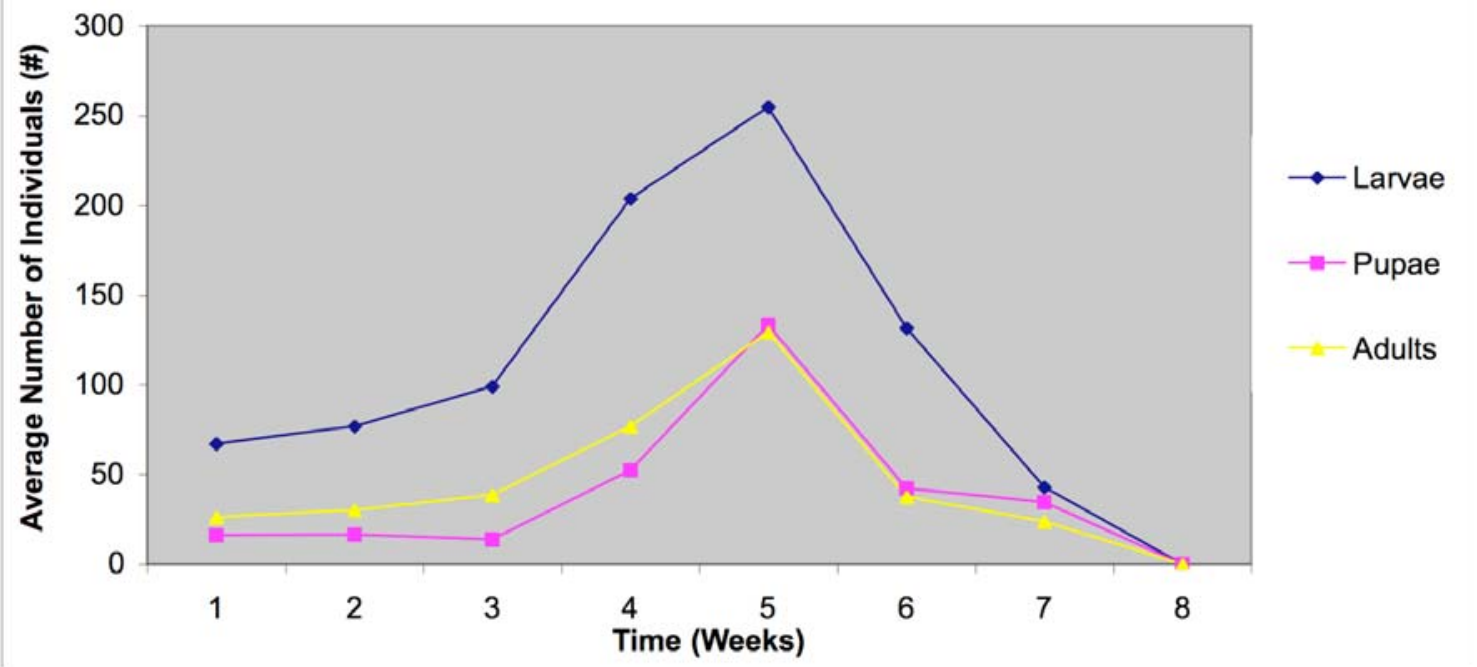


Figure 23: The 2005 MBB population data revealed that only MBB larval populations and the number of parasitized MBB larvae were found to be significantly different in $P$. foveolatus treated subplots (A.) compared to control subplots (B.). MBB adult and pupae population, as well as the number of egg masses were similar in treated and control subplots.

A.

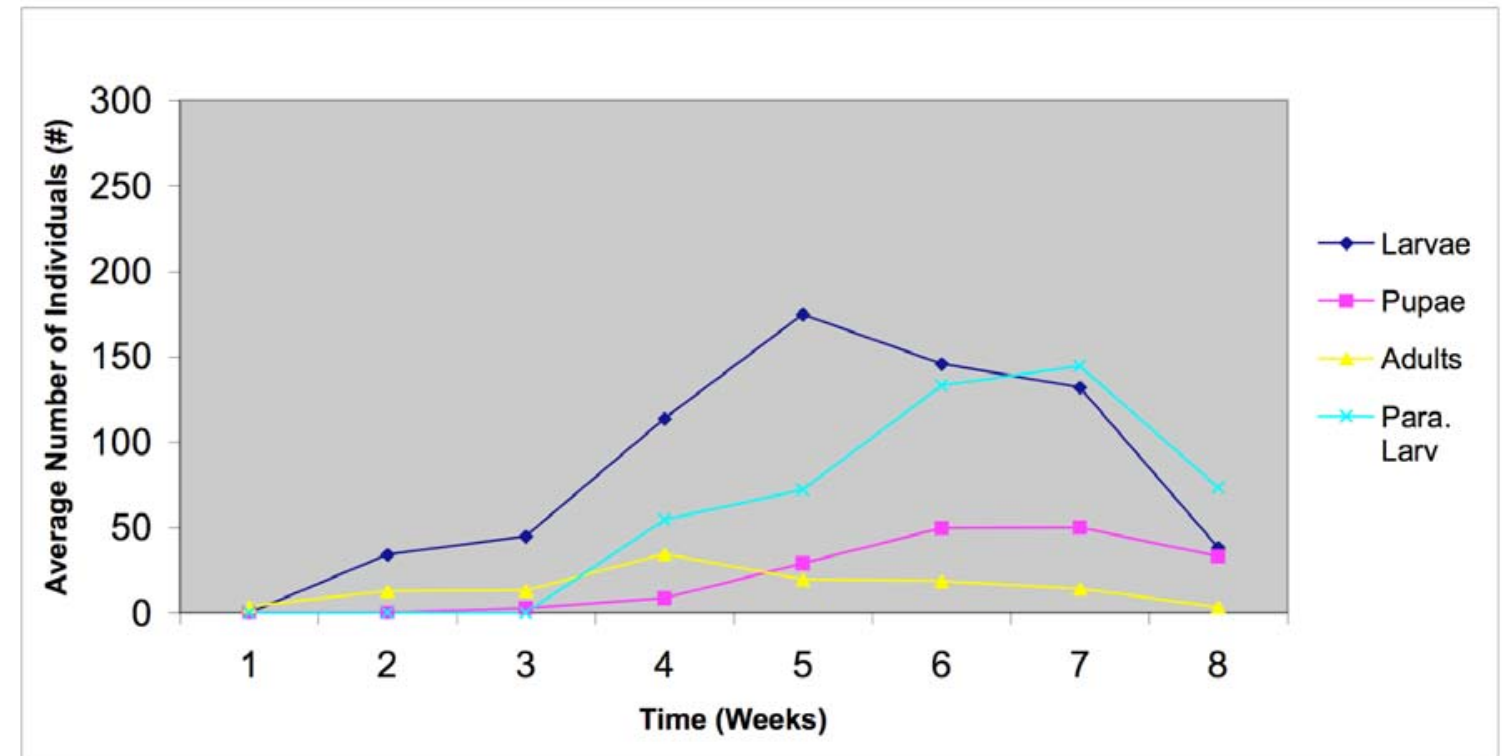

B.

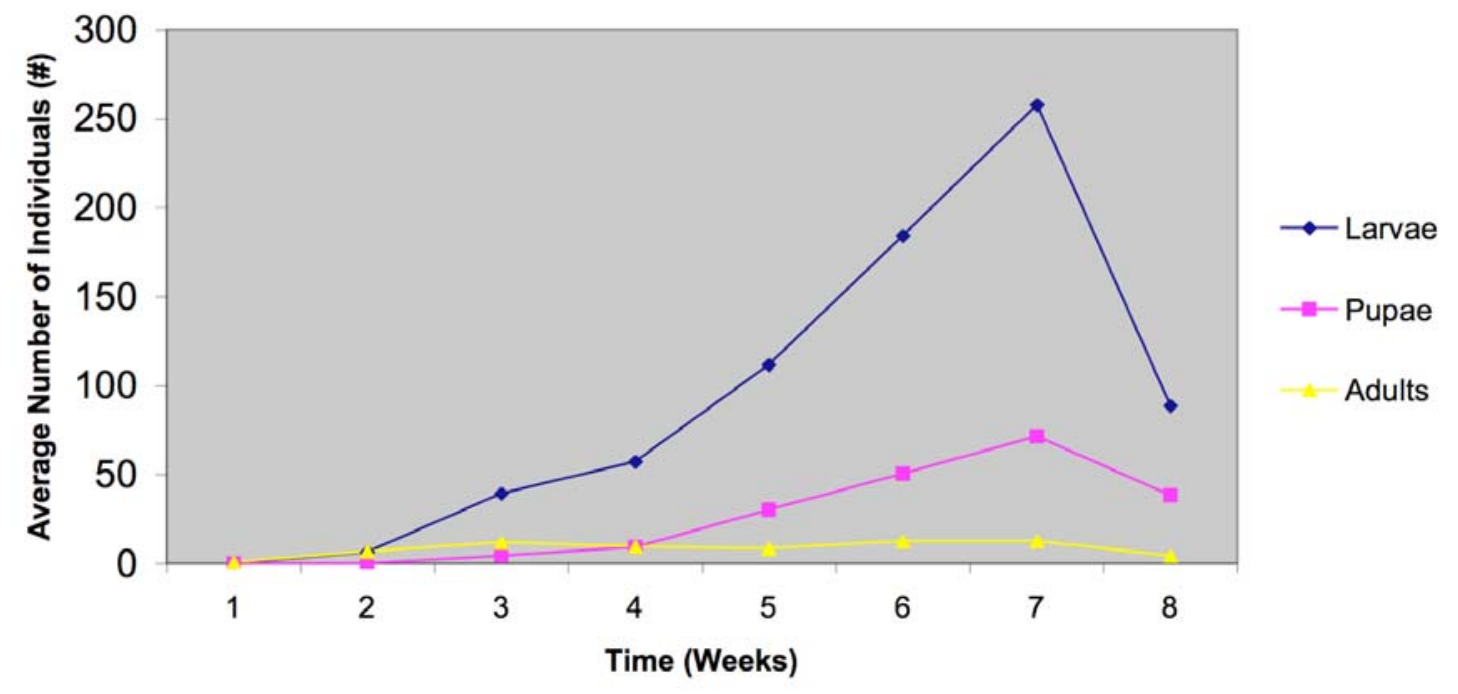


Figure 24: In both the 2004 and 2005 seasons the adult and larval MBB populations among the pole variety, Kentucky Wonder were found to be different in P. foveolatus treated subplots (A.) compared to control subplots (B.). The MBB pupae populations and the number of egg masses were not different either season.

A.

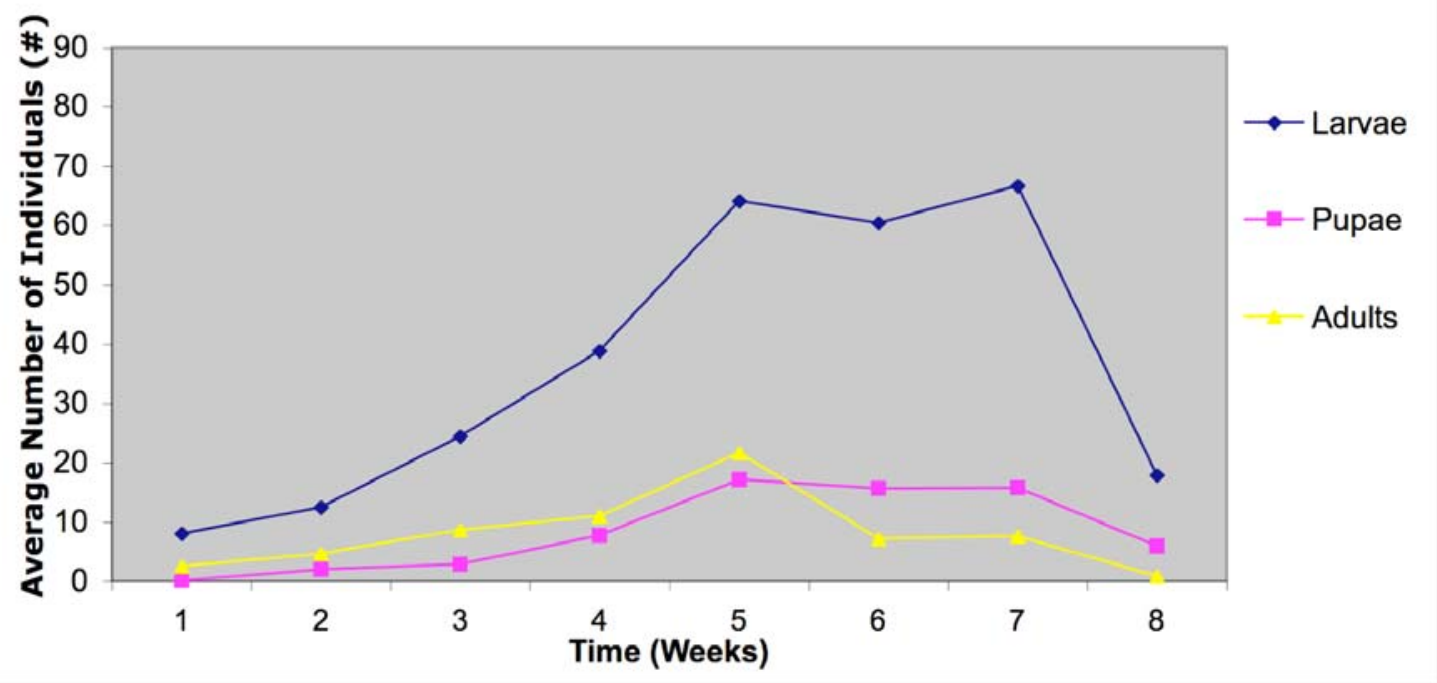

B.

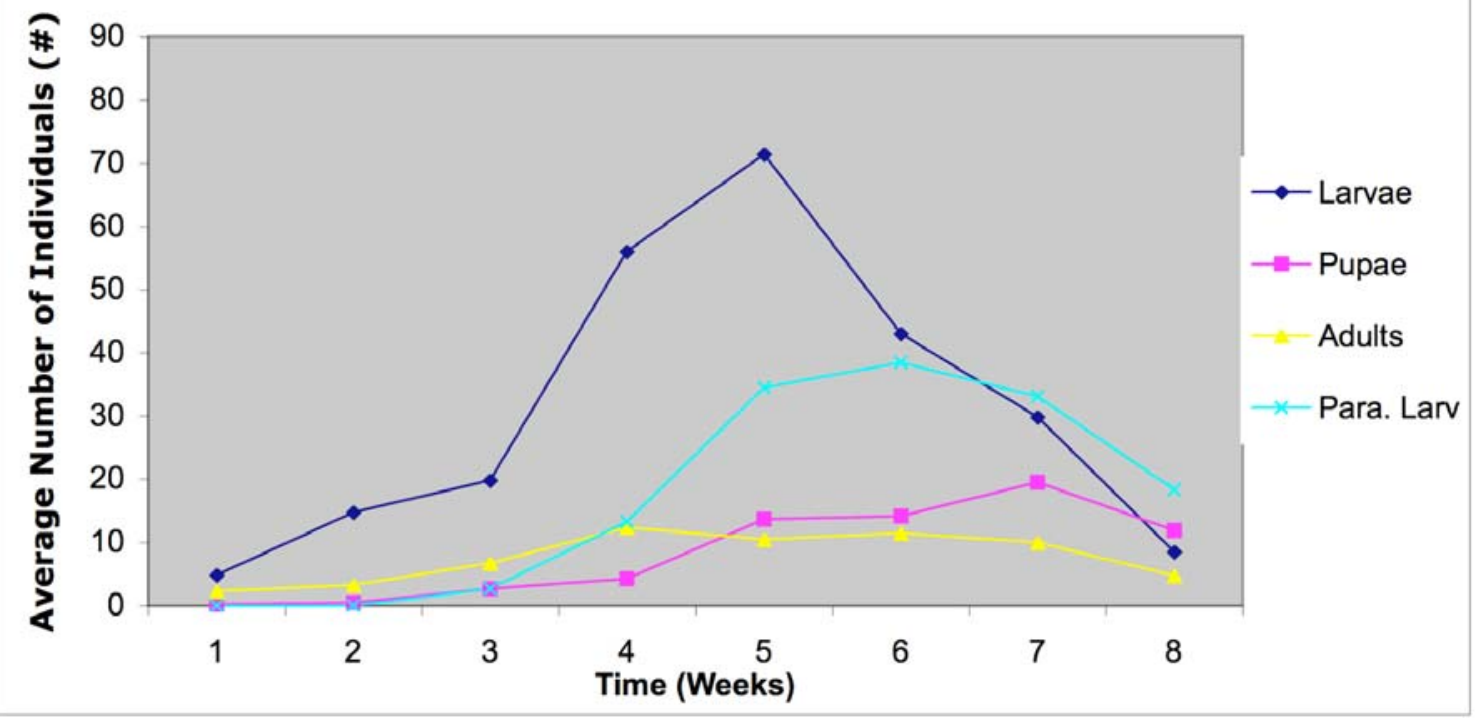


Figure 25: In the 2004 season the average green bean yields from the three cultivars used in the $P$. foveolatus showed that significant differences did exist for the pole cultivar in treated subplots compared to control subplots (A.). However, average green bean yields were found to be similar for the half runner and bush cultivars in treated and control subplots (A.). The average green bean yields from pole, half runner, and bush cultivars were all shown to be similar in $P$. foveolatus treated and control subplots during the 2005 season (B.).

A.

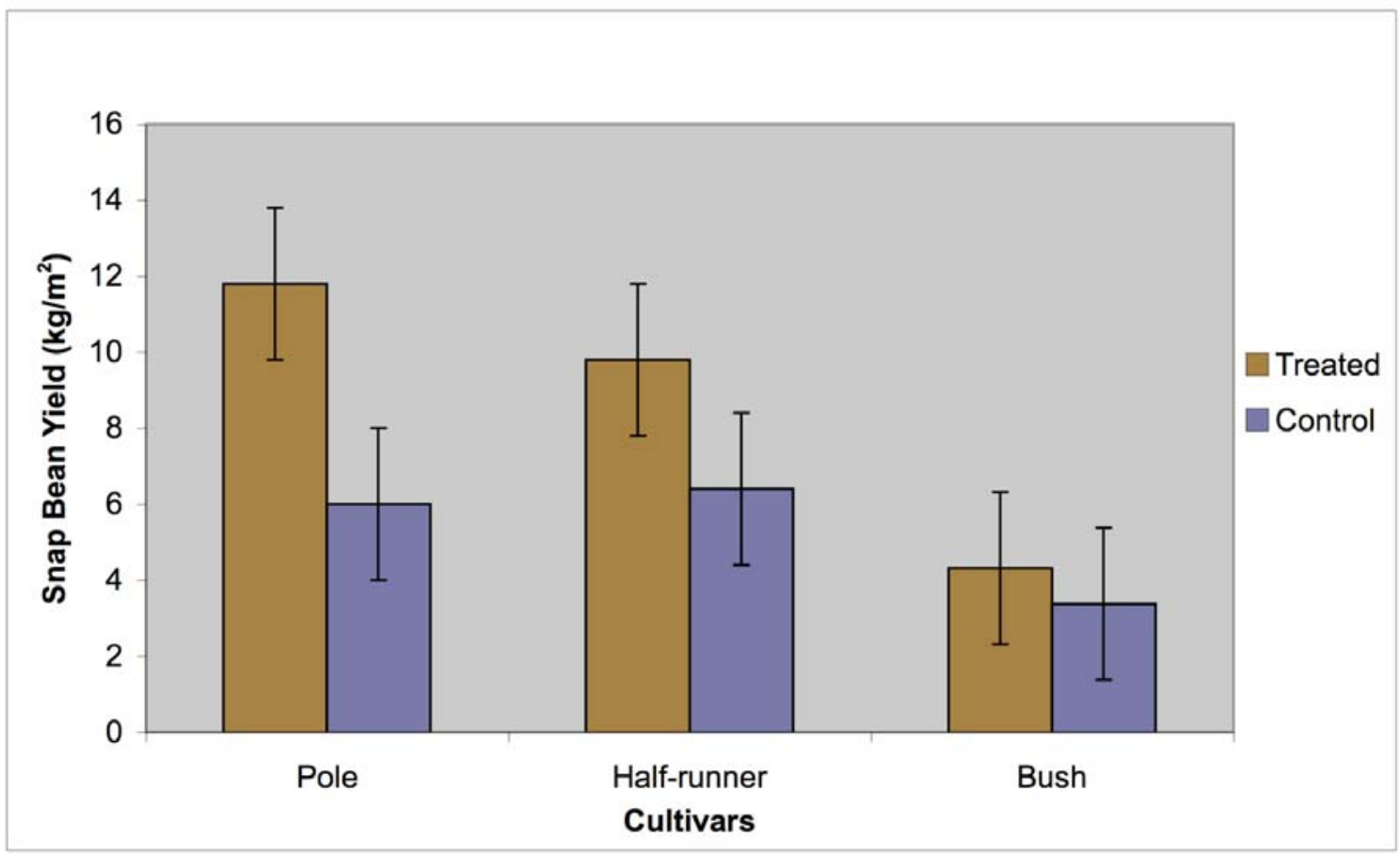

B.

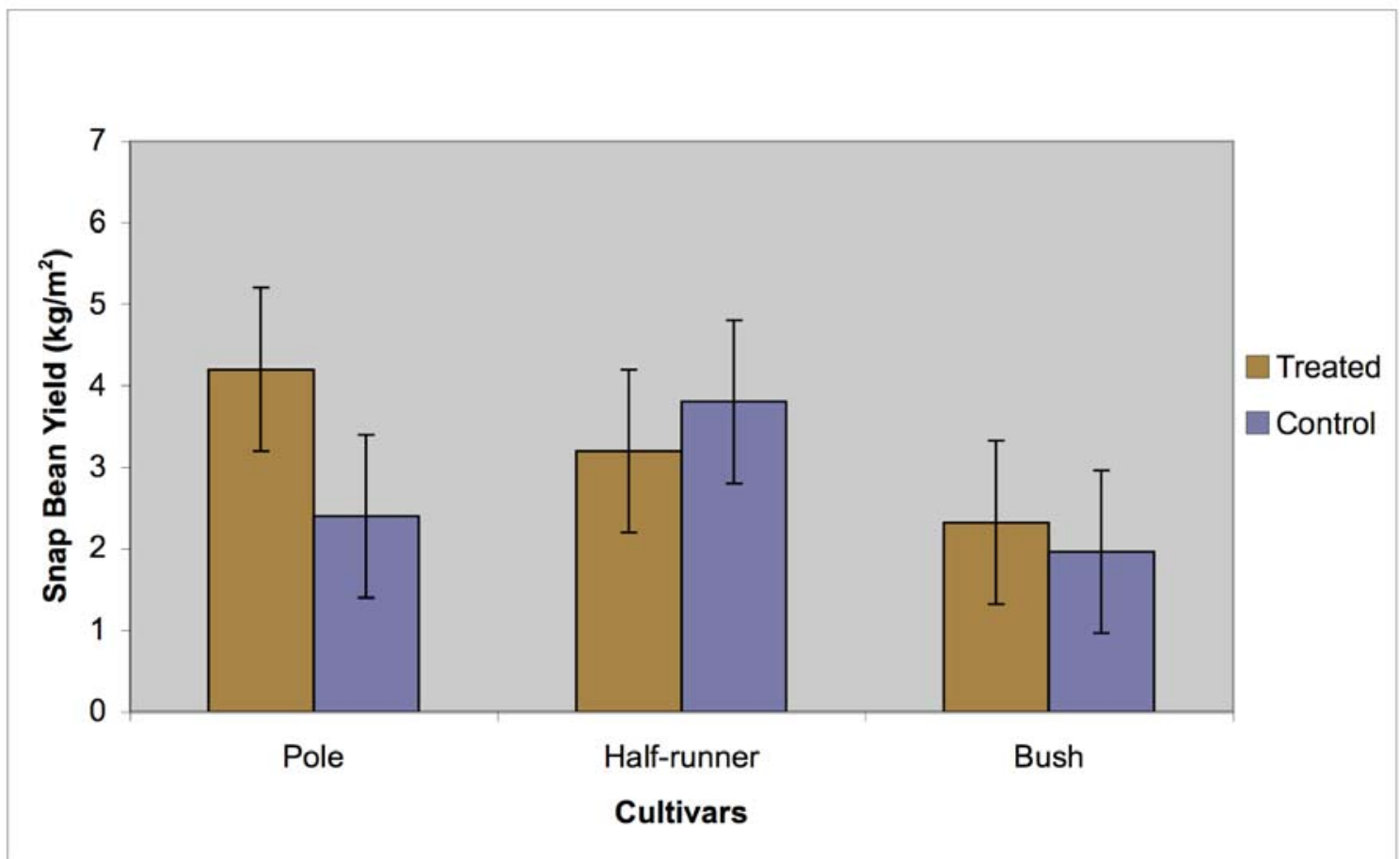


Figure 26: Average MBB population found in the half runner cultivar had significantly different adult, pupae, and larval populations in treated (A.) and control subplots (B.) in the 2004 and 2005 seasons.

A.

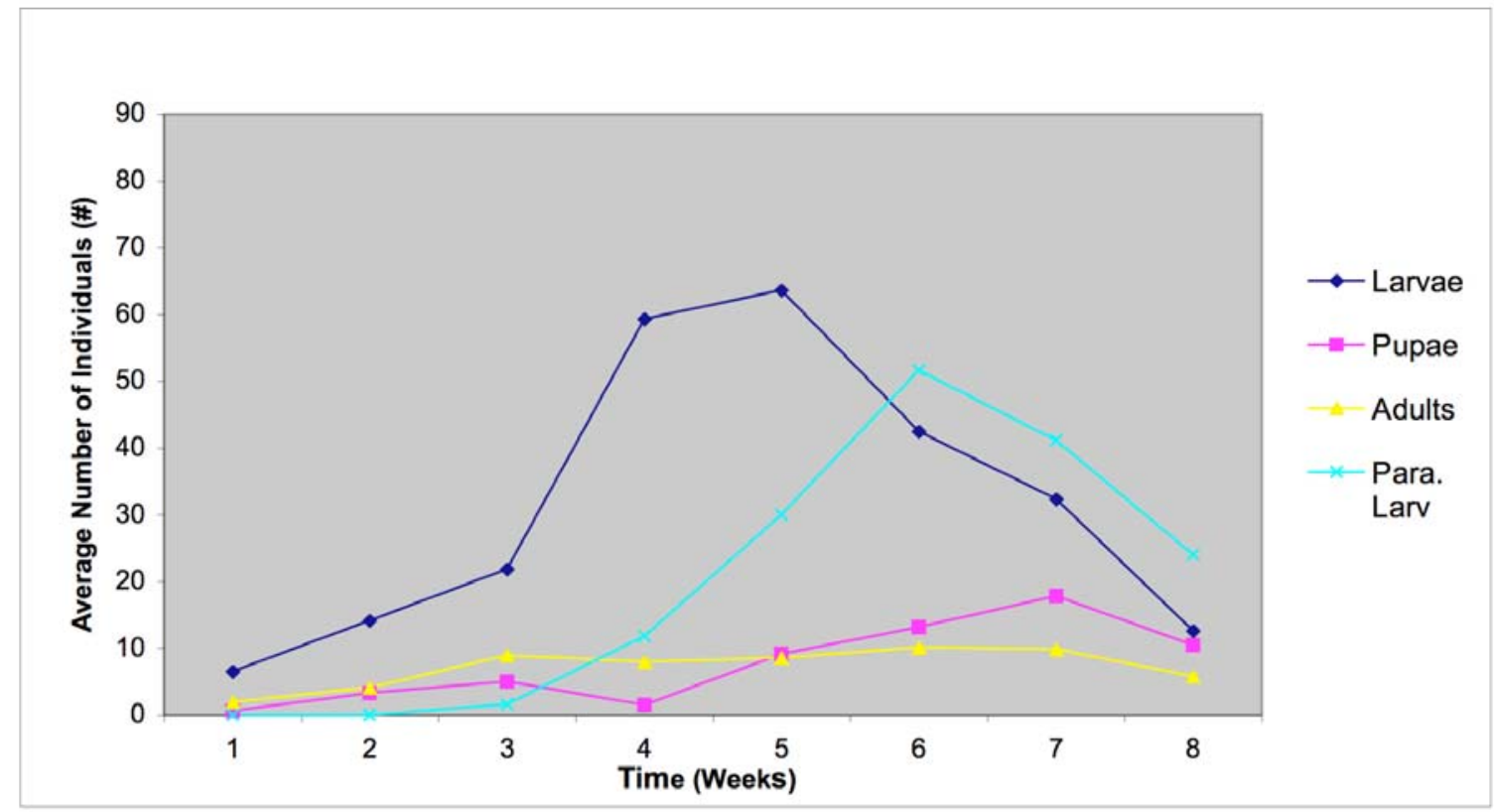

B.

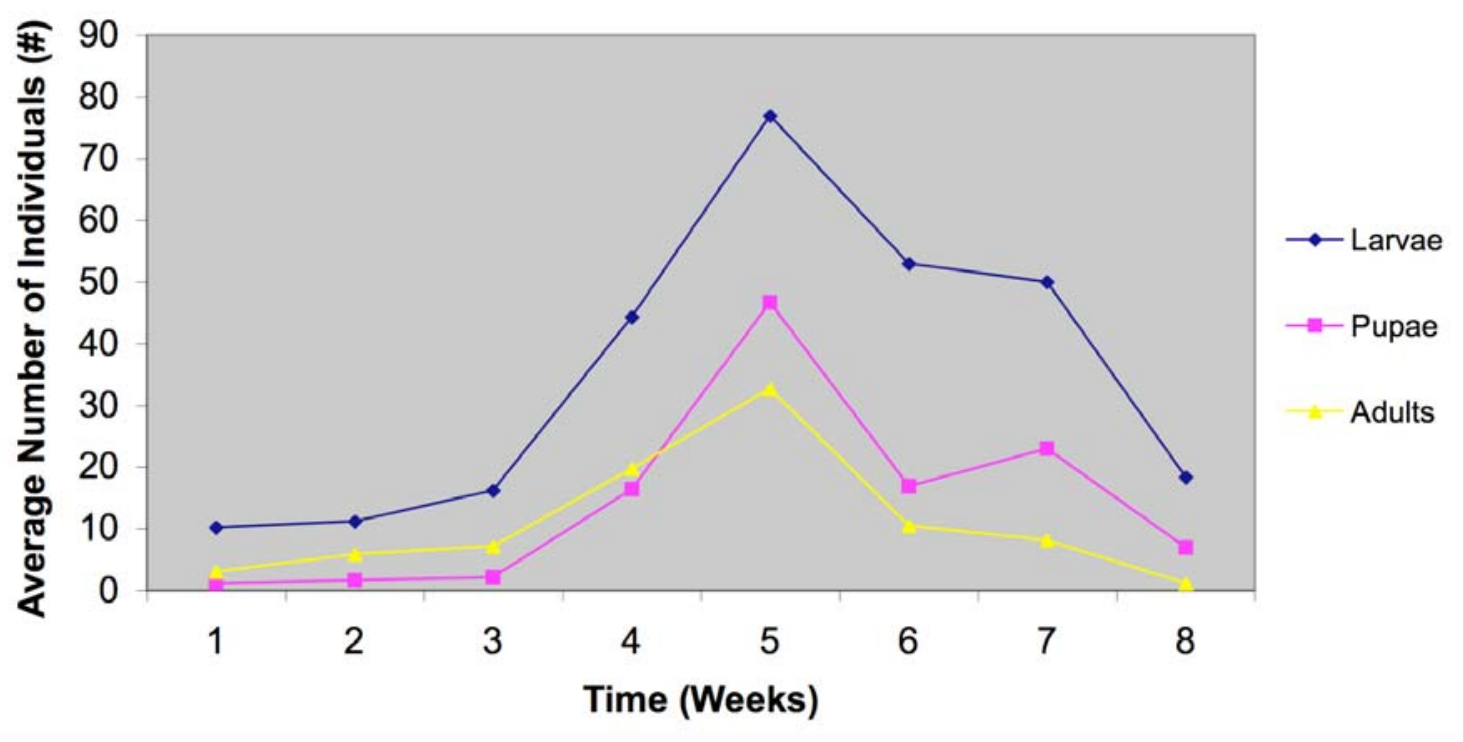


Figure 27: Average MBB population data from the bush cultivar, Provider in the 2004 and 2005 season was similar. It showed that only larval populations remained significant at the end of the season in treated subplots (A.) compared to control subplots (B.). The MBB adult and pupal populations were similar, as well as the number of egg masses.

A.

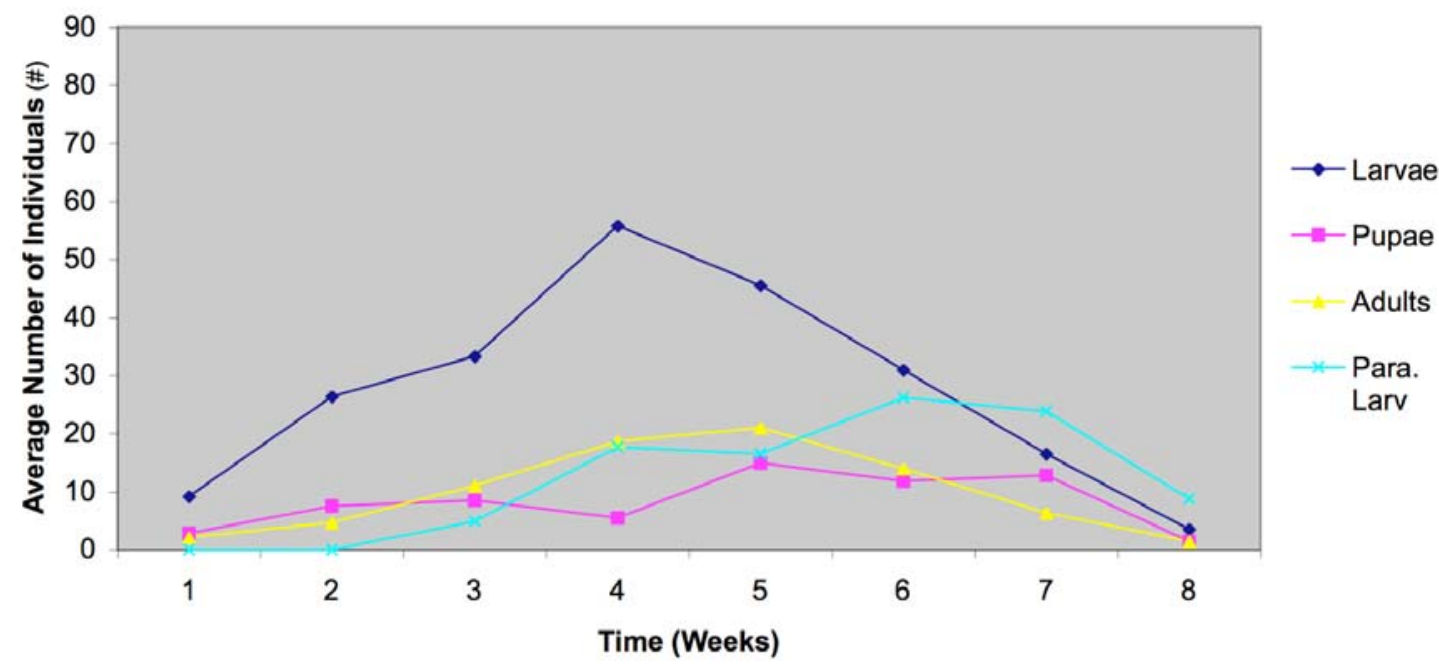

B.

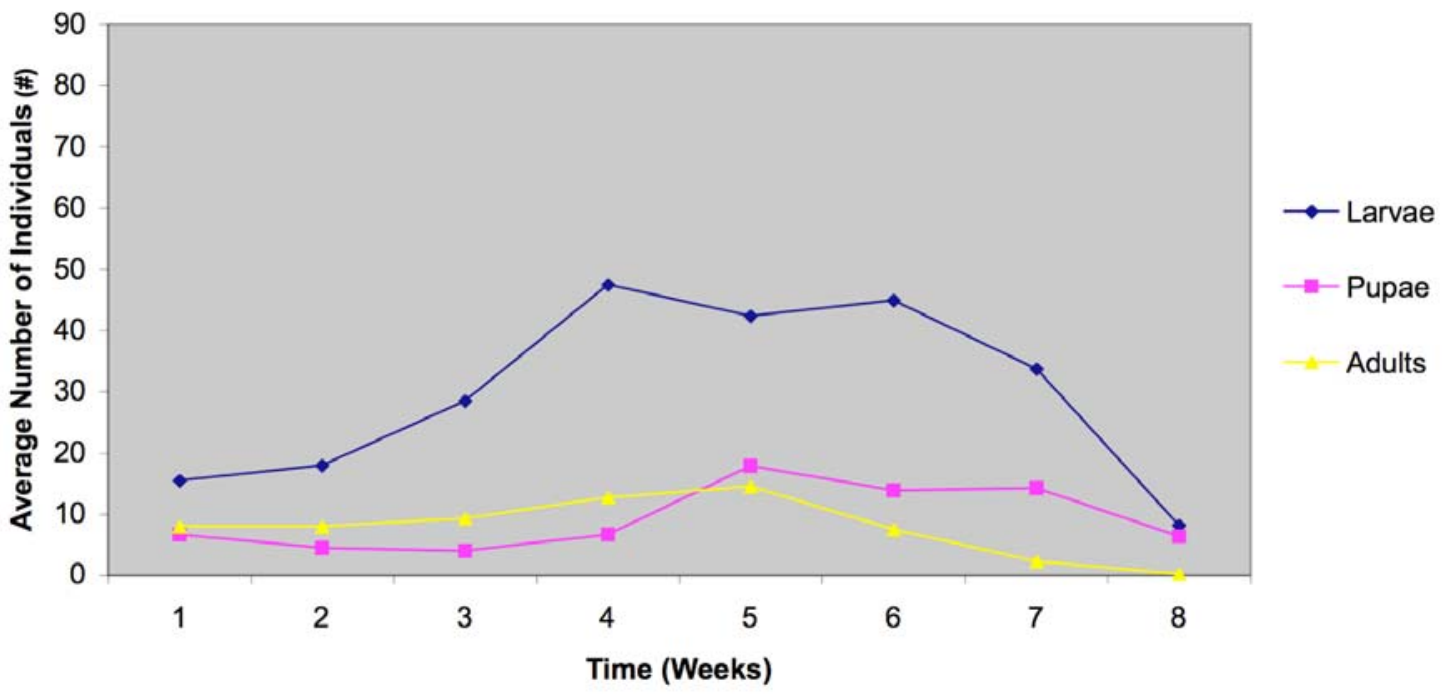


Figure 28: In 2004, the number of parasitized MBB larvae was found be different in pole and half runner cultivars compared to the bush cultivar (A.). In 2005, there were no significant difference found between pole, half runner, and bush cultivars (B.).

A.

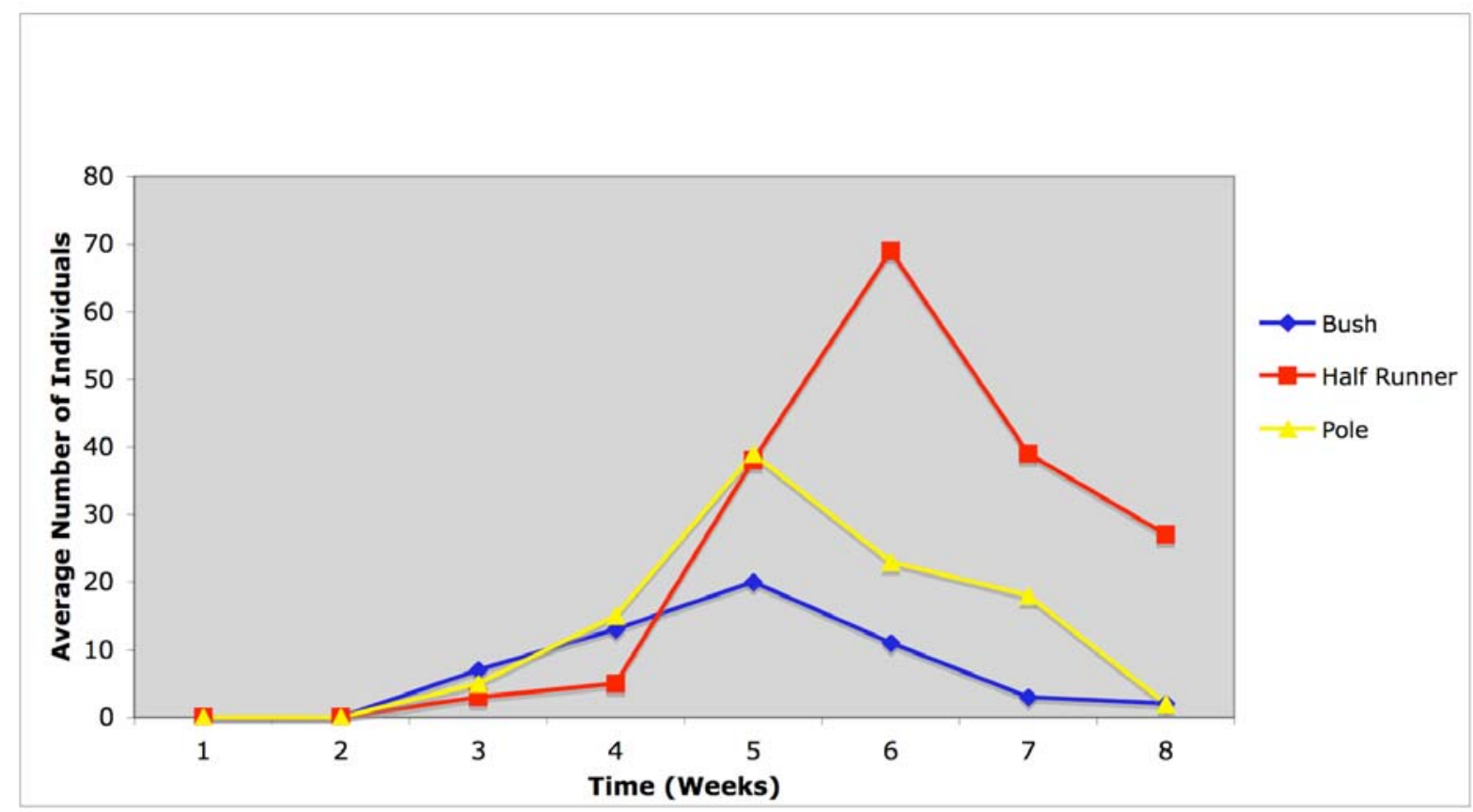

B.

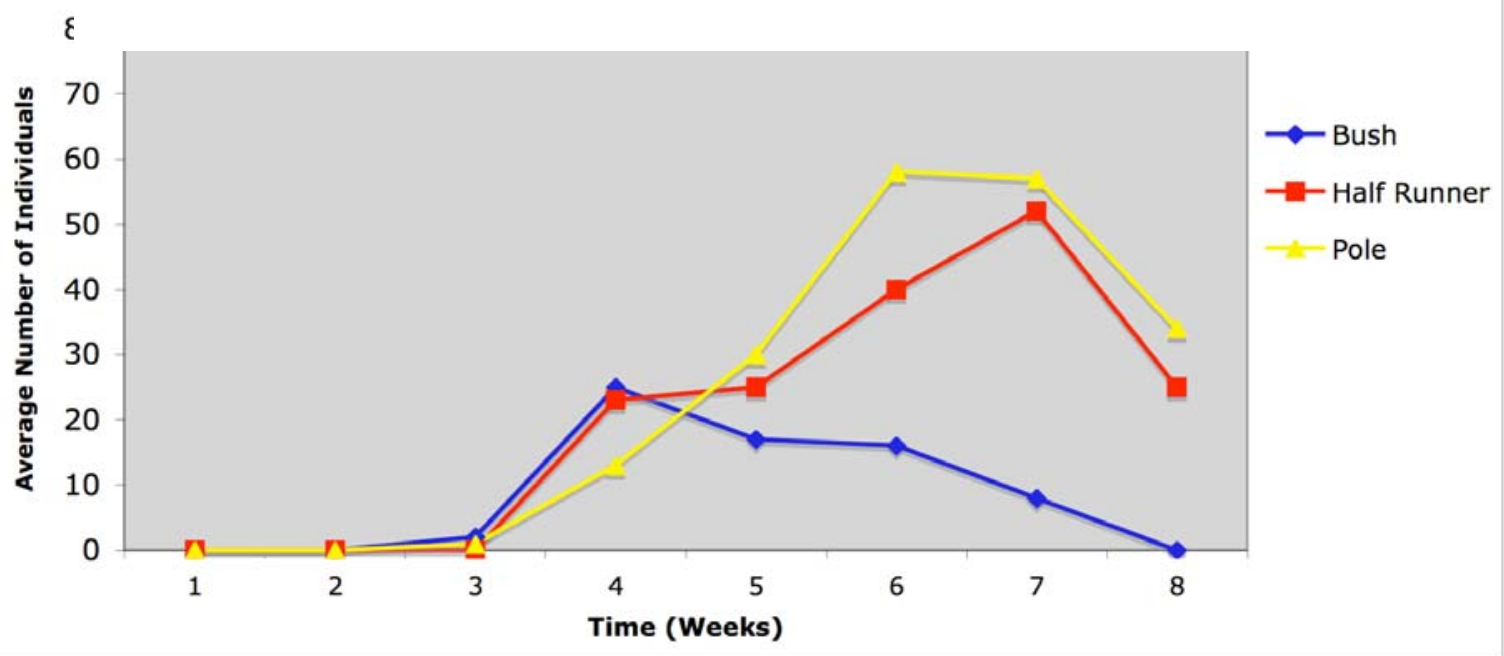


Figure 29. Photograph compares a parasitized MBB pupa (left) to a healthy pupa (right). It is unclear whether the pupa was parasitized as a $4^{\text {th }}$ larval instar that was able to enter pupation or if it was parasitized after entering pupation.

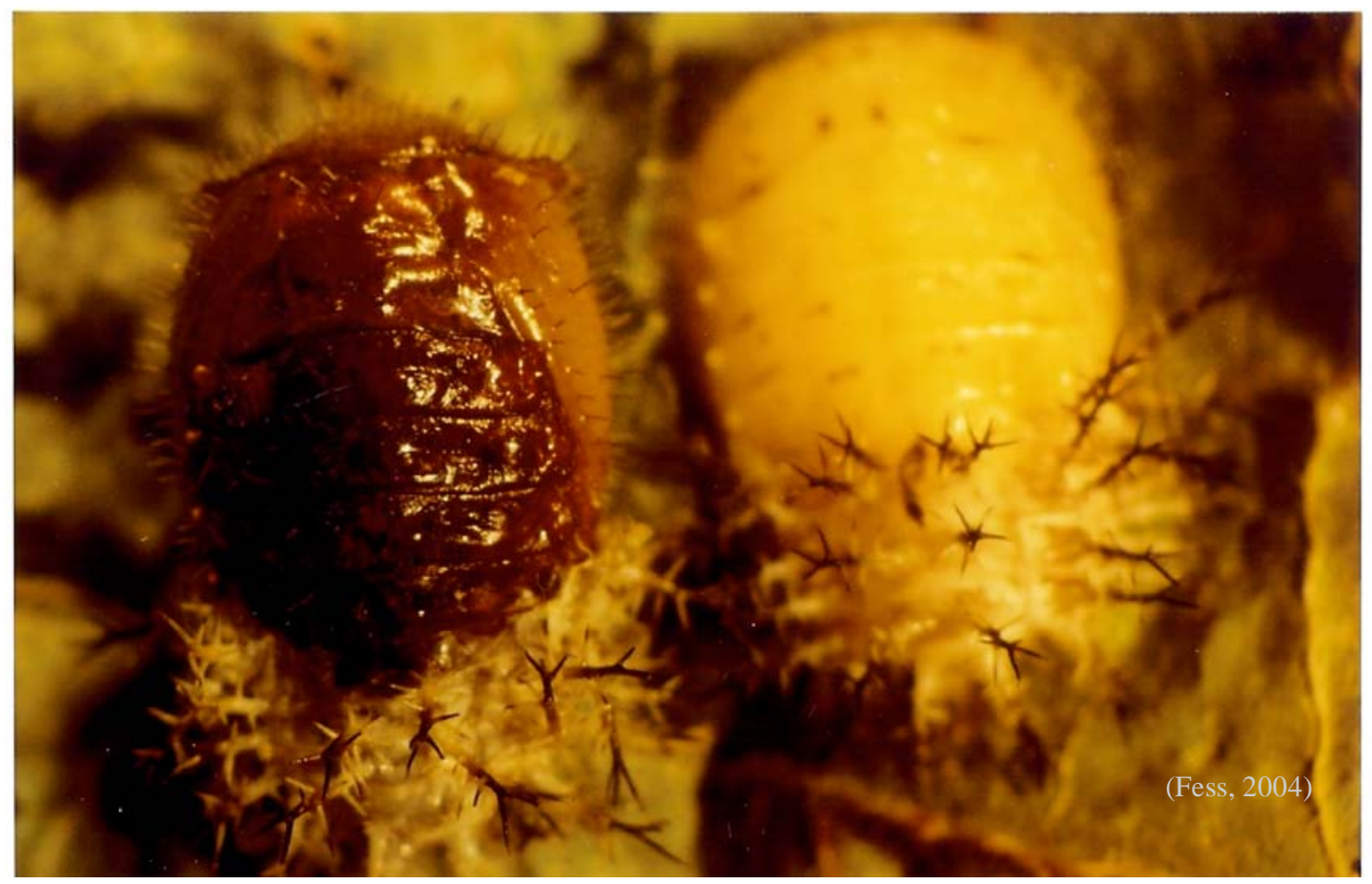

Figure 30. Photograph (20X) of a healthy MBB pupa (left) and larva (right), both of which could be possible hosts to the parasitic wasp, $P$. foveolatus.

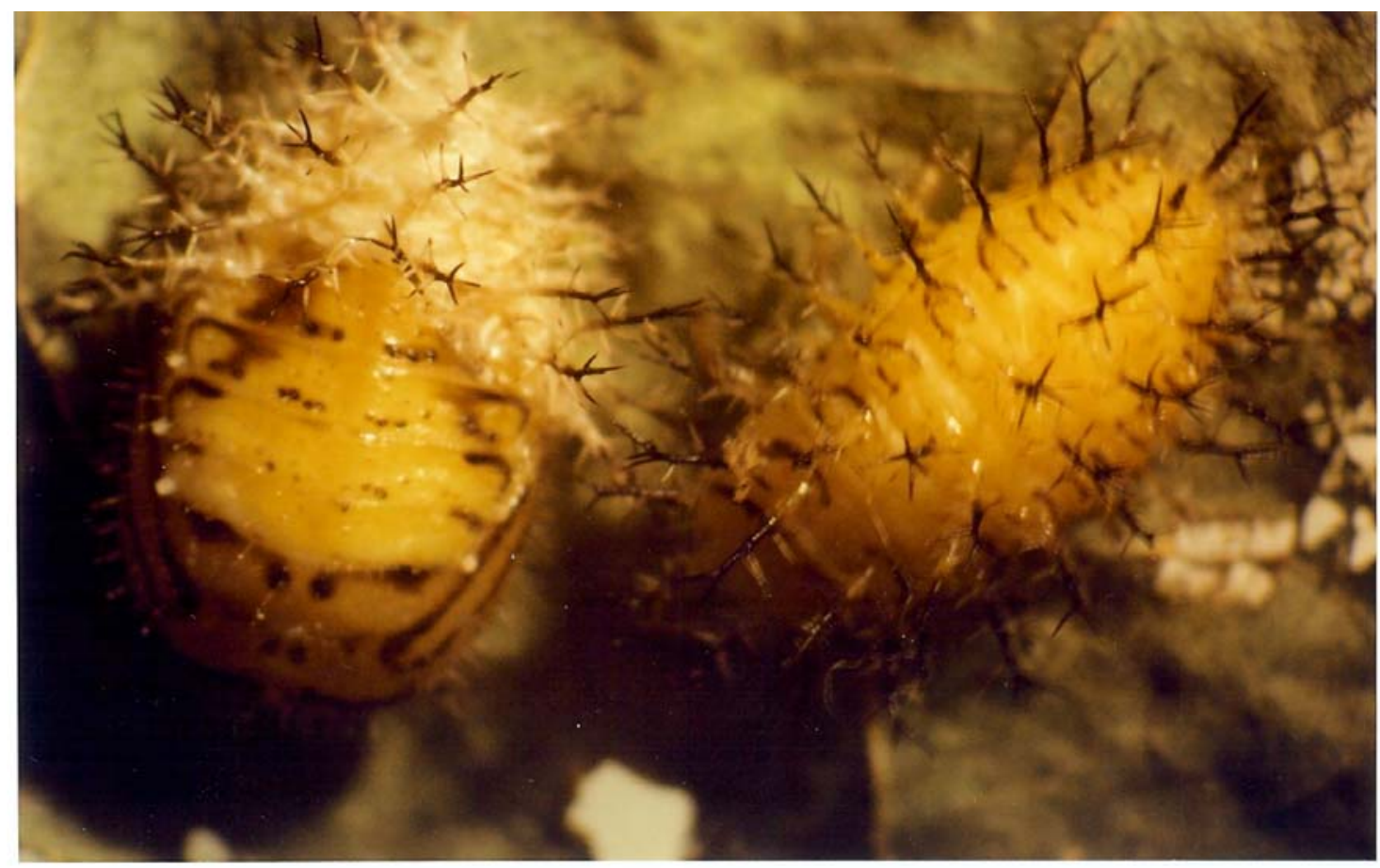




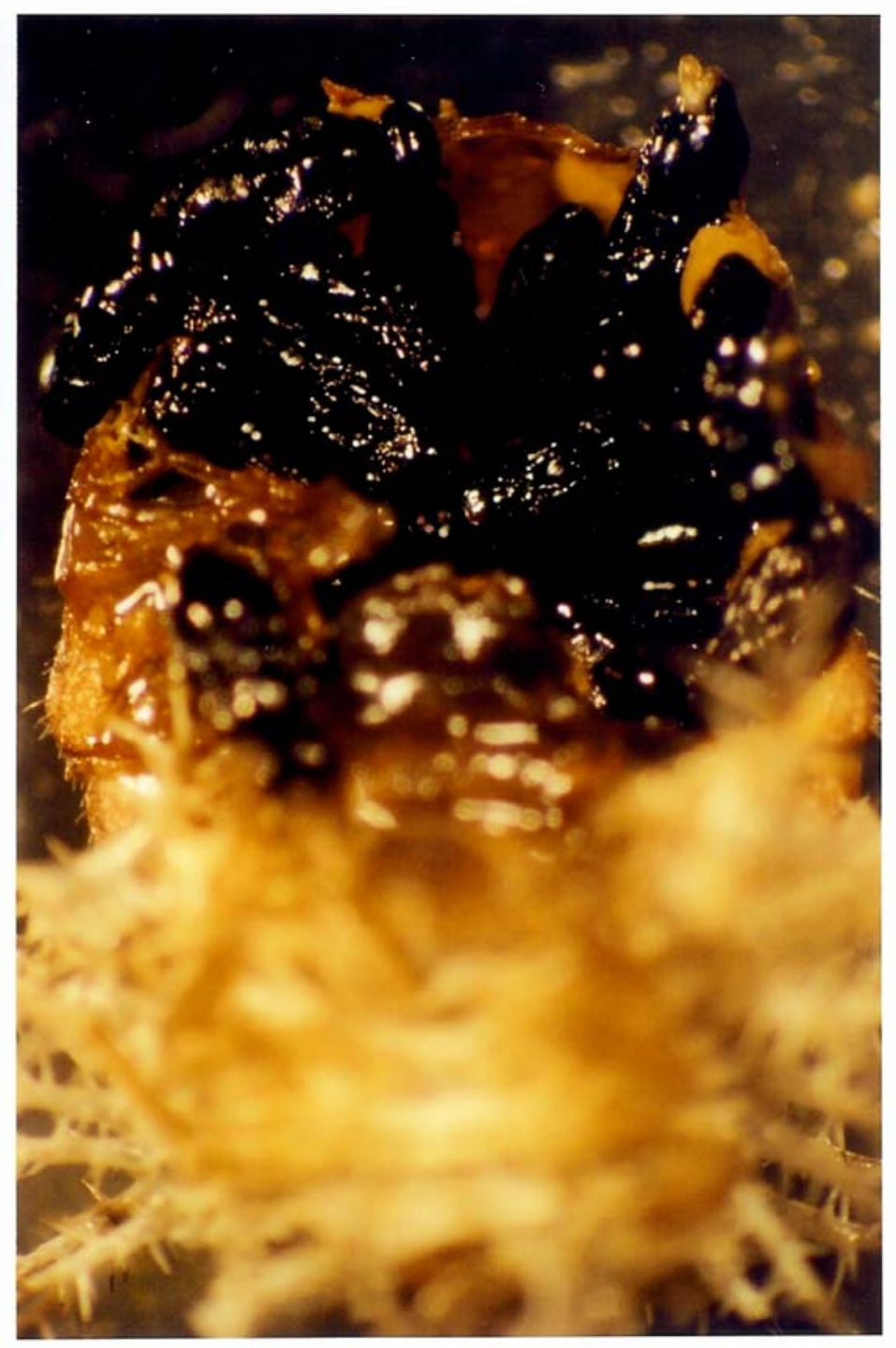

Figure 31: Photograph shows a parasitized MBB pupa that has been dissected to exposed the mature P.foveolatus larvae that have entered pupation, supporting the possibility that the wasps can also develop inside pupa, which can further reduce destructive MBB adult populations. 
Figure 32: Photographs compare snap bean from the $4^{\text {th }}$ staggered planting date in the control (A) and treated subplots (B) in the beginning of August, 2004. The presence of $P$. foveolatus was found to influence the larval and adult MBB populations and bean yields in the late bean plantings.

A

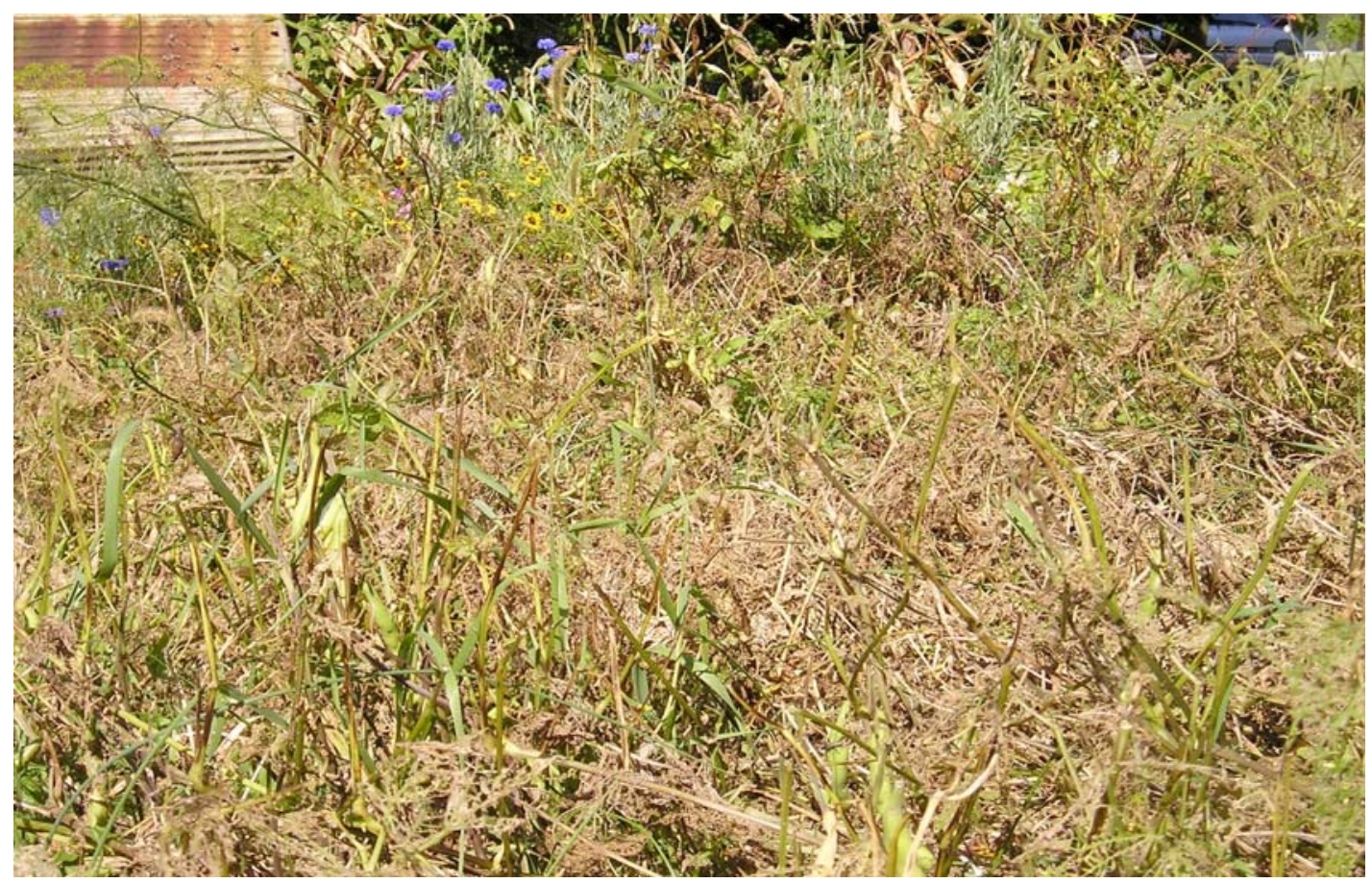

B.

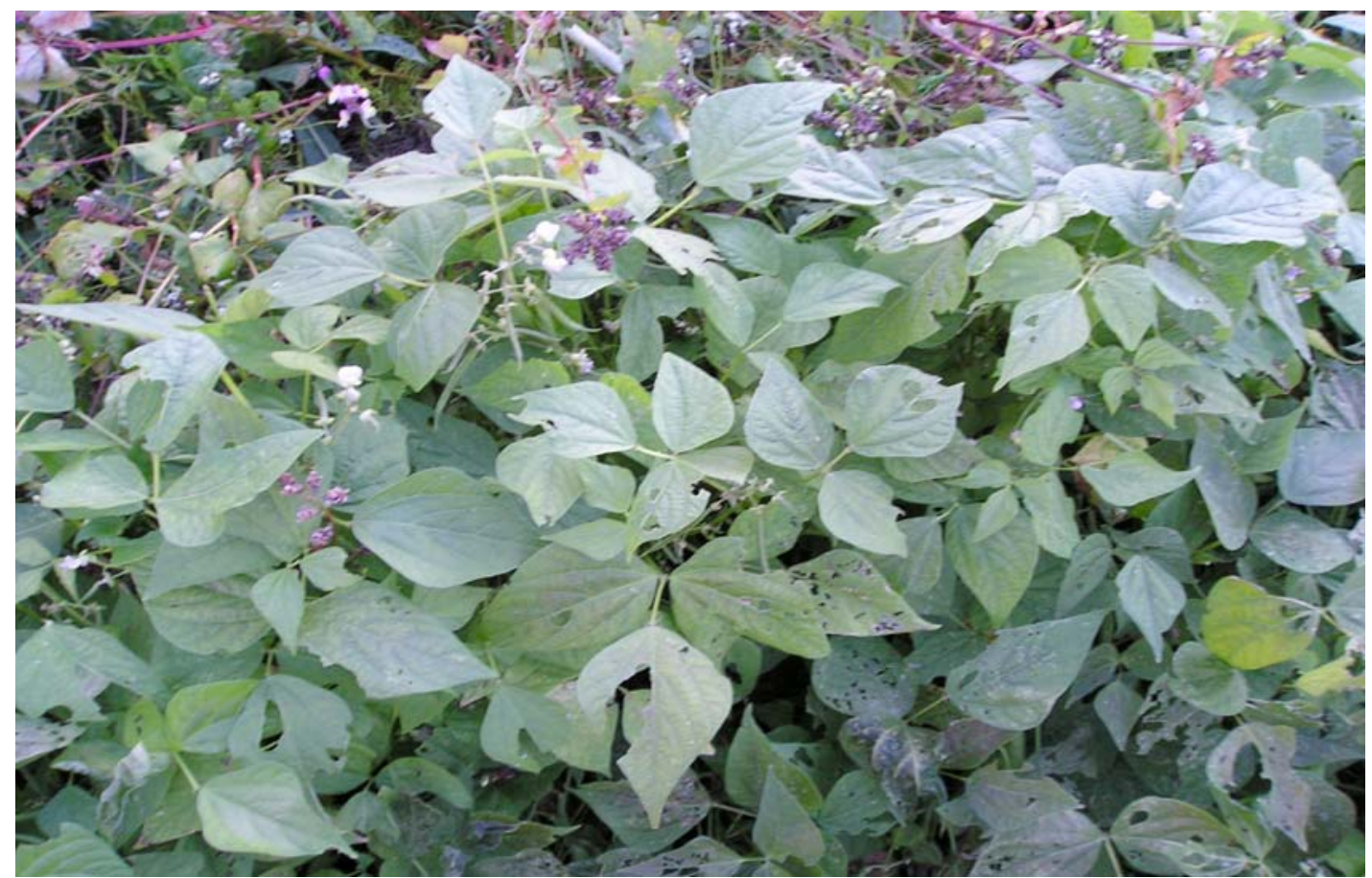




\section{Chapter 3 \\ Snap Bean Variety Trial}

\section{Introduction}

The genus Phaseolus originated in Central and South America and is comprised of over 30 species. However, only five species have been domesticated (Singh, 2001). Among the domesticated Phaseolus species the common or snap bean, Phaseolus vulgaris, is the most widely grown, occupying $85 \%$ of the production area dedicated to all Phaseolus species in the world (Singh, 2001). The genetic base of snap beans available at the market level is narrow because only a small fraction of the wild common bean varieties have been domesticated (Gepts et al., 1996). Few wild varieties have been domesticated largely due to the strict quality requirements demanded by both producers and consumers, along with conservative breeding strategies (Singh, 2001). The reduced gene pool available in modern bean varieties has resulted in plants with inadequate resistance to limiting biotic and abiotic factors (Singh, 2001).

The most devastating biotic factor that snap bean producers in the Eastern U.S. contend with are infestations of Epilachna varivestis, the Mexican bean beetle (MBB) (Perez, 1995). MBB adults and larvae consume mainly the leaves of bean plants but can also devour flowers and forming pods when healthy leaf material becomes less abundant (Sanchez-Arroyo, 2005; Ratcliffe et al., 2004). MBB prefer P. vulgaris to any other known food sources and can completely defoliate a snap bean crop, reducing snap (green) bean yields and ultimately the profits gained by the producers (Reichelderfer, 1979; Sanchez-Arroyo, 2005; Roberts and Douce,1999).

Although MBB can be economically devastating, limited resistance to MBB has been bred into the modern $P$. vulgaris varieties commonly found in the market. Three types of cultivars of $P$. vulgaris are used in the commercial and small-scale production of snap beans; pole, half-runner, and bush cultivars, each with many varieties available. $P$. vulgaris is capable of tolerating small MBB populations without experiencing decreases in the green bean yields (Ratcliffe et al., 2004). However, this limited tolerance is indirectly correlated to $\mathrm{MBB}$ destruction; as MBB consumption increases the tolerance to the resulting damage decreases (Underwood et al., 2000). For example, bush varieties of 
P. vulgaris that are often produced for fresh market consumption, Dade, Tendercrop, Jade, and Provider, are limited in their ability to sustain large damaging populations of $\mathrm{MBB}$, however tend to perform well when MBB populations are maintained below economic thresholds (Perez, 1995). The limited natural resistance to MBB found within the modern common bean varieties has left producers with few options for pest control.

To help increase green bean yields many producers rely on the use of chemical pesticides to help maintain levels of MBB populations present in the bean crop. However, these pesticides have little effect without frequent and/or heavy application (Edwards and Bergman, 1987). The increased exposure to harsh chemicals over the past several decades has lead to a moderate resistance and to decreasing efficiency of commercial insecticides on MBB (USDA, 1954; Dobrin and Hammond, 1983; SanchezArroyo, 2005). All of which adds to the difficulty in controlling large infestations of MBB for producers of green snap beans.

U.S. consumption of fresh green beans has increased tremendously over the past few years. During 1998-2000 an average of 519 million pounds of fresh green beans were consumed annually, up 83\% from 1989-1990 in which 285 million pounds were consumed (Lucier and Lin, 2002). In 1999, Americans consumed approximately 2.1 pounds of fresh green snap beans per capita, spending a total of $\$ 83,348,172$ annually(USDA, 2001; Lucier and Lin, 2002). During this same time, 1998-2000, the production area for fresh snap beans increased in all five of the top fresh-market producing states, Florida, Georgia, California, New York, and North Carolina, compared to the decade earlier, 1988-1990 (Lucier and Lin, 2002).

As consumer demand increases, finding varieties of snap beans that exhibit elevated levels of resistance to MBB could help to decrease the amount of pesticides applied to green bean crops and possibly increase the profits gained by producers. This is especially critical for small-scale organic producers who are prohibited in the use of harsh pesticides and lack efficient alternatives for MBB control. Determining which specific varieties of snap beans have an elevated tolerance to MBB infestation, yet are still productive with low input farming practices is necessary in order to reduce required pesticide applications and develop alternatives for MBB control in snap bean crops produced in the Eastern U.S. 
The information that is available to producers using low input or organic systems does not include details concerning suitable cultivars or varieties that may exhibit elevated tolerance to $\mathrm{MBB}$, or identify those that may still produce well under low to high insect pest pressure. In order to fill some of the gaps in the information available, the main objective of this study is to determine which snap bean varieties (15 varieties) commonly grown in small scale, low input, organic systems exhibit the most tolerance to MBB damage, yet are still productive.

\section{Materials and Methods}

Our study consisted of four plots, each containing one replicate of each of the five varieties of bush, half-runner, and pole green bean cultivars tested for tolerance to MBB damage (Figure 33). All four plots were assigned space in the certified organic small scale market garden found on the WVU Plant and Soil Science Farm (Rt. 705; Morgantown, WV; 39³8'45.08’N 7956’16.98’W) (Figure 34). Each plot of beans measured $9.4 \mathrm{~m}$ x $2.4 \mathrm{~m}$. Soil preparations started with groundbreaking using a rear tine tiller (BCS, Portland, OR) cutting to a depth of approximately $20 \mathrm{~cm}$. Compost from the WVU Plant and Soil Science Farm was applied at a rate of ten tons per acre (dry weight) and subsequently turned under using the same rear tine tiller.

Each plot consisted of fifteen rows; five adjacent rows of bush varieties, halfrunner, and pole bean varieties. The three types or groups of cultivars were randomly assigned a section of the plot, and cultivars within each section were also arranged randomly. All seeds were inoculated with a Rhizobium spp. (N-Dure, Microbials LLC; Kentland, IN) slurry prior to planting, which did not occur until the soil temperature reached $12^{\circ} \mathrm{C}-14^{\circ} \mathrm{C}$. Seeds were sown at a depth of $2.5 \mathrm{~cm}$ below the soil surface at a rate of 27 seeds/meter in $2.4 \mathrm{~m}$ rows placed $0.3 \mathrm{~m}$ apart for bush varieties, $0.5 \mathrm{~m}$ for halfrunner, and $0.6 \mathrm{~m}$ for pole bean varieties. The five varieties of bush beans grown were Black Valentine (Fedco Seeds; untreated), Blue Lake 274 (Peaceful Valley Farm Supply; certified organic), Contender (Peaceful Valley Farm Supply; certified organic), Provider (Fedco Seeds; certified organic), and Royalty (Peaceful Valley Farm Supply; certified organic). The half-runner varieties planted were Mountaineer (Vegetable Warehouse; 
untreated), Painted Lady (Territorial Seed Company, untreated seed), Pink (Fedco Seeds, untreated seed), Spartan (Fedco Seeds, untreated seed), and State (Fedco Seeds, untreated seed). Pole bean varieties used were Blue Lake FM-1K (Fedco Seeds; untreated seed), Kentucky Wonder (Peaceful Valley Farm Supply; certified organic), McCaslan (Fedco Seeds, untreated seed), Purple Podded (Vegetable Warehouse; untreated), and Rattlesnake (Fedco Seeds, untreated seed).

Plots were prepared and planted over a two-day period (May 25-27) during both the 2004 and 2005 seasons. Conditions during this period consisted of a moderately moist soil without any significant precipitation. Each plot was watered promptly after sowing to aid germination. Once seedlings emerged hay mulch (certified organic) produced on the WVU Plant and Soil Science Farm was applied to the entire plot at a depth of $5 \mathrm{~cm}$ to discourage weed growth. Trellises were built for half-runner and pole varieties at this time using $2.4 \mathrm{~m}$ and $3.0 \mathrm{~m}$ untreated pine lumber measuring $4.5 \mathrm{~cm} \times 4.5$ $\mathrm{cm}$.

Weekly observations on each variety began after seedling emergence and included height, growth and developmental stage of $P$. vulgaris, MBB adult population, MBB pupal population, MBB larval population, number of MBB egg masses, and green snap bean yields. Using JMP (SAS Institute, Cary, NC) statistical analyses were performed in order to determine if significant yield and MBB population differences occurred between varieties and/or cultivars using an analysis of variance (ANOVA) with a least significant difference (LSD) of $\mathrm{P}<0.05$.

\section{Measurements}

Cultivar height was averaged using five plants randomly selected within each row. Data were collected in inches using a standard measuring tape, then converted to meters using the following equation: height $(\mathrm{m})=$ height (in) $\times 0.0254 \mathrm{~m}$. The various stages of growth were also noted: vegetative, anthesis or first flower, and pod formation.

All MBB populations were estimated by counting the number of individual egg masses, larvae, regardless of instar, pupae, and adults found on the underside of 75 randomly chosen trifoliate leaves within each row of every cultivar, in each replicate, on 
a weekly basis beginning at seedling emergence. These data were then used to find weekly and seasonal averages.

Beans were harvested by hand weekly as they reached maturity for the particular variety, ranging from 58-70 days from sowing, and weighed in kilograms.

\section{Results}

\section{Cultivar differences}

The adult, pupal, and larval MBB populations, as well as the number of egg masses were found to be similar $(\mathrm{P}>0.05)$ among the bush, half runner, and pole cultivars during both the 2004 and 2005 seasons (Figure 35). The bush cultivar area had a MBB population that averaged 15 adults, 13 pupae, 172 larvae, and 2 egg masses per plot at the end of both seasons. The areas dedicated to the half runner cultivar had a final MBB population that consisted of 20 adults, 18 pupae, 162 larvae, and 3 egg masses, on average over the two years of our study. The pole bean cultivars had a final MBB population that averaged 15 adults, 18 pupae, 208 larvae, and 3 egg masses over two years.

The average total green bean yield was also found to be similar ( $\mathrm{P}>0.05)$ among all three groups of cultivars during both seasons. An average total of $2.0 \mathrm{~kg} / \mathrm{m}^{2}$ of green beans were harvested from the bush cultivars per season, $1.5 \mathrm{~kg} / \mathrm{m}^{2}$ from the half runner cultivars, and $1.1 \mathrm{~kg} / \mathrm{m}^{2}$ from the pole cultivars (Figure 36 ).

The average height for bush cultivars was $0.6 \mathrm{~m}$ whereas half runner and pole cultivars reached $1.2 \mathrm{~m}$ and $2.0 \mathrm{~m}$, respectively.

Anthesis and pod set first occurred in the bush cultivars (late-June), and was followed by the half-runner and pole cultivars approximately 14- 21 days later.

\section{Varietal differences}

Of the bush varieties tested Black Valentine, Contender, Provider, and Royalty were all found to have similar $(\mathrm{P}>0.05) \mathrm{MBB}$ adult, pupae, larval populations and egg mass counts, as well as green bean yield during both seasons (Figure 37). Black Valentine had an average final MBB population of 2 adults, 4 pupae, 42 larvae, and 1 egg 
mass, and yielded $1.5 \mathrm{~kg} / \mathrm{m}^{2}$ of green beans. The variety Contender produced $2.4 \mathrm{~kg} / \mathrm{m}^{2}$ of snap beans on average during both seasons. The average final MBB population found within the Contender variety consisted of 2 adults, 1 pupa, and 37 larvae with 1 egg mass present. The variety Provider had an average final MBB population of 4 adults, 2 pupae, 35 larvae, and 0 egg masses, with an average snap bean yield of $2.6 \mathrm{~kg} / \mathrm{m}^{2}$. Royalty produced $2.4 \mathrm{~kg} / \mathrm{m}^{2}$ of green beans and the MBB population consisted of 4 adults, 5 pupae, 37 larvae, and 1 egg mass.

The snap bean yield and MBB adult, pupae, and larval populations found in the Blue Lake 274 variety were found to be different $(\mathrm{P}<0.05)$ compared to the other bush varieties tested during both seasons. Blue Lake 274 only produced an average $0.7 \mathrm{~kg} / \mathrm{m}^{2}$ of snap beans per replicate and contained a smaller MBB population of 1 adult, 2 pupae, 6 larvae, and 1 egg mass.

The half runner varieties that were tested were all found to have similar $(\mathrm{P}>0.05)$ MBB adult, pupae, and larvae populations, and egg mass counts throughout both the 2004 and 2005 seasons (Figure 38). Green bean yields among the half runner varieties were also all found to be similar over both seasons. The variety Mountaineer had a MBB population of 3 adults, 4 pupae, 56 larvae, and 1 egg mass by the end of each season, and produced an average of $1.4 \mathrm{~kg} / \mathrm{m}^{2}$ of snap beans. Painted Lady had a MBB population of 2 adults, 6 pupae, 51 larvae, and 1 egg mass, while Pink had a MBB population consisting of 4 adults, 6 pupae, 49 larvae, and 1 egg mass. The green bean yield from Painted Lady and Pink was $1.4 \mathrm{~kg} / \mathrm{m}^{2}$ and $1.9 \mathrm{~kg} / \mathrm{m}^{2}$, respectively. Spartan was found to produce $1.3 \mathrm{~kg} / \mathrm{m}^{2}$ of snap beans and hosted a MBB population of 7 adults, 7 pupae, 57 larvae, and 1 egg mass. The average MBB population found at the end of the season within the State cultivar consisted of 3 adults, 7 pupae, 57 larvae, and 1 egg mass. The total average green bean yield harvested from State was $2.3 \mathrm{~kg} / \mathrm{m}^{2}$.

The MBB populations of adults, pupae, and larvae, the number of egg masses, as well as green bean yields from the pole bean cultivars tested were all found to be similar ( $\mathrm{P}>0.05$ ) during both the 2004 and 2005 seasons (Figure 39). The Blue Lake FM-1K cultivar had an average MBB population at the end of each season of 4 adults, 8 pupae, 59 larvae, and 1 egg mass, and produced a total of $1.0 \mathrm{~kg} / \mathrm{m}^{2}$ of green beans. Kentucky Wonder hosted an average final MBB population with 5 adults, 10 pupae, 55 larvae, and 
2 egg masses, and produced a total average green bean yield of $1.3 \mathrm{~kg} / \mathrm{m}^{2}$. The MBB populations on the variety McCaslan averaged 5 adults, 10 pupae, 63 larvae, and 1 egg mass per season, while the Purple Podded variety hosted a final average MBB population of 3 adults, 8 pupae, 35 larvae, and 1 egg mass. The Rattlesnake variety had a final MBB population that had an average of 4 adults, 12 pupae, 49 larvae, and 1 egg mass. The green snap bean harvested from McCaslan, Purple Podded, and Rattlesnake were 1.4 $\mathrm{kg} / \mathrm{m}^{2}, 1.2 \mathrm{~kg} / \mathrm{m}^{2}$, and $1.7 \mathrm{~kg} / \mathrm{m}^{2}$, respectively.

\section{Discussion}

The data collected during the $P$. vulgaris variety trial showed that seasonal differences did not exist for any of the MBB populations or total green bean yields. The data also surprisingly revealed that there were no differences among green bean cultivars or among their respective varieties for any of the MBB populations and the snap bean yields, with exception of the bush variety Blue Lake 274.

The bush variety Blue Lake 274 did not germinate, grow, or produce well during either season. Therefore green bean yield, as well as adult, pupal, and larval MBB populations were found to be significantly different $(\mathrm{P}<0.05)$ compared to the other bush varieties tested. The most probable explanation for this observation is the poor germination that this variety exhibited compared to all the others grown in our study. The reduced plant stand resulted in much smaller green bean yields and MBB populations.

The lack of difference seen between the groups of cultivars, especially the bush cultivars compared to the half runner and pole cultivars, was most surprising since the half runner and pole cultivars are capable of continuous growth and flower production whereas the bush cultivars grow to a specific height range and primarily flower during a short time period. The bush bean cultivars (also) produce flowers and green beans earlier in the season than half runner and pole cultivars. Previous studies have suggested that half runner and pole cultivars may be better at recovering from MBB damage based largely on their increased biomass (Turchin, 1988; Balasubramanian et al., 2004). However, our data suggest the contrary; since bush varieties produced flowers and green 
beans earlier than the half runner and pole bean varieties, the effect of MBB damage was limited and green bean production was not seriously affected by the presence of MBB. The half runner and pole cultivars showed snap bean yields comparable to the bush varieties even though their biomass was greater, and they possess the ability to produce more flowers and therefore more beans. This is likely due to the timing of pod set and bean formation in bush varieties in conjunction with the peak MBB populations we observed in our experiment. Later in the season, during the peak bean production for the taller cultivars (half runner and pole bean), the adult and larval MBB populations were extremely high and resulted in high rates of defoliation, which ultimately reduced green bean yields.

The adult and larval MBB populations found in the market garden of WVU Plant and Soil Science Farm were above economically damaging levels, 1-1.5 larvae per plant, early in the season, but not early enough to affect the bush bean during both the 2004 and 2005 season. The early high populations of MBB adults and larvae could have made it difficult for the half-runner and pole bean plants to recover from the damage caused by their feeding, resulting in the low yields we observed. The large MBB infestation that is commonly found in the test area of the WVU Plant and Soil Science Farm therefore made it difficult for us to observe any MBB varietal preference.

In order for this study to be more effective at determining a MBB varietal preference a few changes can be suggested for future studies. The MBB population in the market garden of the WVU Plant and Soil Science Farm, should be maintained below economically damaging levels using an environmentally low impact method of control, such as the release of the parasitic wasp $P$. foveolatus, in order to reduce bias created by pesticide residue. By reducing the overall number of MBB present in the crop, the population dynamics and movement among the different varieties could be observed more readily. In addition, observations and MBB population counts should be made more frequently, possibly daily, to get a better understanding of the movement of the MBB among the different varieties. Determining what varieties, if any, have less negative responses (i.e. reduced growth and green bean yields) to MBB infestations and damage could help increase profits seen by producers by decreasing their use of pesticides and possibly increasing green bean yields. 


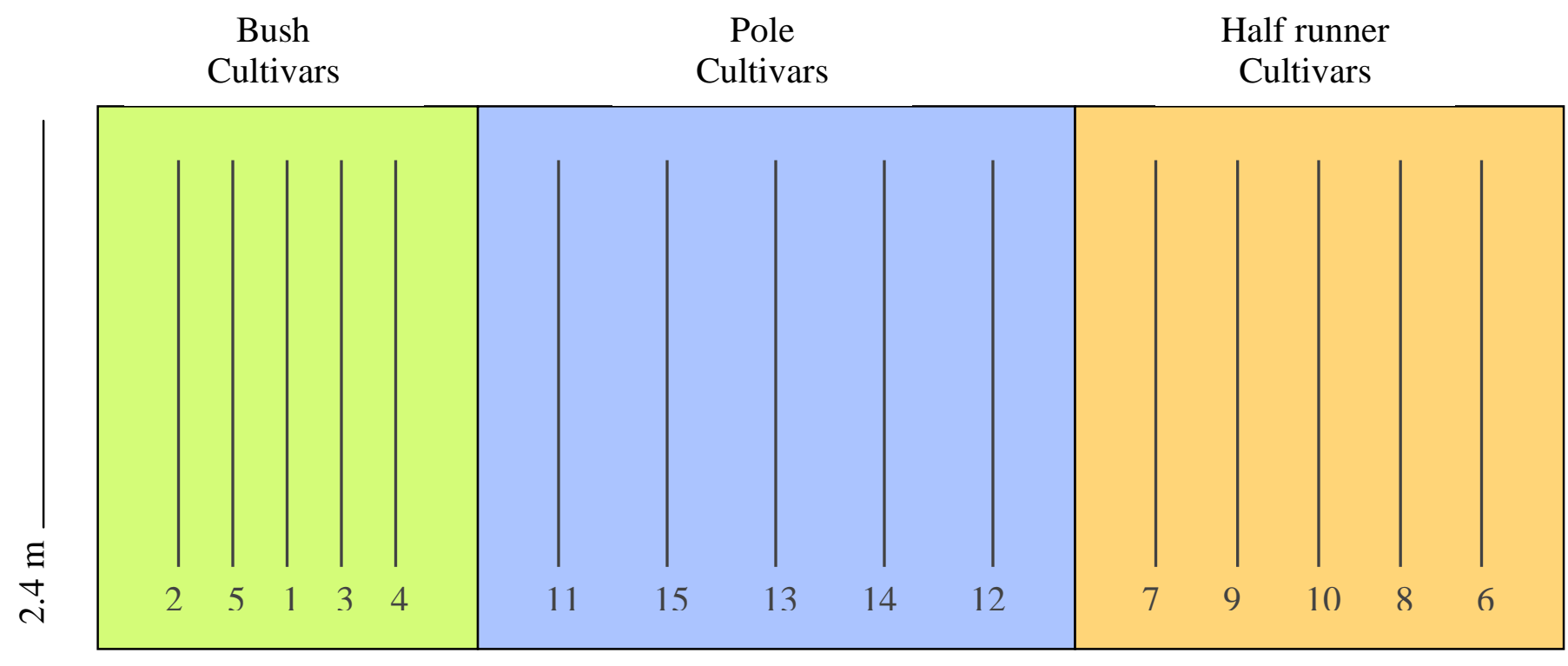

$9.4 \mathrm{~m}$

\section{Varieties Tested}

Bush:

$1=$ Black Valentine

2= Royalty

$3=$ Provider

4= Blue Lake 274

$5=$ Contender
Half Runner:

$6=$ Spartan

$7=$ Mountaineer

$8=$ State

9= Painted Lady

$10=$ Pink
Pole:

11 $=$ Purple Podded

$12=$ Kentucky Wonder

13= McCaslan

14= Rattlesnake

15= Blue Lake FM-1K

Figure 33: Example plot plan for $P$. vulgaris variety trial during the 2004 and 2005 seasons in the certified organic market garden at the WVU Plant and Soil Science Farm. Each of the four replicates had a total of fifteen varieties; five each of bush, half runner, and pole cultivars. Areas for bush, half runner, and pole cultivars were randomly arranged within the plot. Varieties within each cultivar area were randomly assigned to rows. 


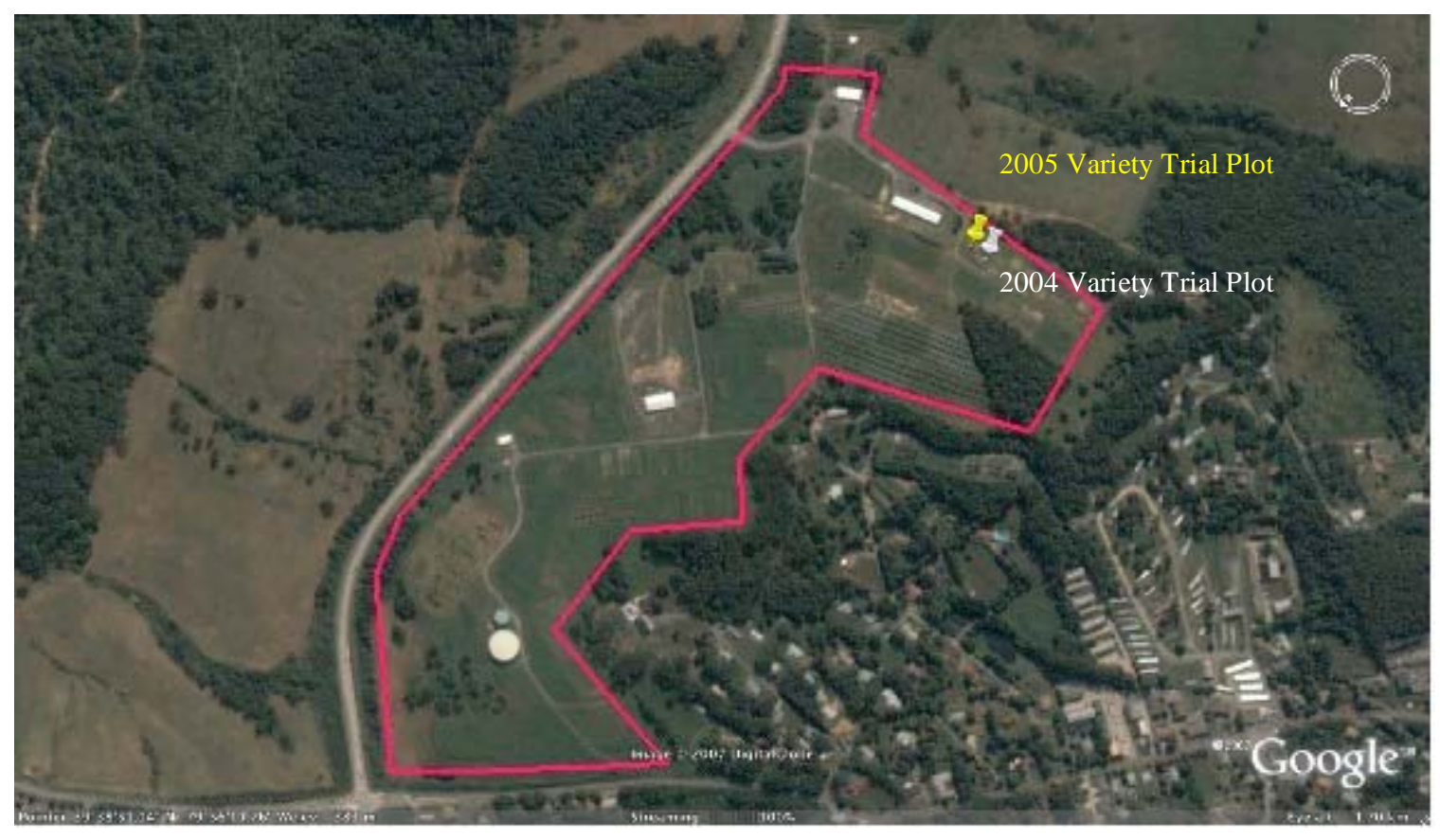

Figure 34: WVU Plant and Soil Science Farm, Rt. 705, Morgantown WV; organic certified.

Pink line shows the perimeter of the WVU organic farm. The plots dedicated to the variety trails were located in the market garden area during both the 2004 and 2005 seasons (Google Earth, 2007). 


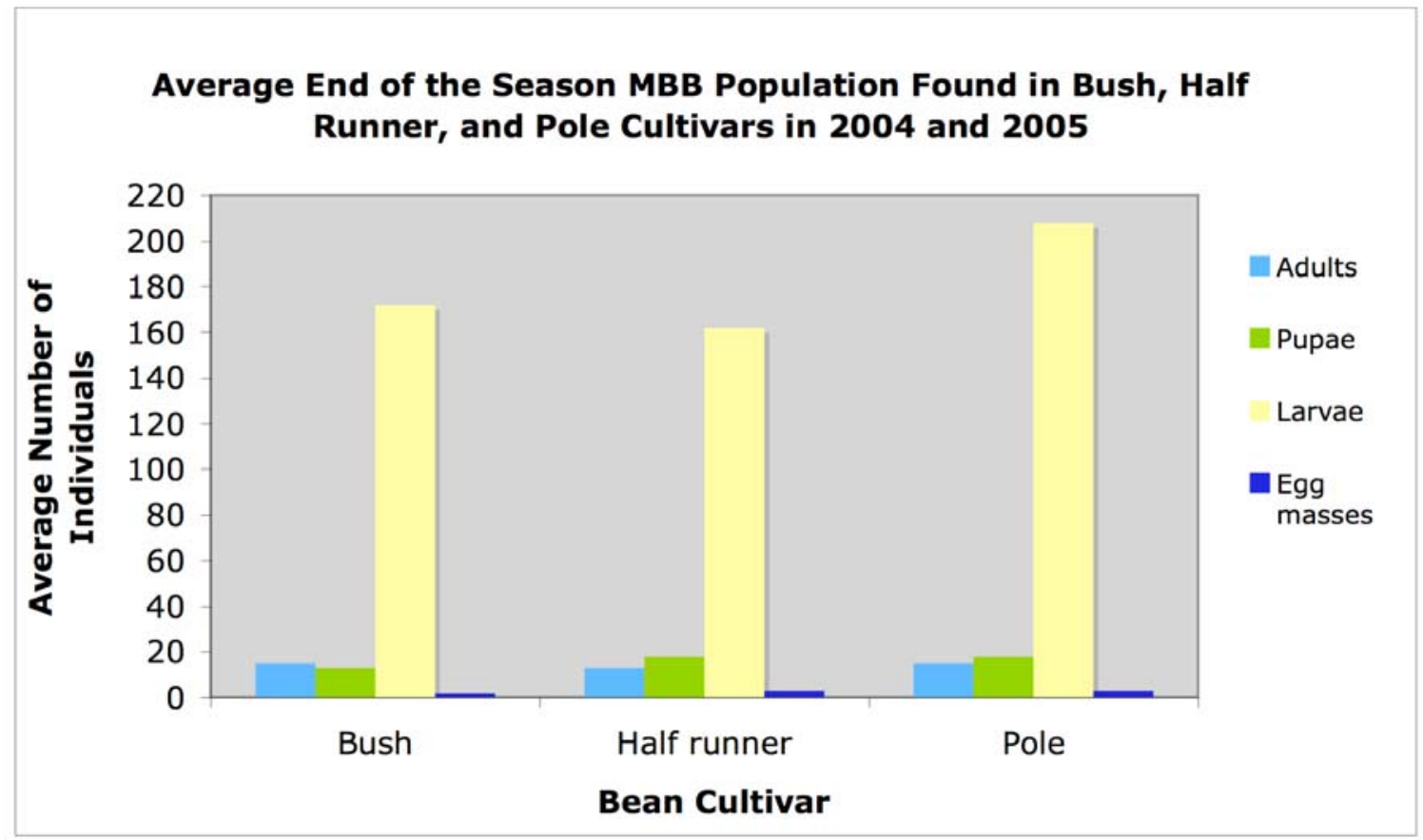

Figure 35: A comparison of the final MBB populations found among the bush, half runner, and pole varieties were similar in 2004 and 2005. Bush, half runner, and pole varieties all hosted similar adult, pupae, and larval populations, as well as egg mass counts

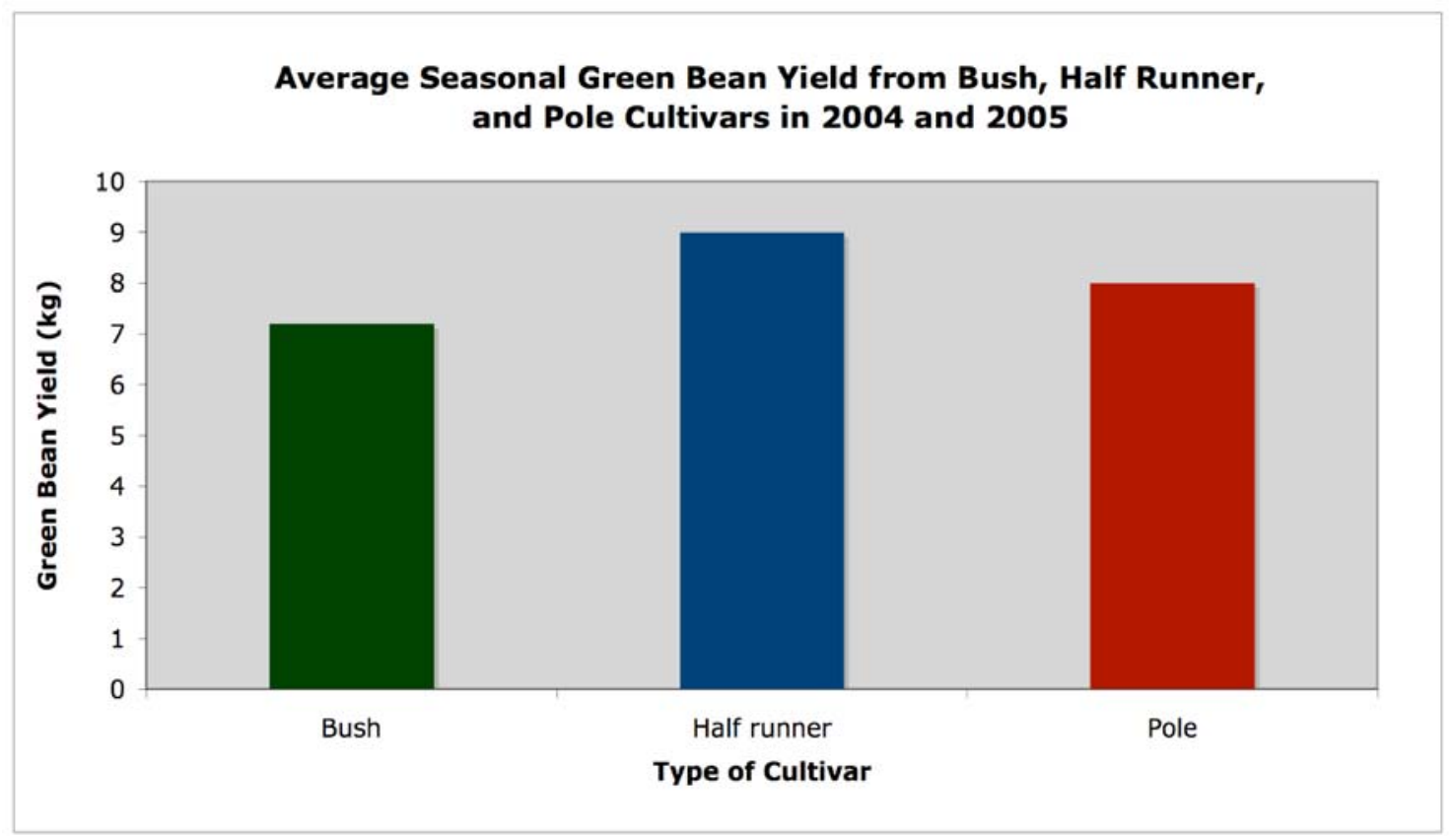

Figure 36: The average seasonal yield of green beans was found to be similar among the bush, half runner, and pole cultivars in both 2004 and 2005. 
Figure 37: The average final MBB populations (A.) were found to be similar among Black Valentine, Contender, Provider, and Royalty bush varieties tested in 2004 and 2005; no differences in MBB adult, pupae, larvae, and egg mass counts were observed. The total average green bean yield from these bush varieties in 2004 and 2005 was also found to be similar (B.). The variety Blue Lake 274 had low germination, which reduced the plant stand during both seasons, and therefore this variety had a significantly lower MBB population and green bean yield.

A.

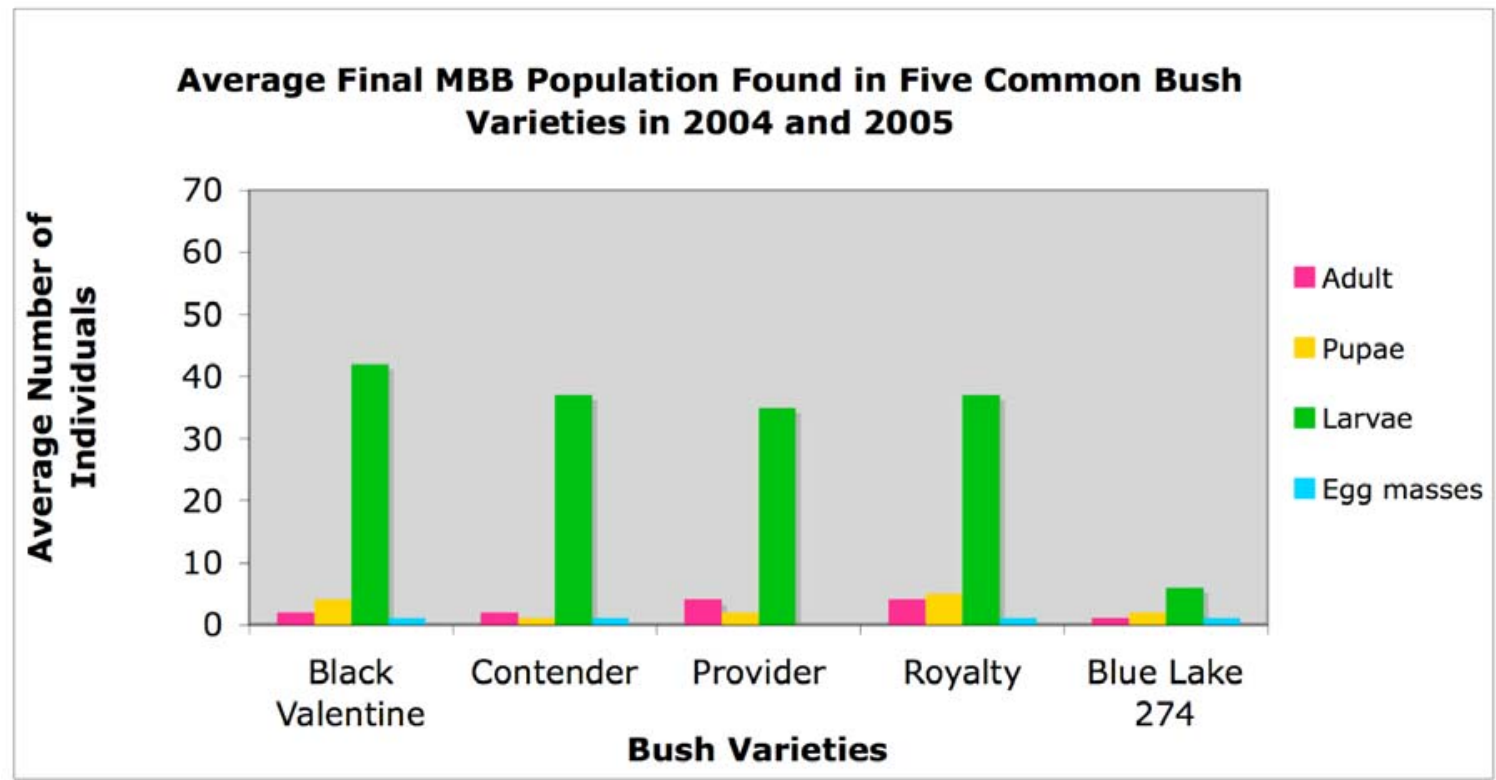

B.

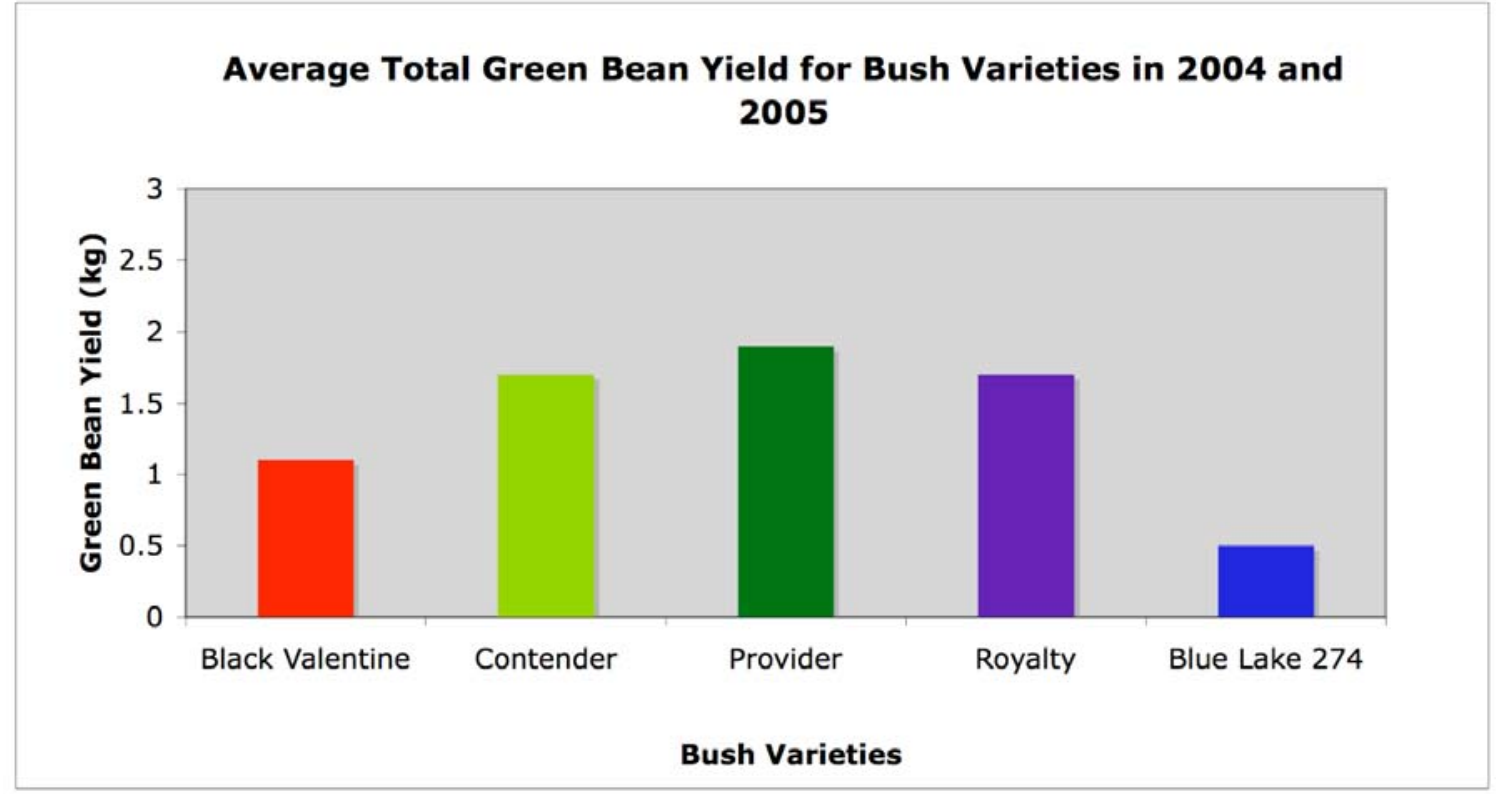


Figure 38: The average final MBB population found among the half runner varieties tested were shown to be similar during both seasons (A.). The average total green bean yield was also found to be similar among the half runner varieties in 2004 and 2005 (B.).

A.

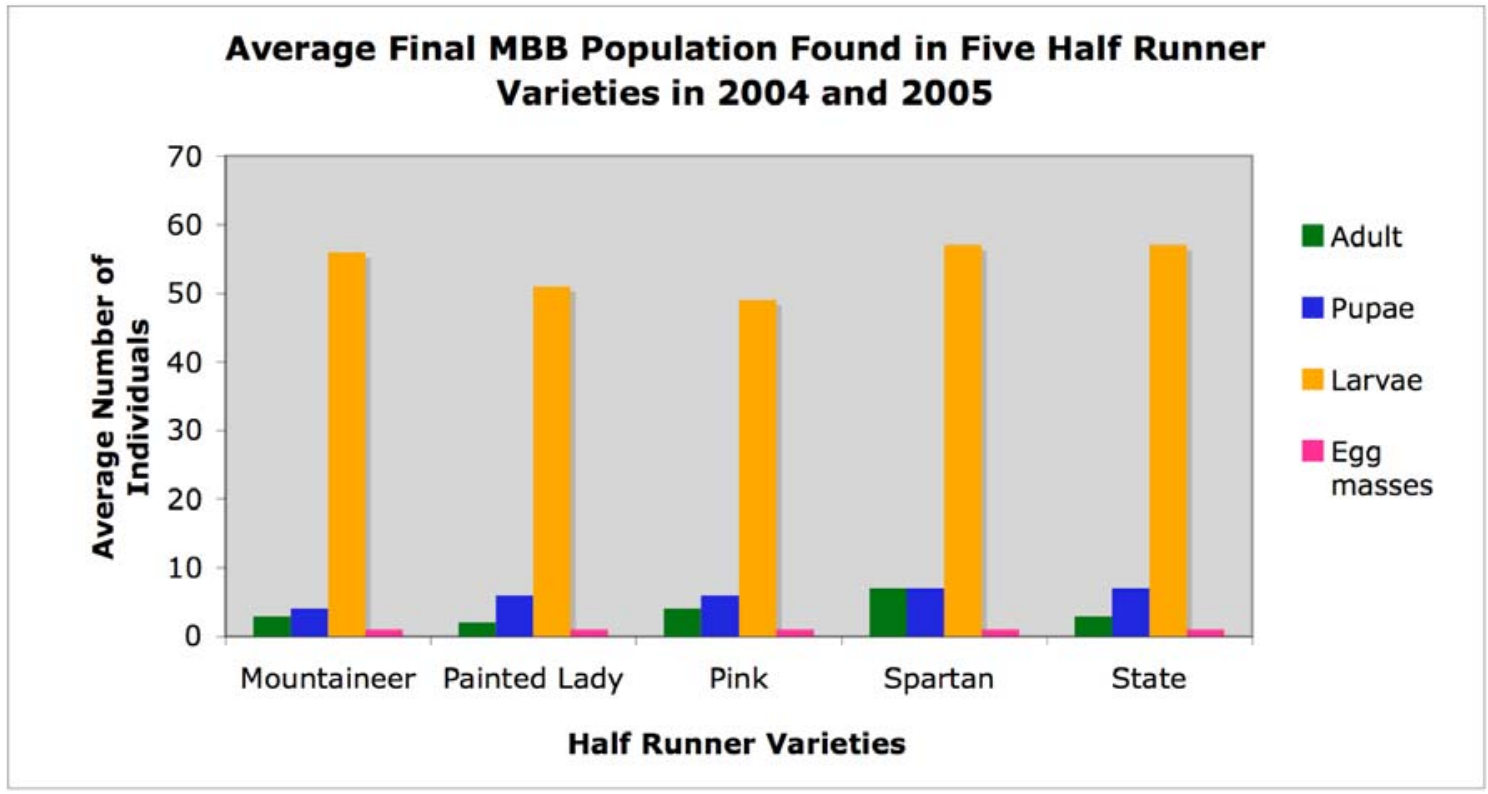

B.

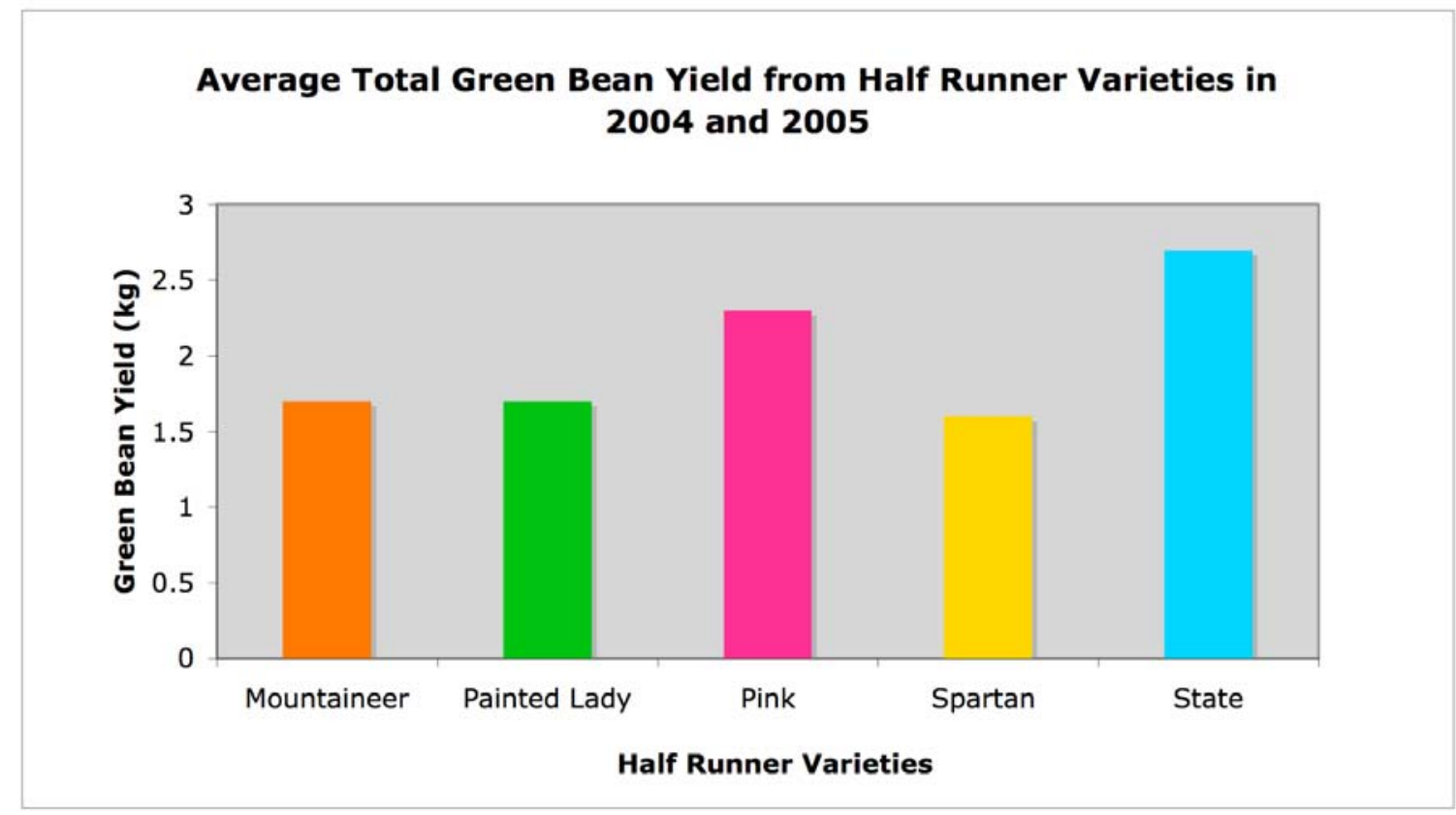


Figure 39: Average final MBB adult, pupae, and larvae populations, as well as egg mass counts, were found to be similar among all the pole varieties tested (A.) in 2004 and 2005. The average seasonal yield from each pole cultivar (B.) was also found to be similar during both seasons.

A.

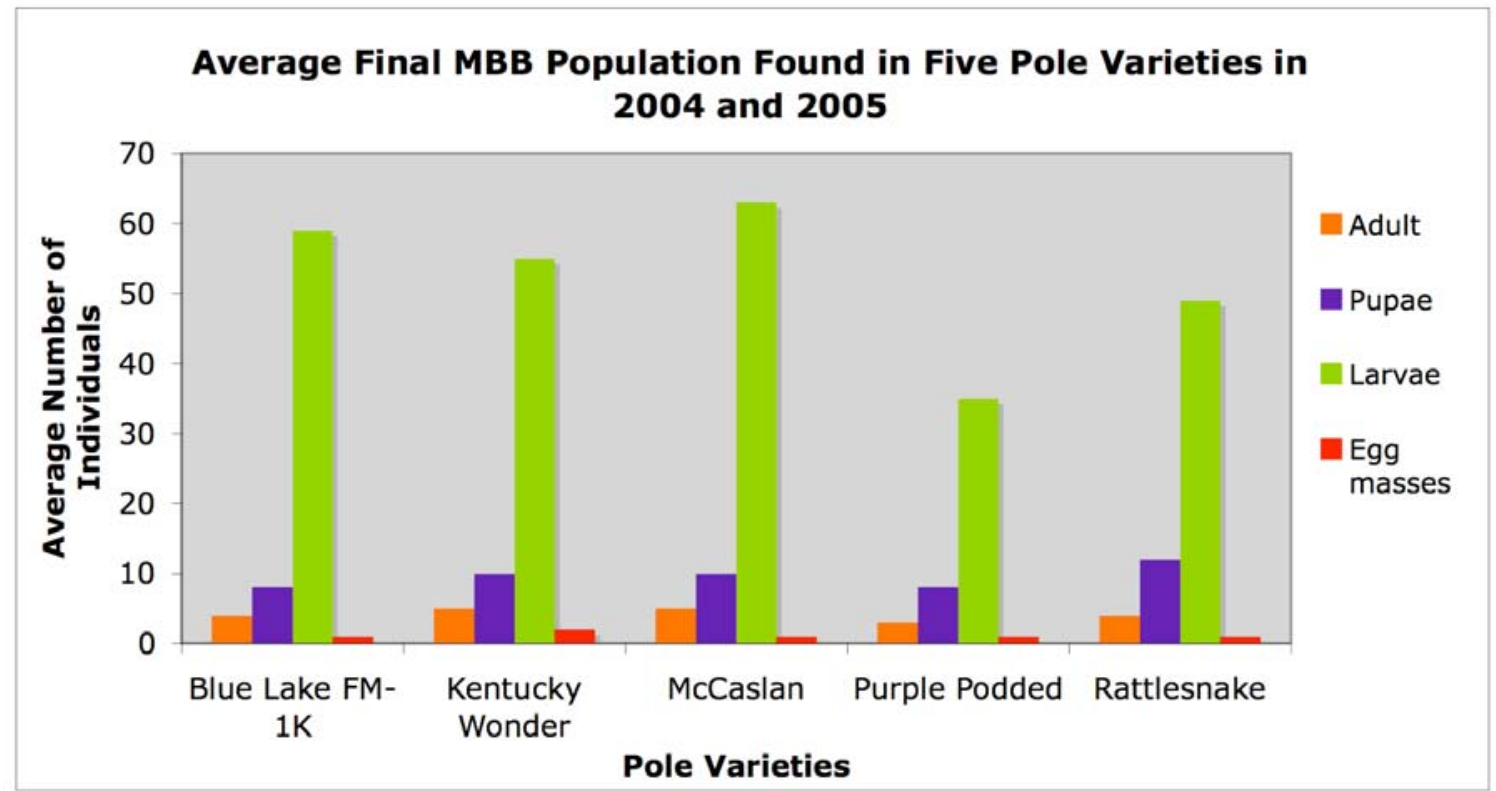

B.

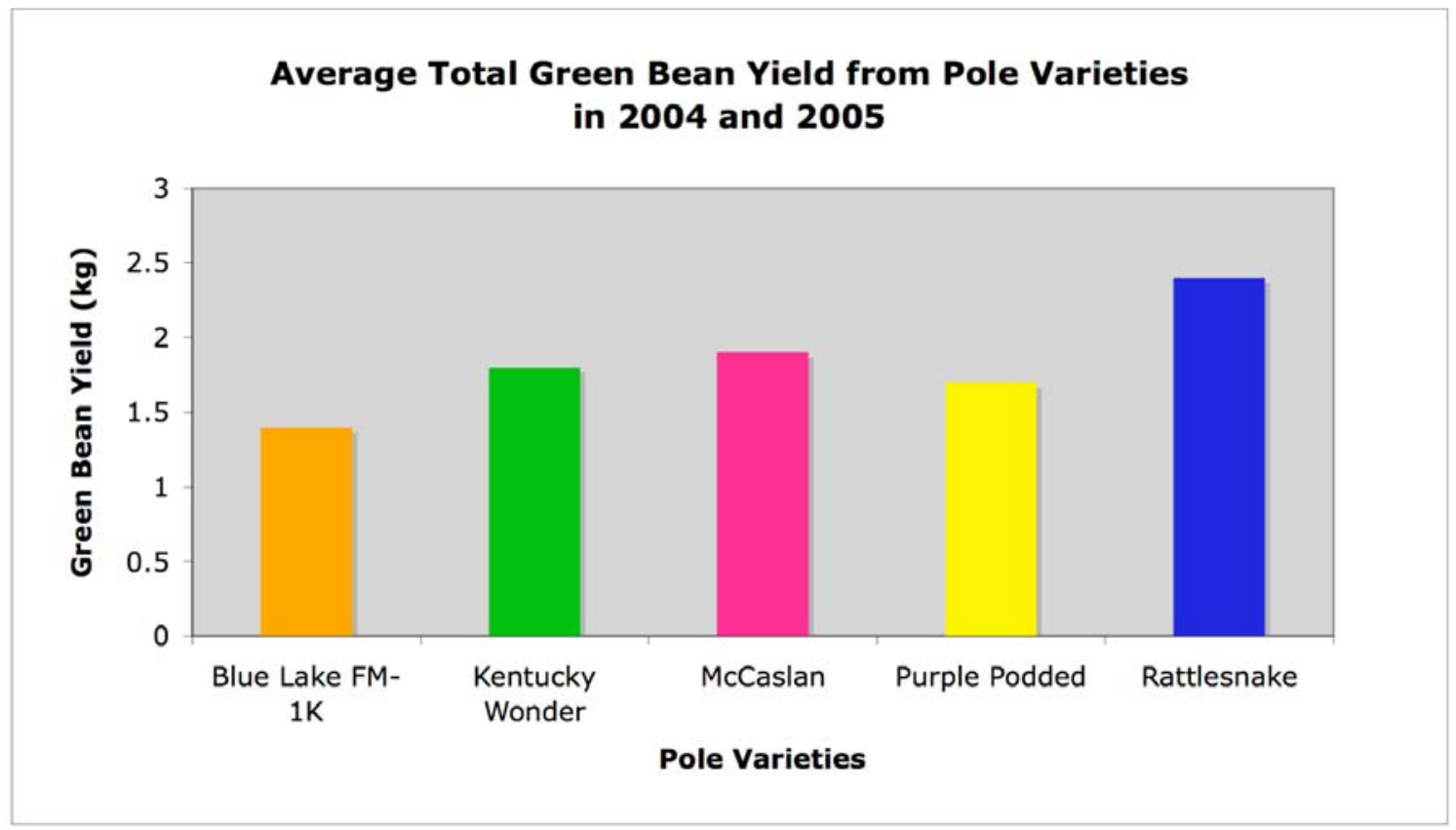




\section{References}

ARC. 2005. Common bean. ARC Centre of Excellence for Integrative Legume Research. Queensland, Australia.

Balasubramaian, P., A. Vandenberg \& P. Hucl. 2004. Planting date and suboptimal seedbed temperature effects on dry bean establishment, phenology, and yield. Canadian Journal of Plant Science 84: 31-36.

Barrigossi, J.F., G.L. Hein \& L.G. Higley. 2001. Life tables and larval dispersal of Mexican bean beetle (Coleoptera: Coccinellidae) on dry bean in the high plains. Environmental Entomology 30: 235-243.

Barrows, E.M. \& M.E. Hooker. 1981. Parasitization of the Mexican bean beetle by Pediobius foveolatus in urban vegetable gardens. Environmental Entomology 10: 782- 786.

Beanland, L., P.L. Phelan, S. Salminen. 2002. Micronutrient interactions on soybean growth and developmental performance of three insect herbivores. Environmental Entomology 32: 641-652.

Bradley, F.M., and B.W. Ellis. 1997. Rodale's organic gardening, the indispensable resource for every gardener. Rodale Press. Emmaus, Pennsylvania. pp 45-50, 345.

Burkhardt, C.C., J.M. Edwards, and L.E. Bennett. 1986. Control of the Mexican bean beetle on pinto beans. Bullentin B- Wyoming Agricultural Experiment Station 885: 189-192.

Cantwell, G.E., W.W. Cantelo \& R. Schroder. 1985. The integration of a bacterium and parasites to control the Colorado potato beetle and the Mexican bean beetle. Journal of Entmological Science 20: 98-103.

Chaves, M.M., J.S. Pereira, J. Maroco, M.L. Rodrigues, C.P.P. Ricardo, M.L. Osorio, I. Carvalho, T. Faria \& C. Pinheiro. 2002. How plants cope with water stress in the field. Photosynthesis and growth. Annals of Botany 89: 907-916.

Dobrin, G.C., and R.B. Hammond. 1983. Residual activity of selected insecticides against adult Mexican bean beetle (Coleoptera: Coccinellidae) on soybean. Journal of Economic Entomology 76: 1456- 1459.

Edwards, R.C. \& M.K. Bergman. 1987. Field crop insects; Mexican bean beetles in soybeans. Purdue University, Cooperative Extension Service. West Lafayette, Indiana.

Ellis, B.W. and F.M. Bradley. 1996. The organic gardener's handbook of natural insect and disease control. Rodale Press. Emmaus, Pennsylvania. pp 34-37, 305.

Fan, Y., E. Groden, F.A. Drummond. 1992. Temperature-dependent development of Mexican bean beetle (Coleoptera: Coccinellidae) under constant and variable temperatures. Journal of Economic Entomology 85: 1762-1770.

Fan, Y., E. Groden, M. Liebman \& R. Alford. 1993. Response of dry bean yield to injury by Mexican bean beetle (Coleoptera: Coccinellidae) in low-input and conventional cropping system. Journal of Economic Entomology 86: 1574-1578.

Flanders, R.V. 1985. Biological control of the Mexican bean beetle; potentials for problems of inoculative releases of Pediobius foveolatus. World Soybean Research Conference. Westview Press, Boulder, Colorado. 
Gent, M., 1990. Factors affecting harvest date of tomato grown under floating row cover. Applied Agricultural Research 5: 112-118.

Gepts, P., P. Miklas, M. Brick, C. Chase, D. Coyne, R. Hannan, P. McClean, J. Myers, J. Steadman. 1996. National Plant Germplasm System, Phaseolus Crop Germplasm Committee Report. USDA. Washington, D.C.

Grubinger, V. 1999. Field report. University of Vermont Extension. Burlington, Vermont.

Hodges, L. 1990. Basic cultural practices for commercial production of green (snap) beans. Horticulture C-29 Vegetables. University of Nebraska Cooperative Extension Service. Lincoln, Nebraska.

Júnior, T.C. Paula, C. Rotter, and B. Hau. 2007. Effects of soil moisture and sowing depth on the development og bean plants grown in sterile soil infested with Rhizoctonia solani and Trichoderms harzianum. European Journal of Plant Pathology 119: 193-202.

Kabissa, B. and W.D Fronk. 1986. Bean foliage consumption by Mexican bean beetle (Coleoptera: Coccinellidae) and its effect on yield. Journal of the Kansas Entomological Society 59: 275-279.

Lambdin, P., J. Horton \& M. Muegge. 1987. Evaluation of selected insecticides for control of Mexican bean beetles and potato leafhoppers on snap beans and lima beans. Tennessee Farm and Home Science. Pages 6-8.

Laurent, P., J.C. Braekman, D. Daloze and J. Pasteels. 2003. Biosynthesis of defensive compounds from beetles and ants. European Journal of Organic Chemistry 15: 2733-2743.

Lizana, C., M. Wentworth, J. Martinez, D. Villegas, R. Meneses, E. Murchie, C. Pastenes, B. Lercari, P. Vernieri, R. Horton \& M. Pinto. 2006. Differential adaptation of two varieties of common bean to abiotic stress. Journal of Experimental Botany 57: 685-697.

Lucier, G. and B.H. Lin. 2002. Commodity Spotlight. Fresh green beans: no strings attached. Economic Research Service. Agricultural Outlook. USDA, Washington, D.C.

Motsenbocker, C.E. \& A.R. Bonanno. 1989. Row cover effects on air and soil temperatures and yield of muskmelon. HortScience 24: 601-603.

Nelson, J.L., R. Brevig, \& M. Young. 1986. Response of vegetable to floating row cover and plant protectors in central Oregon. Irrigated Crops Research in Central Oregon 1985. Special Report 747. pp 84-88.

NJDA. 2004. Mexican bean beetle parasitoid Pediobius foveolatus (Hymenoptera: Eulophidae). New Jersey Department of Agriculture Phillip Alampi Beneficial Insectary. Trenton, New Jersey.

Osorio, J., M.L. Osorio, M.M Chaves, J.S. Periera. 1998. Water deficits are more important in delaying growth than in changing patterns of carbon allocation in Eucalyptus globules. Tree physiology 18: 363-373.

Patalappa and G.P. ChannaBasavanna. 1979. Seasonal incidence and life history of Pediobius fovelatus (Hymenoptera: Eulophidae), a parasite of Henosepilachna vigintioctopuncata (Fabricius) (Coleoptera: Coccinellidae). Mysore Journal of Agricultural Science 13: 191-196. 
Perez, A. 1995. Fresh-market snap beans: an economic assessment of the feasibility of providing multiple-peril crop insurance. Economic Research Service, USDA. Washington D.C.

Peterson, R., L.G. Higley, F.J. Haile, J.A. Barrigossi. 1998. Mexican bean beetle (Coleoptera: Coccinellidae) injury affects photosynthesis of Glycine max and Phaseolus vulgaris. Physiological and Chemical Ecology 27: 373-381.

Ratcliffe, S.T., M.E. Gray \& K.L Steffey. 2004. Mexican bean beetle, Epilachna varivestis. University of Illinois Extension Service. Urbana-Champaign, Illinois.

Reichelderfer, K.H. 1979. Economic feasibility of a biological control technology: using a parasitic wasp, Pediobius foveolatus, to manage Mexican bean beetles on soybeans. Agricultural Economic Report No. 430. U.S Department of Agriculture, Washington, D.C.

Robbins, G., W. Hudson, T. Dorsey, T. Scudder, M. Mayer. 2002. Biological control of the Mexican bean beetle Epilachna varivestis (Coleoptera: Coccinellidae) using the parasitic wasp Pediobius foveolatus (Hymenoptera: Eulophidae). New Jersey Department of Agriculture Phillip Alampi Beneficial Insectary. Trenton, New Jersey.

Roberts, P. \& G.K. Douce. 1999. Foliage feeding insects. University of Georgia Cooperative Extension Service. Tifton, GA.

Sanchez-Arroyo, H. 2005. Mexican bean beetles, Epilachna varivestis Mulsant. University of Florida Extension Service, Institute of Food and Agricultural Sciences. Gainsville, FL.

Schaefer, P.W., R.J Dysart, R.V. Flanders, T.L. Burger \& K. Ikebe. 1983. Mexican bean beetle (Coleoptera: Coccinellidae) larval parasite Pediobius foveolatus (Hymenoptera: Eulophidae) from Japan: field release in the United States. Environmental Entomology 12: 852-854.

Shepard, M., \& G.T. Gale. 1977. Superparasitism of Epilachna varivestis (Col: Coccinellidae) by Pediobius foveolatus (Hym: Eulophidae): influence of temperature and parasitoid-host ratio. Entomophaga 22: 315- 321.

Singh, S.P. 2001. Broadening the genetic base of common bean cultivars: a review. Crop Science 41: 1659-1675.

Sorensen, K.A, J.R. Baker, C.C. Carter \& D.L Stephan. 2004. Insect and related pests of vegetables. Center for Integrated Pest Management, North Carolina State University. North Carolina Coopertive Service. Raleigh, NC.

Stevens, L.M., A.L. Steinhauer \& J.R . Coulson. 1975. Suppression of Mexican bean beetle on soybeans with annual inoculative releases of Pediobius foveolatus. Environmental Entomology 4: 497-452.

Stoner, K.A. 2002. Experiments with using a parasitic wasp for biological control of Mexican bean beetle on snap beans. Alternatives to Insecticides for Managing Vegetable Insects. The Connecticut Agricultural Experimental Station, New Haven, CT.

Stoner, K.A. 2004. Using Pediobius foveolatus as a biological control for Mexican bean beetle on organic vegetable farms. The Connecticut Agricultural Experimental Station, New Haven, CT.

Turchin, P. 1988. The effect of host-plant density of the numbers of Mexican bean beetles, Epilachna varivestis. The American Midland Naturalist 119: 15-20. 
Tuckey, D.M. 2001. Crop profile for snap beans in Virginia. Virginia Cooperative Extension. Saluda, Virginia.

Underwood, N., W. Morris, K. Gross \& J. Lockwood. 2000. Induced resistance to Mexican bean beetles in soybean: variation among genotypes and lack of correlation with constitutive resistance. Oecologia 122: 83-89.

Underwood, N. 1998. The timing of induced resistance and induced susceptibility in the soybean- Mexican bean beetle system. Oecologia 114: 376-381.

USDA. 1954. Chronological history of the development of insecticides and control equipment from 1854 through 1954. USDA Agricultural Research Service Washington, D.C.

USDA. 2001. Green beans: quantity purchased, dollars spent, average retail price per pound or pint, and average price per serving, 1999. USDA Economic Research Service Washington, D.C.

USDA. 2002. West Virginia; Vegetables and melons harvested for sale: 2002 and 1997. 2002 Census of Agriculture- State Data. USDA National Agricultural Statistic Services. Washington, D.C.

Waterer, D.R. 1992. Influence of planting date and row covers on yields and crop values for bell peppers in Saskatchewan. Canadian Journal of Plant Science 72: 527-533.

Whalon, M, D. Mota-Sanchez and L. Duynslager. 2003. Resistant species profile: Epilachna varivestis. Resistant Pest Management: Arthropod Database. Michigan State University, East Lansing, MI.

Wilson, K.G., R.E. Stinner \& R.L. Rabb. 1982. Effects of temperature, relative humidity, and host plant on larval survival of the Mexican bean beetle, Epilachna varivestis Mulsant. Environmental Entomology 11: 121-126.

Wilson, H.R. 1989. Soybean insect defoliation assessment. OPMS Circular \#FC-22 Ohio State University Extension Service. Columbus, Ohio. 


\section{APPENDIX A}

Analysis of variance of MBB population densities found in row cover plots in 2004 and 2005. Orthogonal contrasts were done to estimate effect within significant interactions.

Row Cover 2004

Egg mass

\begin{tabular}{|l|l|l|}
\hline \multicolumn{1}{|c|}{ Source } & \multicolumn{1}{c|}{ DF } & \multicolumn{1}{c|}{ F Ratio } \\
\hline Row Cover 2004 & 1 & 0.98 \\
\hline Cultivar & 4 & 0.77 \\
\hline Sample (weeks) & 7 & $4.89^{*}$ \\
\hline Row Cover 2004*Cultivar & 4 & 0.35 \\
\hline Row Cover 2004*Sample (weeks) & 7 & 0.14 \\
\hline Cultivar*Sample (weeks) & 28 & 0.59 \\
\hline Row Cover 2004*Cultivar*Sample (weeks) & 28 & 0.32 \\
\hline Error & 160 & $1.87^{\dagger}$ \\
\hline
\end{tabular}

*Indicates a significant interaction

${ }^{\dagger}$ Error mean square

Larvae

\begin{tabular}{|l|l|l|}
\hline \multicolumn{1}{|c|}{ Source } & DF & \multicolumn{1}{c|}{ F Ratio } \\
\hline Row Cover 2004 & 1 & $24.56^{*}$ \\
\hline Cultivar & 4 & 1.52 \\
\hline Sample (weeks) & 7 & $18.74^{*}$ \\
\hline Row Cover 2004*Cultivar & 4 & 0.43 \\
\hline Row Cover 2004*Sample (weeks) & 7 & $6.46^{*}$ \\
\hline Cultivar*Sample (weeks) & 28 & 0.16 \\
\hline Row Cover 2004*Cultivar*Sample (weeks) & 28 & 0.39 \\
\hline Error & 160 & $114.10^{\dagger}$ \\
\hline
\end{tabular}

*Indicates a significant interaction

${ }^{\dagger}$ Error mean square 


Pupae Source
\begin{tabular}{|l|l|l|}
\hline \multicolumn{2}{|c|}{ DF } & F Ratio \\
\hline Row Cover 2004 & 1 & $18.45^{*}$ \\
\hline Cultivar & 4 & 1.48 \\
\hline Sample (weeks) & 7 & $5.01^{*}$ \\
\hline Row Cover 2004*Cultivar & 4 & 0.62 \\
\hline Row Cover 2004*Sample (weeks) & 7 & $3.84^{*}$ \\
\hline Cultivar*Sample (weeks) & 28 & 0.35 \\
\hline Row Cover 2004*Cultivar*Sample (weeks) & 28 & 0.26 \\
\hline Error & 160 & $40.98^{\dagger}$ \\
\hline
\end{tabular}

*Indicates a significant interaction

${ }^{\dagger}$ Error mean square

Adults

\begin{tabular}{|l|l|l|}
\hline \multicolumn{1}{|c|}{ Source } & \multicolumn{1}{c|}{ DF } & \multicolumn{1}{c|}{ F Ratio } \\
\hline Row Cover 2004 & 1 & $27.92^{*}$ \\
\hline Cultivar & 4 & 0.36 \\
\hline Sample (weeks) & 7 & $7.71^{*}$ \\
\hline Row Cover 2004*Cultivar & 4 & 0.14 \\
\hline Row Cover 2004*Sample (weeks) & 7 & $5.36^{*}$ \\
\hline Cultivar*Sample (weeks) & 28 & 0.29 \\
\hline Row Cover 2004*Cultivar*Sample (weeks) & 28 & 0.27 \\
\hline Error & 160 & $29.29^{\dagger}$ \\
\hline
\end{tabular}

* Indicates a significant interaction

${ }^{\dagger}$ Error mean square 
Orthogonal contrast within row cover treatment-by-sampling (weeks) interaction for MBB larvae, pupae, and adult populations in 2004

\begin{tabular}{|c|c|c|c|c|}
\hline Time (weeks) & Row Cover & Larvae & Pupae & Adults \\
\hline 1 & $\begin{array}{l}0 \\
1\end{array}$ & $\begin{array}{ll}6.67 & a \\
-4.44 & b\end{array}$ & $\begin{array}{ll}4.00 & \mathrm{a} \\
6.66 & \mathrm{a}\end{array}$ & $\begin{array}{ll}0.66 & \mathrm{a} \\
0.40 & \mathrm{a}\end{array}$ \\
\hline 2 & $\begin{array}{l}0 \\
1\end{array}$ & $\begin{array}{ll}11.2 & \mathrm{a} \\
4.44 & \mathrm{~b}\end{array}$ & $\begin{array}{ll}6.20 & a \\
2.22 & b\end{array}$ & $\begin{array}{ll}3.60 & \mathrm{a} \\
1.00 & \mathrm{~b}\end{array}$ \\
\hline 3 & $\begin{array}{l}0 \\
1\end{array}$ & $\begin{array}{ll}18.1 & a \\
2.60 & b\end{array}$ & $\begin{array}{ll}5.93 & a \\
-2.53 & b\end{array}$ & $\begin{array}{ll}6.20 & \mathrm{a} \\
1.13 & \mathrm{~b}\end{array}$ \\
\hline 4 & $\begin{array}{l}0 \\
1\end{array}$ & $\begin{array}{ll}28.5 & a \\
9.60 & b\end{array}$ & $\begin{array}{ll}10.27 & a \\
0.73 & b\end{array}$ & $\begin{array}{ll}11.2 & \mathrm{a} \\
1.33 & \mathrm{~b}\end{array}$ \\
\hline 5 & $\begin{array}{l}0 \\
1\end{array}$ & $\begin{array}{ll}33.0 & a \\
17.7 & b\end{array}$ & $\begin{array}{ll}13.2 & \mathrm{a} \\
2.27 & \mathrm{~b}\end{array}$ & $\begin{array}{ll}13.67 & \mathrm{a} \\
2.86 & \mathrm{~b}\end{array}$ \\
\hline 6 & $\begin{array}{l}0 \\
1\end{array}$ & $\begin{array}{ll}11.2 & \mathrm{a} \\
14.3 & \mathrm{a}\end{array}$ & $\begin{array}{ll}6.73 & \mathrm{a} \\
5.80 & \mathrm{a}\end{array}$ & $\begin{array}{ll}4.67 & \mathrm{a} \\
2.00 & \mathrm{a}\end{array}$ \\
\hline 7 & $\begin{array}{l}0 \\
1\end{array}$ & $\begin{array}{ll}0.73 & \mathrm{a} \\
7.67 & \mathrm{a}\end{array}$ & $\begin{array}{l}4.20 \\
6.00\end{array}$ & $\begin{array}{l}1.80 \\
3.20\end{array}$ \\
\hline 8 & $\begin{array}{l}0 \\
1\end{array}$ & $\begin{array}{ll}-3.55 & \mathrm{a} \\
2.73 & \mathrm{a}\end{array}$ & $\begin{array}{ll}0.00 & \mathrm{a} \\
0.80 & \mathrm{a}\end{array}$ & $\begin{array}{l}0.00 \\
0.33\end{array}$ \\
\hline
\end{tabular}

For each sampling week, means in a column followed by the same letter are not significant. Prob $>F$ 0 control subplots 1 treatment subplots

Row Cover 2005

Egg mass

\begin{tabular}{|l|l|l|}
\hline \multicolumn{1}{|c|}{ Source } & \multicolumn{1}{c|}{ DF } & \multicolumn{1}{c|}{ F Ratio } \\
\hline Row Cover 2005 & 1 & 0.93 \\
\hline Cultivar & 4 & 1.24 \\
\hline Sample (weeks) & 7 & $11.39^{*}$ \\
\hline Row Cover 2005*Cultivar & 4 & 0.16 \\
\hline Row Cover 2005*Sample (weeks) & 7 & 0.67 \\
\hline Cultivar*Sample (weeks) & 28 & 1.00 \\
\hline Row Cover 2005*Cultivar*Sample (weeks) & 28 & 0.66 \\
\hline Error & 145 & $0.39^{\dagger}$ \\
\hline
\end{tabular}

*Indicates a significant interaction

${ }^{\dagger}$ Error mean square 


\begin{tabular}{|l|l|l|}
\hline \multicolumn{1}{|c|}{ Source } & \multicolumn{1}{c|}{ DF } & \multicolumn{1}{c|}{ F Ratio } \\
\hline Row Cover 2005 & 1 & $29.00^{*}$ \\
\hline Cultivar & 4 & 1.41 \\
\hline Sample (weeks) & 7 & $28.87^{*}$ \\
\hline Row Cover 2005*Cultivar & 4 & 0.34 \\
\hline Row Cover 2005*Sample (weeks) & 7 & $4.63^{*}$ \\
\hline Cultivar*Sample (weeks) & 28 & 0.33 \\
\hline Row Cover 2005*Cultivar*Sample (weeks) & 28 & 0.19 \\
\hline Error & 145 & $63.88^{\dagger}$ \\
\hline
\end{tabular}

*Indicates a significant interaction

${ }^{\dagger}$ Error mean square

Pupae

\begin{tabular}{|l|l|l|}
\hline \multicolumn{1}{|c|}{ Source } & \multicolumn{1}{c|}{ DF } & \multicolumn{1}{c|}{ F Ratio } \\
\hline Row Cover 2005 & 1 & $20.85^{*}$ \\
\hline Cultivar & 4 & 1.44 \\
\hline Sample (weeks) & 7 & $11.11^{*}$ \\
\hline Row Cover 2005*Cultivar & 4 & 0.50 \\
\hline Row Cover 2005*Sample (weeks) & 7 & $3.88^{*}$ \\
\hline Cultivar*Sample (weeks) & 28 & 0.39 \\
\hline Row Cover 2005*Cultivar*Sample (weeks) & 28 & 0.21 \\
\hline Error & 145 & $8.29^{\dagger}$ \\
\hline
\end{tabular}

*Indicates a significant interaction

${ }^{\dagger}$ Error mean square 
Adults

\begin{tabular}{|l|l|l|}
\hline \multicolumn{1}{|c|}{ Source } & DF & \multicolumn{1}{c|}{ F Ratio } \\
\hline Row Cover 2005 & 1 & $22.52^{*}$ \\
\hline Cultivar & 4 & 0.49 \\
\hline Sample (weeks) & 7 & $11.28^{*}$ \\
\hline Row Cover 2005*Cultivar & 4 & 0.26 \\
\hline Row Cover 2005*Sample (weeks) & 7 & $0.0002^{*}$ \\
\hline Cultivar*Sample (weeks) & 28 & 0.77 \\
\hline Row Cover 2005*Cultivar*Sample (weeks) & 28 & 0.13 \\
\hline Error & 145 & $0.92^{\dagger}$ \\
\hline
\end{tabular}

*Indicates a significant interaction

${ }^{\dagger}$ Error mean square

Orthogonal contrast within row cover treatment-by-sampling (weeks) interaction for MBB larvae, pupae, and adult populations in 2005.

\begin{tabular}{|c|c|c|c|c|}
\hline Time (weeks) & Row Cover & Larvae & Pupae & Adults \\
\hline 1 & $\begin{array}{l}0 \\
1\end{array}$ & $\begin{array}{ll}1.77 & \mathrm{a} \\
0.00 & \mathrm{a}\end{array}$ & $\begin{array}{ll}-1.11 & a \\
-3.33 & a\end{array}$ & $\begin{array}{ll}0.26 & a \\
-1.11 & a\end{array}$ \\
\hline 2 & $\begin{array}{l}0 \\
1\end{array}$ & $\begin{array}{ll}1.53 & \mathrm{a} \\
0.20 & \mathrm{a}\end{array}$ & $\begin{array}{ll}-3.33 & a \\
-1.11 & a\end{array}$ & $\begin{array}{ll}0.47 & \mathrm{a} \\
0.33 & \mathrm{a}\end{array}$ \\
\hline 3 & $\begin{array}{l}0 \\
1\end{array}$ & $\begin{array}{ll}5.77 & a \\
-4.44 & b\end{array}$ & $\begin{array}{ll}4.44 & a \\
-4.44 & b\end{array}$ & $\begin{array}{ll}1.66 & a \\
-3.88 & b\end{array}$ \\
\hline 4 & $\begin{array}{l}0 \\
1\end{array}$ & $\begin{array}{ll}5.60 & \mathrm{a} \\
1.87 & \mathrm{~b}\end{array}$ & $\begin{array}{ll}0.53 & a \\
-2.22 & b\end{array}$ & $\begin{array}{ll}1.00 & \mathrm{a} \\
0.40 & \mathrm{a}\end{array}$ \\
\hline 5 & $\begin{array}{l}0 \\
1\end{array}$ & $\begin{array}{ll}8.87 & \mathrm{a} \\
1.53 & \mathrm{~b}\end{array}$ & $\begin{array}{ll}2.33 & \mathrm{a} \\
0.33 & \mathrm{a}\end{array}$ & $\begin{array}{ll}2.13 & \mathrm{a} \\
0.20 & \mathrm{~b}\end{array}$ \\
\hline 6 & $\begin{array}{l}0 \\
1\end{array}$ & $\begin{array}{ll}24.1 & a \\
8.33 & b\end{array}$ & $\begin{array}{ll}5.33 & \mathrm{a} \\
0.60 & \mathrm{~b}\end{array}$ & $\begin{array}{l}2.20 \\
1.87\end{array}$ \\
\hline 7 & $\begin{array}{l}0 \\
1\end{array}$ & $\begin{array}{l}29.7 \\
14.1\end{array}$ & $\begin{array}{ll}7.47 & \mathrm{a} \\
2.20 & \mathrm{~b}\end{array}$ & $\begin{array}{l}2.20 \\
1.13\end{array}$ \\
\hline 8 & $\begin{array}{l}0 \\
1\end{array}$ & $\begin{array}{ll}9.27 & \mathrm{a} \\
5.47 & \mathrm{~b}\end{array}$ & $\begin{array}{l}3.67 \mathrm{a} \\
1.67 \mathrm{a}\end{array}$ & $\begin{array}{l}0.33 \\
0.60\end{array}$ \\
\hline
\end{tabular}

For each sampling week, means in a column followed by the same letter are not significant. Prob $>\mathrm{F}$ 0 control subplots 1 treatment subplots 


\section{APPENDIX B}

Analysis of variance of MBB population densities found in row cover plots in 2004 and 2005. Orthogonal contrasts were done to estimate effect within significant interactions.

Staggered Planting Date 2004

Egg mass

\begin{tabular}{|l|l|l|}
\hline \multicolumn{1}{|c|}{ Source } & DF & \multicolumn{1}{|c|}{ F Ratio } \\
\hline Staggered Planting 2004 & 1 & 1.91 \\
\hline Planting Date & 3 & $10.17^{*}$ \\
\hline Sample (weeks) & 7 & $4.81^{*}$ \\
\hline Staggered Planting 2004*Planting Date & 3 & 1.09 \\
\hline Staggered Planting 2004*Sample (weeks) & 7 & 0.97 \\
\hline Planting Date*Sample (weeks) & 21 & $1.76^{*}$ \\
\hline Staggered Planting 2004*Cultivar*Sample (weeks) & 21 & 0.923 \\
\hline Error & 128 & $0.70^{\dagger}$ \\
\hline
\end{tabular}

*Indicates a significant interaction

${ }^{\dagger}$ Error mean square

\section{Larvae}

\begin{tabular}{|l|l|l|}
\hline \multicolumn{1}{|c|}{ Source } & DF & \multicolumn{1}{c|}{ F Ratio } \\
\hline Staggered Planting 2004 & 1 & 0.15 \\
\hline Planting Date & 3 & $2.78^{*}$ \\
\hline Sample (weeks) & 7 & $11.79^{*}$ \\
\hline Staggered Planting 2004*Planting Date & 3 & 0.23 \\
\hline Staggered Planting 2004*Sample (weeks) & 7 & 0.72 \\
\hline Planting Date*Sample (weeks) & 21 & $2.40^{*}$ \\
\hline Staggered Planting 2004*Cultivar*Sample (weeks) & 21 & 0.60 \\
\hline Error & 128 & $123.36^{\dagger}$ \\
\hline
\end{tabular}

*Indicates a significant interaction

${ }^{\dagger}$ Error mean square 
Pupae

\begin{tabular}{|l|l|l|}
\hline \multicolumn{1}{|c|}{ Source } & \multicolumn{1}{c|}{ DF } & \multicolumn{1}{|c|}{ F Ratio } \\
\hline Staggered Planting 2004 & 1 & $4.37^{*}$ \\
\hline Planting Date & 3 & $4.16^{*}$ \\
\hline Sample (weeks) & 7 & $6.86^{*}$ \\
\hline Staggered Planting 2004*Planting Date & 3 & 0.30 \\
\hline Staggered Planting 2004*Sample (weeks) & 7 & $2.36^{*}$ \\
\hline Planting Date*Sample (weeks) & 21 & 0.95 \\
\hline Staggered Planting 2004*Cultivar*Sample (weeks) & 21 & 0.97 \\
\hline Error & 128 & $26.47^{\dagger}$ \\
\hline
\end{tabular}

*Indicates a significant interaction

${ }^{\dagger}$ Error mean square

Orthogonal contrast within staggered planting treatment-by-sampling (weeks) interaction for MBB pupae populations in 2004

\begin{tabular}{|c|c|c|}
\hline Time (weeks) & Subplot & Pupae \\
\hline 1 & $\begin{array}{l}0 \\
1\end{array}$ & $\begin{array}{ll}0.58 & \mathrm{a} \\
1.08 & \mathrm{a}\end{array}$ \\
\hline 2 & $\begin{array}{l}0 \\
1\end{array}$ & $\begin{array}{ll}2.23 & \mathrm{a} \\
1.25 & \mathrm{a}\end{array}$ \\
\hline 3 & & $\begin{array}{ll}3.83 & \mathrm{a} \\
3.08 & \mathrm{a}\end{array}$ \\
\hline 4 & $\begin{array}{l}0 \\
1\end{array}$ & $\begin{array}{ll}12.42 & \mathrm{a} \\
4.08 & \mathrm{~b}\end{array}$ \\
\hline 5 & $\begin{array}{l}0 \\
1\end{array}$ & $\begin{array}{ll}8.42 & \mathrm{a} \\
4.00 & \mathrm{~b}\end{array}$ \\
\hline 6 & $\begin{array}{l}0 \\
1\end{array}$ & $\begin{array}{ll}5.33 & \mathrm{a} \\
5.92 & \mathrm{a}\end{array}$ \\
\hline 7 & $\begin{array}{l}0 \\
1\end{array}$ & $\begin{array}{ll}3.75 & \mathrm{a} \\
3.75 & \mathrm{a}\end{array}$ \\
\hline 8 & $\begin{array}{l}0 \\
1\end{array}$ & $\begin{array}{cc}-7.77 & \mathrm{a} \\
1.00 & \mathrm{a}\end{array}$ \\
\hline
\end{tabular}

For each sampling week, means in a column followed by the same letter are not significant. Prob $>F$

0 control subplots

1 treatment subplots 
Adults

\begin{tabular}{|l|l|l|}
\hline \multicolumn{1}{|c|}{ Source } & \multicolumn{1}{c|}{ DF } & \multicolumn{1}{|c|}{ F Ratio } \\
\hline Staggered Planting 2004 & 1 & $7.09^{*}$ \\
\hline Planting Date & 3 & 0.13 \\
\hline Sample (weeks) & 7 & $7.51^{*}$ \\
\hline Staggered Planting 2004*Planting Date & 3 & 0.44 \\
\hline Staggered Planting 2004*Sample (weeks) & 7 & 1.87 \\
\hline Planting Date*Sample (weeks) & 21 & 0.29 \\
\hline Staggered Planting 2004*Cultivar*Sample (weeks) & 21 & 0.17 \\
\hline Error & 128 & $30.89^{\dagger}$ \\
\hline
\end{tabular}

*Indicates a significant interaction

${ }^{\dagger}$ Error mean square

Staggered Planting Date 2005

Egg mass Source
\begin{tabular}{|l|l|l|}
\hline \multicolumn{1}{|c|}{ DF } & \multicolumn{1}{c|}{ F Ratio } \\
\hline Staggered Planting 2005 & 1 & 0.01 \\
\hline Planting Date & 3 & 0.85 \\
\hline Sample (weeks) & 6 & $8.59^{*}$ \\
\hline Staggered Planting 2005*Planting Date & 3 & 0.85 \\
\hline Staggered Planting 2005*Sample (weeks) & 6 & 0.92 \\
\hline Planting Date*Sample (weeks) & 18 & $2.49^{*}$ \\
\hline Staggered Planting 2005*Cultivar*Sample (weeks) & 18 & 0.96 \\
\hline Error & 112 & $0.58^{\dagger}$ \\
\hline
\end{tabular}

*Indicates a significant interaction

${ }^{\dagger}$ Error mean square 


\begin{tabular}{|l|l|l|}
\hline \multicolumn{1}{|c|}{ Source } & \multicolumn{1}{c|}{ DF } & \multicolumn{1}{|c|}{ F Ratio } \\
\hline Staggered Planting 2005 & 1 & 0.40 \\
\hline Planting Date & 3 & $6.14^{*}$ \\
\hline Sample (weeks) & 6 & $9.51^{*}$ \\
\hline Staggered Planting 2005*Planting Date & 3 & 1.39 \\
\hline Staggered Planting 2005*Sample (weeks) & 6 & 0.70 \\
\hline Planting Date*Sample (weeks) & 18 & 1.49 \\
\hline Staggered Planting 2005*Cultivar*Sample (weeks) & 18 & 0.17 \\
\hline Error & 112 & $193.23^{\dagger}$ \\
\hline
\end{tabular}

*Indicates a significant interaction

${ }^{\dagger}$ Error mean square

\section{Pupae}

\begin{tabular}{|l|l|l|}
\hline \multicolumn{1}{|c|}{ Source } & \multicolumn{1}{c|}{ DF } & \multicolumn{1}{c|}{ F Ratio } \\
\hline Staggered Planting 2005 & 1 & 0.84 \\
\hline Planting Date & 3 & $0.01^{*}$ \\
\hline Sample (weeks) & 6 & $<0.01^{*}$ \\
\hline Staggered Planting 2005*Planting Date & 3 & 0.93 \\
\hline Staggered Planting 2005*Sample (weeks) & 6 & 0.91 \\
\hline Planting Date*Sample (weeks) & 18 & 0.27 \\
\hline Staggered Planting 2005*Cultivar*Sample (weeks) & 18 & 0.98 \\
\hline Error & 112 & $17.43^{\dagger}$ \\
\hline
\end{tabular}

* Indicates a significant interaction

${ }^{\dagger}$ Error mean square 
Adults

\begin{tabular}{|l|l|l|}
\hline \multicolumn{1}{|c|}{ Source } & \multicolumn{1}{c|}{ DF } & \multicolumn{1}{|c|}{ F Ratio } \\
\hline Staggered Planting 2005 & 1 & $4.45^{*}$ \\
\hline Planting Date & 3 & 2.58 \\
\hline Sample (weeks) & 6 & $4.82^{*}$ \\
\hline Staggered Planting 2005*Planting Date & 3 & 2.19 \\
\hline Staggered Planting 2005*Sample (weeks) & 6 & 0.82 \\
\hline Planting Date*Sample (weeks) & 18 & 0.82 \\
\hline Staggered Planting 2005*Cultivar*Sample (weeks) & 18 & 0.48 \\
\hline Error & 112 & $5.14^{\dagger}$ \\
\hline
\end{tabular}

*Indicates a significant interaction

${ }^{\dagger}$ Error mean square 


\section{APPENDIX C}

Analysis of variance of MBB population densities found in row cover plots in 2004 and 2005. Orthogonal contrasts were done to estimate effect within significant interactions.

P. foveolatus 2004

\begin{tabular}{|l|l|l|}
\hline \multicolumn{1}{|c|}{ Sgg mass } & \multicolumn{1}{c|}{ DF } & \multicolumn{1}{c|}{ F Ratio } \\
\hline P. foveolatus 2004 & 1 & 0.20 \\
\hline Cultivar & 5 & 2.25 \\
\hline Sample (weeks) & 7 & $5.92^{*}$ \\
\hline P. foveolatus 2004*Cultivar & 5 & 1.09 \\
\hline P. foveolatus 2004*Sample (weeks) & 7 & 1.60 \\
\hline Cultivar*Sample (weeks) & 35 & 0.61 \\
\hline P. foveolatus 2004*Cultivar*Sample (weeks) & 35 & 0.82 \\
\hline Error & 192 & $0.63^{\dagger}$ \\
\hline
\end{tabular}

*Indicates a significant interaction

${ }^{\dagger}$ Error mean square

Larvae

\begin{tabular}{|l|l|l|}
\hline \multicolumn{1}{|c|}{ Source } & \multicolumn{1}{c|}{ DF } & \multicolumn{1}{c|}{ F Ratio } \\
\hline P. foveolatus 2004 & 1 & $0.01^{*}$ \\
\hline Cultivar & 5 & 0.17 \\
\hline Sample (weeks) & 7 & $<.0001^{*}$ \\
\hline P. foveolatus 2004*Cultivar & 5 & 0.92 \\
\hline P. foveolatus 2004*Sample (weeks) & 7 & 0.18 \\
\hline Cultivar*Sample (weeks) & 35 & 0.65 \\
\hline P. foveolatus 2004*Cultivar*Sample (weeks) & 35 & 1.00 \\
\hline Error & 192 & $188.00^{\dagger}$ \\
\hline
\end{tabular}

*Indicates a significant interaction

${ }^{\dagger}$ Error mean square 
Pupae

\begin{tabular}{|l|l|l|}
\hline \multicolumn{1}{|c|}{ Source } & \multicolumn{1}{c|}{ DF } & \multicolumn{1}{c|}{ F Ratio } \\
\hline P. foveolatus 2004 & 1 & 2.50 \\
\hline Cultivar & 5 & 0.80 \\
\hline Sample (weeks) & 7 & $5.74 *$ \\
\hline P. foveolatus 2004*Cultivar & 5 & 0.82 \\
\hline P. foveolatus 2004*Sample (weeks) & 7 & $2.69 *$ \\
\hline Cultivar*Sample (weeks) & 35 & 0.35 \\
\hline P. foveolatus 2004*Cultivar*Sample (weeks) & 35 & 0.57 \\
\hline Error & 192 & $118.65^{\dagger}$ \\
\hline
\end{tabular}

*Indicates a significant interaction

${ }^{\dagger}$ Error mean square

Adults

\begin{tabular}{|l|l|l|}
\hline \multicolumn{1}{|c|}{ Source } & \multicolumn{1}{c|}{ DF } & \multicolumn{1}{c|}{ F Ratio } \\
\hline P. foveolatus 2004 & 1 & 2.28 \\
\hline Cultivar & 5 & 0.37 \\
\hline Sample (weeks) & 7 & $7.37^{*}$ \\
\hline P. foveolatus 2004*Cultivar & 5 & 0.98 \\
\hline P. foveolatus 2004*Sample (weeks) & 7 & $2.22^{*}$ \\
\hline Cultivar*Sample (weeks) & 35 & 0.16 \\
\hline P. foveolatus 2004*Cultivar*Sample (weeks) & 35 & 0.57 \\
\hline Error & 192 & $102.95^{\dagger}$ \\
\hline
\end{tabular}

*Indicates a significant interaction

${ }^{\dagger}$ Error mean square 


Egg mass Source
\begin{tabular}{|l|l|l|}
\hline \multicolumn{1}{|c|}{ DF } & F Ratio \\
\hline P. foveolatus 2005 & 1 & 1.47 \\
\hline Cultivar & 5 & 0.17 \\
\hline Sample (weeks) & 6 & $4.84^{*}$ \\
\hline P. foveolatus 2005*Cultivar & 5 & 1.38 \\
\hline P. foveolatus 2005*Sample (weeks) & 6 & 0.80 \\
\hline Cultivar*Sample (weeks) & 30 & 0.85 \\
\hline P. foveolatus 2005*Cultivar*Sample (weeks) & 30 & 0.74 \\
\hline Error & 168 & $1.19^{\dagger}$ \\
\hline
\end{tabular}

*Indicates a significant interaction

${ }^{\dagger}$ Error mean square

Larvae

\begin{tabular}{|l|l|l|}
\hline \multicolumn{1}{|c|}{ Source } & \multicolumn{1}{c|}{ DF } & \multicolumn{1}{c|}{ F Ratio } \\
\hline P. foveolatus 2005 & 1 & $30.51^{*}$ \\
\hline Cultivar & 5 & 1.79 \\
\hline Sample (weeks) & 6 & 0.22 \\
\hline P. foveolatus 2005*Cultivar & 5 & $33.19^{*}$ \\
\hline P. foveolatus 2005*Sample (weeks) & 6 & $2.68^{*}$ \\
\hline Cultivar*Sample (weeks) & 30 & 0.65 \\
\hline P. foveolatus 2005*Cultivar*Sample (weeks) & 30 & 0.13 \\
\hline Error & 168 & $159.66^{\dagger}$ \\
\hline
\end{tabular}

*Indicates a significant interaction

${ }^{\dagger}$ Error mean square 
Pupae

\begin{tabular}{|l|l|l|}
\hline \multicolumn{1}{|c|}{ Source } & \multicolumn{1}{c|}{ DF } & \multicolumn{1}{c|}{ F Ratio } \\
\hline P. foveolatus 2005 & 1 & $19.49^{*}$ \\
\hline Cultivar & 5 & 2.08 \\
\hline Sample (weeks) & 6 & $29.49^{*}$ \\
\hline P. foveolatus 2005*Cultivar & 5 & 0.66 \\
\hline P. foveolatus 2005*Sample (weeks) & 6 & 5.29 \\
\hline Cultivar*Sample (weeks) & 30 & 0.25 \\
\hline P. foveolatus 2005*Cultivar*Sample (weeks) & 30 & 0.57 \\
\hline Error & 168 & $19.56^{\dagger}$ \\
\hline
\end{tabular}

*Indicates a significant interaction

${ }^{\dagger}$ Error mean square

Adult

\begin{tabular}{|l|l|l|}
\hline \multicolumn{1}{|c|}{ Source } & \multicolumn{1}{c|}{ DF } & \multicolumn{1}{c|}{ F Ratio } \\
\hline P. foveolatus 2005 & 1 & $24.03^{*}$ \\
\hline Cultivar & 5 & 1.53 \\
\hline Sample (weeks) & 6 & $8.06^{*}$ \\
\hline P. foveolatus 2005*Cultivar & 5 & 0.73 \\
\hline P. foveolatus 2005*Sample (weeks) & 6 & 1.77 \\
\hline Cultivar*Sample (weeks) & 30 & 1.00 \\
\hline P. foveolatus 2005*Cultivar*Sample (weeks) & 30 & 1.00 \\
\hline Error & 168 & $5.00^{\dagger}$ \\
\hline
\end{tabular}

*Indicates a significant interaction

${ }^{\dagger}$ Error mean square 